University of Louisville

ThinkIR: The University of Louisville's Institutional Repository

Electronic Theses and Dissertations

$5-2020$

\title{
The retinoblastoma protein mediates metabolic reprogramming in lung cancer.
}

Lindsey R. Conroy

University of Louisville

Follow this and additional works at: https://ir.library.louisville.edu/etd

Part of the Biochemistry Commons

\section{Recommended Citation}

Conroy, Lindsey R., "The retinoblastoma protein mediates metabolic reprogramming in lung cancer." (2020). Electronic Theses and Dissertations. Paper 3405.

https://doi.org/10.18297/etd/3405

This Doctoral Dissertation is brought to you for free and open access by ThinkIR: The University of Louisville's Institutional Repository. It has been accepted for inclusion in Electronic Theses and Dissertations by an authorized administrator of ThinkIR: The University of Louisville's Institutional Repository. This title appears here courtesy of the author, who has retained all other copyrights. For more information, please contact thinkir@louisville.edu. 


\title{
THE RETINOBLASTOMA PROTEIN MEDIATES METABOLIC REPROGRAMMING IN LUNG CANCER
}

\author{
By \\ Lindsey R. Conroy \\ B.S. Indiana University Southeast 2014 \\ M.S. University of Louisville 2017 \\ A Dissertation \\ Submitted to the Faculty of the \\ School of Medicine at the University of Louisville \\ In Partial Fulfillment of the Requirements for the Degree of \\ Doctor of Philosophy in \\ Biochemistry and Molecular Genetics \\ Department of Biochemistry and Molecular Genetics \\ University of Louisville \\ Louisville, Kentucky
}

May 2020 



\section{THE RETINOBLASTOMA PROTEIN MEDIATES METABOLIC REPROGRAMMING IN LUNG CANCER}

\begin{tabular}{c} 
By \\
Lindsey R. Conroy \\
B.S. Indiana University Southeast 2014 \\
M.S. University of Louisville 2017 \\
A Dissertation Approved on \\
January 24, 2020 \\
by the Following Dissertation Committee: \\
\hline Brian Clem, Ph.D. \\
\hline Alan Cheng, Ph.D. \\
\hline Barbara Clark, Ph.D. \\
\hline Douglas Dean, Ph.D.
\end{tabular}




\section{DEDICATION}

This dissertation is dedicated to my husband, Graham. You have always believed in me and encouraged me to pursue my goals. Thank you for your patience and for being my support system through the ups and downs of graduate school. 


\section{ACKNOWLEDGEMENTS}

I would like to thank my mentor, Dr. Brian Clem for his support and guidance over the past few years. I appreciate the opportunities he has given me to advance my training and begin my scientific career. I would also like to thank my committee members, Drs. Cheng, Clark, Dean, and Hill, for their feedback and advice which helped to guide my project. I would like to thank all of the current and former members of the Clem lab, especially Dr. Traci Kruer and Susan

Dougherty, M. S. for the animal training which was crucial to my dissertation project. I would like to acknowledge the University of Louisville Center for Regulatory and Environmental Analytical Metabolomics and the James Graham Brown Cancer Center NMR facility for their spectroscopy services, and a special thanks to Dr. Pawel Lorkiewicz for his data analysis. I would also like to thank Dr.

Ramon Sun and his graduate student Lyndsay Young for their assistance with the steady state metabolomics studies. I would also like to acknowledge the wonderful students and employees of the Clinical Translational Research Building $4^{\text {th }}$ floor for all the lunch breaks, potlucks, and shared loved of science that created an amazing work environment. Lastly, I would like to thank my family and friends for their support of my academic pursuits and encouragement when times were tough. 


\title{
ABSTRACT \\ THE RETINOBLASTOMA PROTEIN MEDIATES METABOLIC REPROGRAMMING IN LUNG CANCER
}

\author{
Lindsey R. Conroy
}

January 24,2020

Lung cancer is among the most frequently diagnosed cancers and is the leading cause of cancer-related deaths worldwide. One of the hallmark events in lung cancer pathogenesis is deregulation of the cell cycle. The retinoblastoma protein $(\mathrm{pRb})$ is a tumor suppressor that is deleted, mutated, or inactivated in most lung cancer cases. Canonically, pRb functions to regulate cell cycle progression by repressing the transcriptional activity of the E2F family of transcription factors, inhibiting $S$ phase entry. Although the cell cycle functions of $p R b$ have been well established, recent studies have highlighted a functional role for $\mathrm{pRb}$ in controlling cellular metabolism. This body of work describes the role of $\mathrm{pRb}$ in mediating metabolic reprogramming in both in vitro and in vivo models of lung cancer.

To define metabolic pathways regulated by $\mathrm{pRb}$ in vitro, I performed several metabolic assays and stable-isotope labeled metabolomics studies in A549 lung adenocarcinoma cells. pRb activity was manipulated via treatment with palbociclib, a CDK4/6 inhibitor which inhibits the phosphorylation and subsequent inactivation of $\mathrm{pRb}$. Palbociclib decreases nucleotide biosynthesis by reducing activity of 
glucose 6-phosphate dehydrogenase, the rate limiting enzyme in the pentose phosphate pathway (PPP), without altering glycolysis. Additionally, palbociclib increases glutamine dependency for mitochondrial function and sensitizes A549 cells to the glutaminase inhibitor, CB-839. The effects of palbociclib on both the PPP and glutamine utilization occur in an pRb-dependent manner.

Separately, using a combination of steady-state and stable-isotope labeled metabolomics, I assessed global changes in metabolism resulting from the loss of the gene encoding $\mathrm{pRb}(R b 1)$ in Kras-driven lung tumors in vivo. Depletion of $R b 1$ in a mutant Kras-driven mouse model of lung cancer enhances glucose metabolism, via upregulation of key genes within glycolysis, without altering mitochondrial pyruvate oxidation. Moreover, pRb-deficient tumors do not exhibit alterations in glutamine anaplerosis or utilization of alternative nutrient sources (e.g. circulating lactate) compared to lung tumors with intact pRb.

Together the work described in this dissertation expands our knowledge of the metabolic phenotype resulting from $\mathrm{pRb}$ dysfunction in lung cancer, and highlights specific metabolic perturbations that may be exploited therapeutically based on $\mathrm{pRb}$ status in patient lung tumors. 
TABLE OF CONTENTS

Page

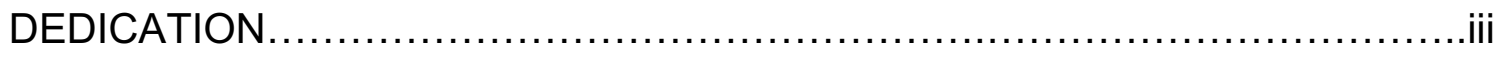

ACKNOWLEDGEMENTS .......................................................

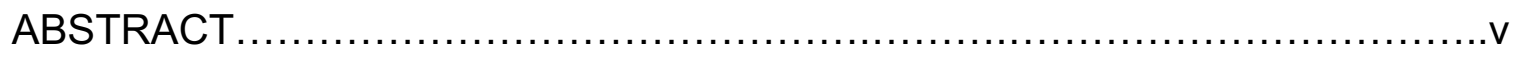

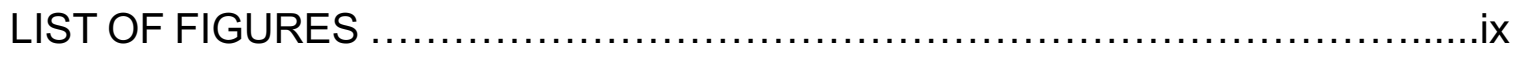

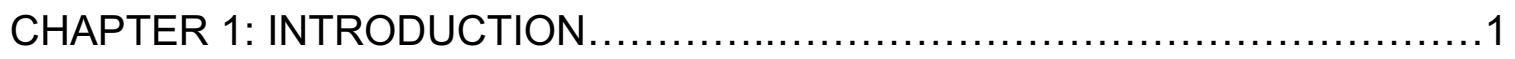

CHAPTER 2: PALBOCICLIB TREATMENT ALTERS NUCLEOTIDE BIOSYNTHESIS AND GLUTAMINE DEPENDENCY IN A549 CELLS

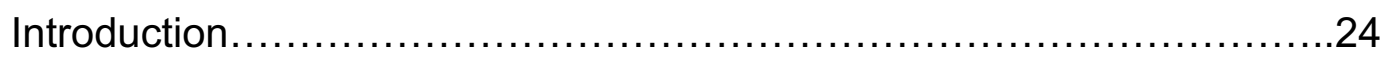

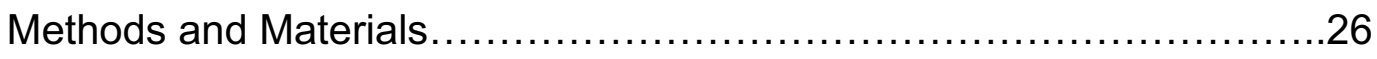

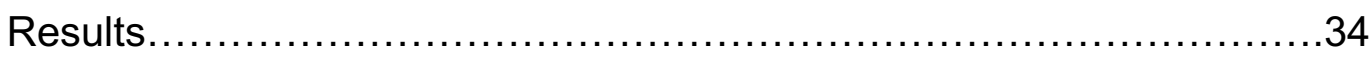

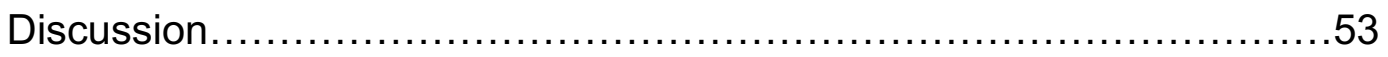

CHAPTER 3: LOSS OF RB1 ENHANCES GLYCOLYTIC METABOLISM IN KRASDRIVEN LUNG TUMORS IN VIVO

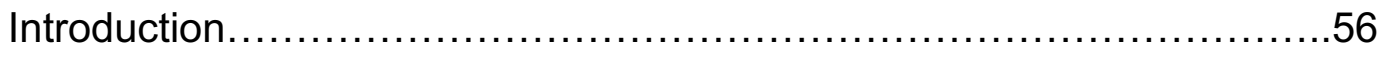

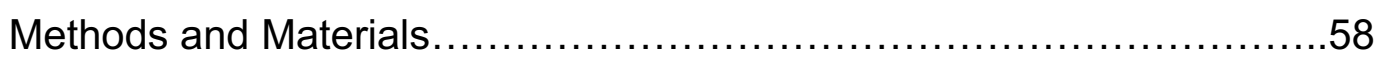

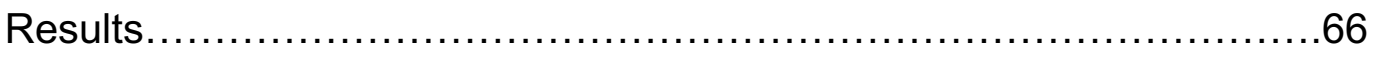

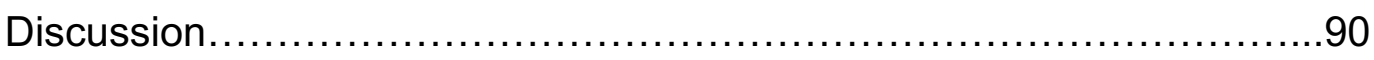

CHAPTER 4: CONCLUSIONS AND FUTURE DIRECTIONS.....................94 


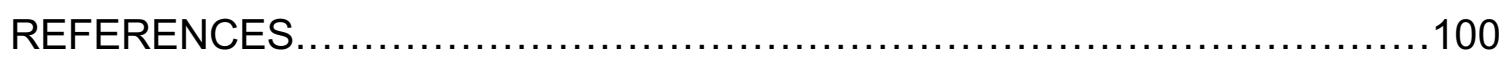

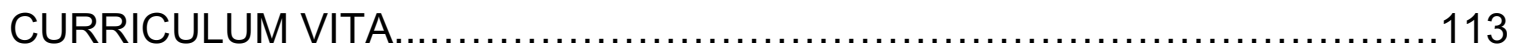




\section{LIST OF FIGURES}

$\begin{array}{lll}\text { Figure } & \text { Page }\end{array}$

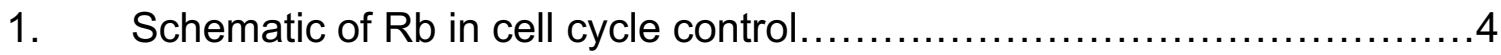

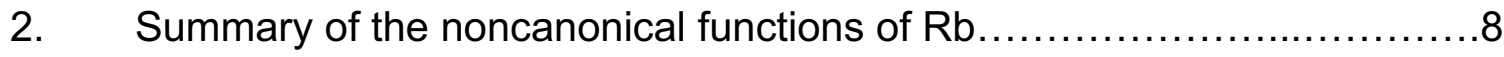

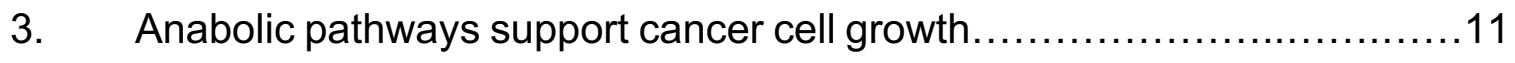

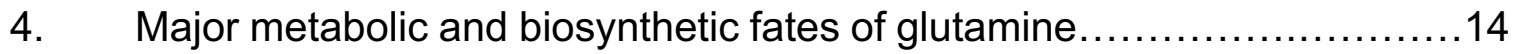

5. Palbociclib decreases $\mathrm{pRb}$ phosphorylation and proliferation of A549 lung

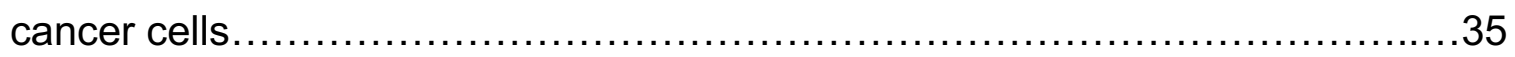

6. Palbociclib has no effect on glucose uptake but decreases ${ }^{3} \mathrm{H}_{2} \mathrm{O}$ production

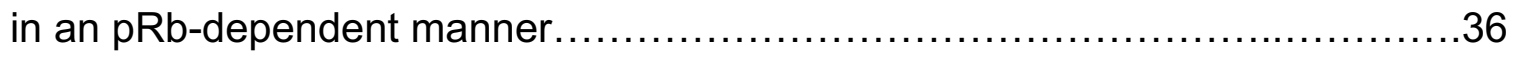

7. Palbociclib does not alter glycolytic function in vitro......................38

8. Cartoon of $\left[\mathrm{U}-{ }^{13} \mathrm{C}\right]$-glucose fate mapping though glycolysis ................39 9. Palbociclib does not alter glucose carbon incorporation into glycolytic intermediates in $\mathrm{A} 549$ cells....................................................

10. Cartoon of $\left[\mathrm{U}-{ }^{13} \mathrm{C}\right]$-glucose fate mapping though the pentose phosphate pathway.

11. Palbociclib decreases glucose carbon incorporation into the PPP in A549 cells

12. Palbociclib decreases G6PD activity and RRM2 transcript levels in A549 cells. .44 
13. Palbociclib increases mitochondrial respiration in A549 cells

14. Cartoon of $\left[\mathrm{U}-{ }^{13} \mathrm{C}\right]$-glucose fate mapping through the $1^{\text {st }}$ turn of the TCA cycle.

15. Palbociclib increases PC-mediated anaplerosis in A549 cells..............48

16. Palbociclib increases glutamine dependency in A549 cells................49

17. Palbociclib does not alter expression of genes within glutamine

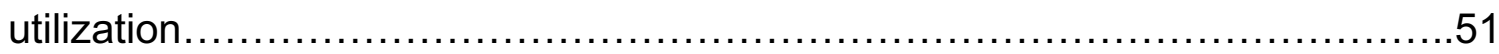

18. Palbociclib sensitizes A549 cells to glutaminase inhibition.................52

19. Loss of $R b 1$ accelerates lung cancer progression in a Kras-driven model of

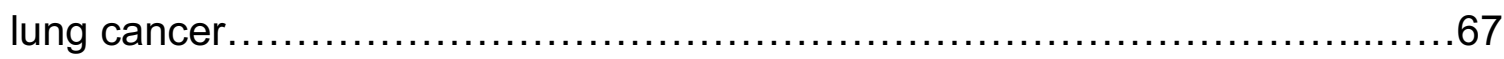

20. Confirmation of loss of $R b 1$ in resulting Kras-driven lung tumors...........68

21. Rb1 loss qualitatively alters the steady state relative abundance of metabolites in Kras-driven lung tumors.......................................69 22. $R b 1^{-/}$mice exhibit increased labeled plasma glucose and lactate when

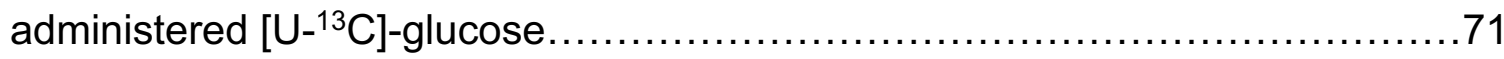

23. Cartoon of $\left[\mathrm{U}-{ }^{13} \mathrm{C}\right]$-glucose fate mapping though glycolysis................72

24. Loss of $R b 1$ increases glucose carbon incorporation into glycolytic intermediates in vivo. .73

25. Loss of $R b 1$ increases expression of key glycolytic enzymes in Kras-driven

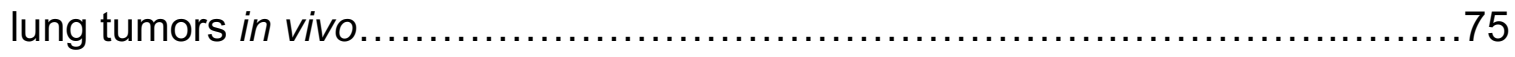
26. Cartoon of $\left[\mathrm{U}-{ }^{13} \mathrm{C}\right]-$ glucose fate mapping through the $1^{\text {st }}$ turn of the TCA cycle. .76 
27. Loss of $R b 1$ does not affect pyruvate metabolism in Kras-driven lung tumors in vivo....... .77

28. Loss of $R b 1$ does not affect gene expression of TCA cycle enzymes in Krasdriven lung tumors in vivo .78

29. Cartoon of $\left[\mathrm{U}-{ }^{13} \mathrm{C},{ }^{15} \mathrm{~N}\right]$-glutamine fate mapping through the TCA cycle. .80

30. Loss of $R b 1$ does not influence glutaminolysis in vivo......................81

31. Loss of $R b 1$ does not influence reductive carboxylation in vivo.

32. Genetic deletion of $R b 1$ does not regulate genes within glutamine utilization in vivo. .84

33. Rb1 deletion does not affect lactate carbon oxidation in Kras-driven lung tumors in vivo .85

34. Cartoon of $\left[\mathrm{U}-{ }^{13} \mathrm{C}\right]$-lactate fate mapping through the $1^{\text {st }}$ turn of the TCA cycle. .87

35. Loss of $R b 1$ does not affect lactate carbon oxidation in Kras-driven lung tumors in vivo .88

36. Genetic loss of $R b 1$ does not regulate lactate import in vivo. .89 


\section{CHAPTER 1: INTRODUCTION}

\section{Lung Cancer}

Lung cancer is among the most frequently diagnosed cancers and is the leading cause of cancer-related mortality worldwide, with an estimated 1.6 million deaths each year (1-3). The overall five-year survival rate for lung cancer patients is only $18 \%$, with more than half of these patients succumbing to their disease within the first year of diagnosis (1). The most common risk factor for developing lung cancer is tobacco smoking, which comprises over $80 \%$ of all cases in the United States as well as other countries with prevalent tobacco use (4). However, environmental exposures including second-hand smoke, radon, air pollution, occupational carcinogens, and genetic susceptibility have a role in lung cancer development $(2,5,6)$. Approximately $85 \%$ of patients are diagnosed with having non-small cell lung cancer (NSCLC), of which lung adenocarcinoma (LUAD) and lung squamous cell carcinoma (LUSC) are the most common subtypes, while small cell lung cancer (SCLC) accounts for the remaining 15\% of diagnoses (3). Each subtype has distinct oncogenic drivers, epidemiology, and therapeutic options, which differentially impact patient outcomes. This dissertation will focus on the NSCLC subtype as it is accounts for the majority of lung cancer diagnoses.

A NSCLC diagnosis is defined by the TNM staging system, where stage is categorized by the primary tumor $(T)$, the extent of lymph node involvement $(N)$, 
and distant metastasis (M) (7). Common metastasis sites for NSCLC are the brain, liver, and bone (8). Often, NSCLC is detected at more advanced-stages, resulting in a poorer clinical outcome for patients; however, this is beginning to improve with better screening methods and more efficacious therapies $(1,2,4,7)$. Over the past two decades, the treatment of lung cancer has changed from the use of nonspecific cytotoxic therapies to targeted or personalized strategies based on the genetic alterations of the patient's tumor (5). Among the many cellular processes genetically altered during lung cancer pathogenesis, the most prevalent involves disruption of cell cycle control.

\section{The Cell Cycle}

The mammalian cell cycle is comprised of five sequential phases: $G_{0}, G_{1}$, $\mathrm{S}, \mathrm{G}_{2}$, and $\mathrm{M}$. During two of these phases, cells must complete two fundamental events to ensure proper cell division. First, in S phase, the cell must generate a single and faithful copy of its genetic material, while in $M$ phase, the cell must partition all of its cellular compartments into two identical daughter cells. The two other phases of the cell cycle, $\mathrm{G}_{1}$ and $\mathrm{G}_{2}$, are considered "gap" phases. During these times, cells prepare themselves for successful entry and completion of the $\mathrm{S}$ and $\mathrm{M}$ phases, respectively. In the absence of mitogenic signaling or when cells cease proliferation, they exit the cell cycle and remain in $\mathrm{G}_{0}$. In this non-dividing phase, cells are referred to as quiescent, or in a state of cell cycle arrest. Cells in $\mathrm{G}_{0}$ account for the majority of non-proliferative cells in the human body.

Over the last several decades, extensive research has been conducted on the regulation of cell cycle in both normal and malignant cells. One of the central 
players of cell cycle progression are the cyclin-dependent kinases (CDKs). The activity of these serine/threonine kinases is tightly regulated by their ability to form complexes with larger proteins called cyclins. Transitioning from one cell cycle phase to the next occurs in an orderly fashion due to the different cyclin-CDK complexes that form and activate their respective downstream targets during specific cell cycle phases (9). Timely activation of cyclin-CDK complexes is controlled by expression of the INK4 and the kinase inhibitory (WAF/KIP) family of proteins, which inhibit the association of CDKs with cyclins (10). In addition to cyclin-CDK regulation, there are several cell cycle checkpoints in place that ensure cells preserve genome integrity and chromosomal stability (11).

\section{$G_{1}$ to $S$ Phase Transition}

Quiescent cells $\left(\mathrm{G}_{0}\right)$ enter the cell cycle in response to mitogenic or growth factor signals, resulting in increased intracellular levels of D-type cyclins (D1-3). Cyclin D then localizes to the nucleus where it forms active Cyclin D-CDK4 or Cyclin D-CDK6 complexes that phosphorylate the retinoblastoma protein $[p R b$, $R B 1$ (gene), also referred to as $\mathrm{Rb}$ ] and other members of the "pocket" protein family $(12,13)$. The $p R b$ pocket proteins ( $p R b, p 107$, and $p 130)$ negatively regulate the transition from $\mathrm{G}_{1}$ to $S$ phase by binding to the E2F family of transcription factors and repressing the expression of genes required for cellular processes, including DNA replication (14). Phosphorylation of $p R b$ by Cyclin D-CDK4/6 complexes induces a conformational change that promotes its dissociation from E2Fs, thereby enabling the transcription of genes required for DNA synthesis and transition from $G_{1}$ to $S$ phase (Figure 1) (15). pRb is then hyperphosphorylated 


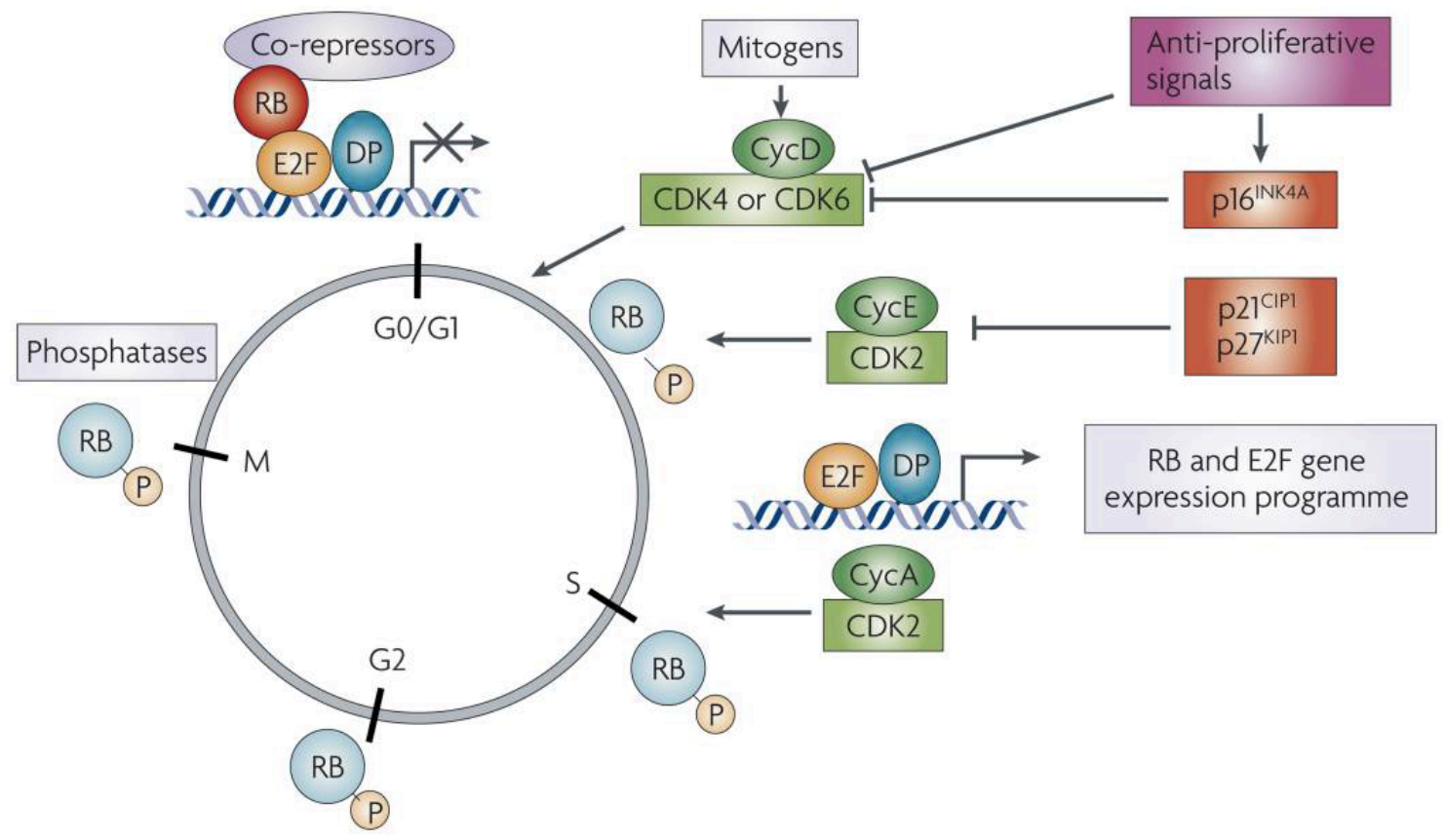

Figure 1. Schematic of $R \mathbf{b}$ in cell cycle control. In early $G_{1}$, Rb physically associates with $\mathrm{E} 2 \mathrm{~F}$ transcription factors, blocking their transactivation domain. In late $\mathrm{G}_{1}, \mathrm{Rb}$ phosphorylation releases $\mathrm{E} 2 \mathrm{Fs}$, allowing the expression of genes that encode products necessary for $\mathrm{S}$-phase progression. $\mathrm{Rb}$ and $\mathrm{p}-\mathrm{Rb}$ indicate unphosphorylated and phosphorylated $\mathrm{Rb}$, respectively (15). Reprinted with permission from [Springer Nature] : [Nature] [NATURE REVIEWS CANCER] (Tailoring to RB: tumour suppressor status and therapeutic response, Erik S. Knudsen and Karen E. Knudsen), [@MACMILLIAN PUBLISHERS LIMITED] (2008). 
during the late $\mathrm{G}_{1}$ phase by the cyclin $\mathrm{E}-\mathrm{CDK} 2$ complex, which reinforces $\mathrm{pRb}$ inactivation and irreversible initiation of the gene expression program of $S$ phase $(11,16)$. This stage is referred to as the restriction point. Alterations of the molecular players involved in the restriction point are crucial for cancer initiation, as it allows cancer cells to proliferate independently of mitogenic or growth factor stimuli.

Alterations of the $p R b-E 2 F$ Pathway in Lung Cancer

Genetic alterations of the $G_{1}$ to $S$ phase transition have been reported to play a key role in the pathogenesis and progression of both NSCLC and SCLC via very different mechanisms (11). In SCLC, pRb is inactivated in more than $90 \%$ of cases as a result of point mutations and abnormal mRNA expression (17). Conversely, the majority of NSCLC cases exhibit abnormalities in the upstream regulators of $\mathrm{pRb}$, such as overexpression of Cyclin D1 or deletion of the p16 INK4A gene, which results in increased cyclin-CDK activity and $\mathrm{pRb}$ constitutive inactivation through hyperphosphorylation $(18,19)$. p16 $16^{\text {INK4A }}$ loss and Cyclin D1 overexpression are always inversely correlated with RB1 loss, suggesting they exert their activities via $\mathrm{pRb}$ during lung transformation. Additionally, RB1 is mutated in $15-30 \%$ of NSCLC cases, which correlates to poorer overall survival for these patients.

Given the prevalence of aberrations in cell cycle control in lung tumors, modulation of the cell cycle machinery has become an important therapeutic strategy for the treatment of lung cancer. As discussed above, CDKs are often dysregulated and overactive in lung cancer, resulting in uncontrolled cell cycle 
progression, in part through inactivating $\mathrm{pRb}$. As such, selective inhibition of CDKs has the potential to inhibit tumor cell proliferation by inducing cell cycle arrest (11). Over the past three decades, extensive research has been done to develop small molecule inhibitors of CDKs. First generation pan-CDK inhibitors evaluated in clinical trials showed partial responses in NSCLC patients when combined with standard cytotoxic agents; however, their toxicity and low activity excluded them from being FDA approved (20). Further investigation has shifted from the use of general pan-CDK inhibitors to the development of compounds that target specific CDKs. Among these inhibitors, palbociclib (PD-0332991), a potent small-molecule CDK4/6 inhibitor has been FDA-approved for the treatment of women with breast cancer (21), and has shown efficacy in preclinical studies of NSCLC (22-26).

Canonical \& Noncanonical Functions of the Retinoblastoma Protein

The $R B 1$ gene product was initially discovered in retinoblastomas and is the first reported tumor suppressor protein (27). In addition to retinoblastoma, genetic alterations of $R B 1$ have been found in osteosarcomas, renal cell carcinomas, as well as adenocarcinomas of the breast, prostate, cervix, and lung (SCLC) (27). Even in cancers without mutations or deletion of $R B 1$ itself, disruption of other nodes of the $\mathrm{pRb}-\mathrm{E} 2 \mathrm{~F}$ pathways are observed, suggesting loss of $\mathrm{pRb}$ function is a hallmark of human cancer (28). Following its discovery, extensive characterization has been done on pRb's role in cell cycle progression. In addition to its interaction with the E2F family of transcription factors, $\mathrm{pRb}$ has been found to associate with over 100 proteins, including a variety of transcription factors and chromatin-associated proteins (29). Additionally, pRb forms regulatory complexes 
that can either repress or activate transcription (30-32). Due to its broad range of binding partners, the direct targets of $\mathrm{pRb}$ activity are diverse and regulate other processes such as differentiation, angiogenesis, genome stability, and apoptosis (Figure 2) (33). Beyond cell cycle, other dysregulated cellular activities contribute to malignant immortalization and transformation of normal lung tissue. Most of these are intimately connected, such as cell cycle control and metabolic regulation. Nutrient metabolism provides the required intermediates that allow cell cycle progression, so accordingly alterations in metabolic pathways are observed in the vast majority of human cancers.

\section{Cancer Metabolism}

Metabolism describes the complex, integrated network of chemical reactions in which macromolecules are broken down or synthesized. These processes are classified into two branches: catabolic pathways that produce energy (namely adenosine triphosphate, ATP) and anabolic pathways that synthesize molecules and require energy expenditure. This metabolic network is tightly regulated in response to external stimuli through subsequent signaling pathways and both positive and negative allosteric control of rate-limiting enzymes. This allows for the rapid response to ever-changing cellular demands that vary based on cell type, microenvironment, and proliferative state (34). Cancer cells reprogram metabolic pathways in order to fulfill the biosynthetic requirements associated with increased proliferation. Specifically, tumor cells alter their metabolic activity to support either anabolic growth during nutrient-rich conditions 


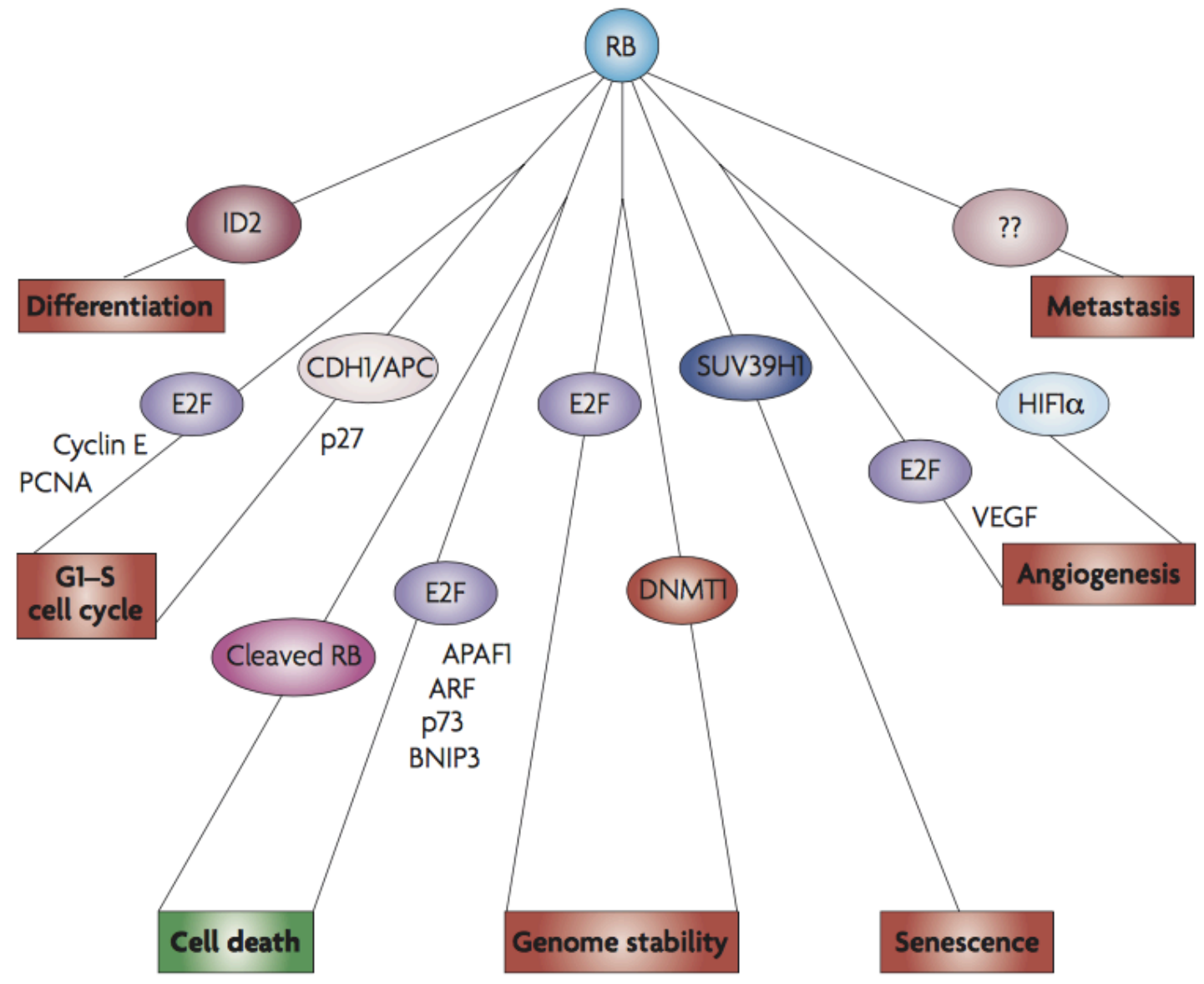

Figure 2. Summary of the noncanonical functions of $\mathbf{R b}$. $\mathrm{Rb}$ regulates several cellular processes relevant to cancer via interaction with numerous binding partners and transcription factors (33). Reprinted with permission from [Springer Nature] : [Nature] [NATURE REVIEWS CANCER] (Cellular mechanisms of tumour suppression by the retinoblastoma gene), (Deborah L. Burkhart and Julien Sage), [@MACMILLIAN PUBLISHERS LIMITED] (2008). 
or catabolism to maintain survival during nutrient deprivation (35). The dependencies on specific metabolic substrates exhibited by tumor cells are driven by specific oncogenes and tumor suppressor genes that promote or inhibit tumorigenesis, respectively. This reprogramming ability of tumor cells is recognized as one of the hallmarks of cancer by Drs. Hanahan and Weinberg and is now a field of extensive research (36). The major metabolic pathways that differ between cancer cells and non-transformed cells are described below.

\section{Glucose Metabolism and the Warburg Effect}

To fulfill the biosynthetic demands of rapid proliferation, tumor cells must increase the import of nutrients from their environment. Increased glucose uptake is a distinguishing feature of tumor cells and is observed in most human cancers $(34,37)$. This difference is widely exploited diagnostically in Positron Emission Tomography (PET) imaging where patients are administered radiolabeled analogs of glucose such as ${ }^{18} \mathrm{~F}$-fluorodeoxyglucose to visualize tumors (37). Under physiologic oxygen concentrations, normal cells catabolize glucose to pyruvate, the end product of glycolysis, followed by its conversion to acetyl-CoA to fuel the tricarboxylic acid cycle (TCA cycle). The TCA cycle generates reduced nicotinamide adenine dinucleotide (NADH) and flavin adenine dinucleotide $\left(\mathrm{FADH}_{2}\right)$ cofactors, which serve as a source of electrons for mitochondrial respiration and ATP (adenosine triphosphate) production. This process generates up to 36 ATP per molecule of oxidized glucose. In contrast, cancer cells, even in the presence of oxygen, preferentially use glycolysis to generate a larger fraction of cellular ATP, a much less efficient form of energy production that yields only 2 
ATP per molecule of glucose (35-43). This phenomenon was first described by Dr. Otto Warburg and is referred to as "aerobic glycolysis" or the "Warburg effect"; wherein cancer cells increase glycolytic flux and divert pyruvate from the TCA cycle to generate lactate regardless of oxygen availability $(44,45)$. This was originally postulated to result from mitochondrial dysfunction in cancer cells that necessitated the exclusive use of glycolysis for energy production. However, recent studies have shown intact tumors enhance both glycolysis and oxidative phosphorylation simultaneously to meet both the anabolic and bioenergetic demands of proliferation $(35,46)$.

To compensate for the lower energy yield, cancer cells increase both the rate of glucose uptake and glycolysis by increasing expression of glucose transporters and glycolytic enzymes $(37,47)$. Additionally, increased glycolytic flux in cancer cells generates intermediates that are required to supply subsidiary anabolic pathways with the necessary substrates to support cell growth and proliferation (Figure 3). Both glucose-6-phosphate and fructose-6-phosphate serve as substrates for the pentose phosphate pathway (PPP), which generates the ribose moiety for nucleotide synthesis. Likewise, 3-phosphoglycerate participates in one-carbon metabolism, where it is converted to formate, an additional substrate for nucleotide synthesis. Glyceraldehyde-3-phosphate can be converted to glycerol-3-phosphate, the carbon backbone required to synthesize several types of lipids. Further, when glucose is catabolized by the TCA cycle, it provides the necessary intermediates for nonessential amino acid production. 


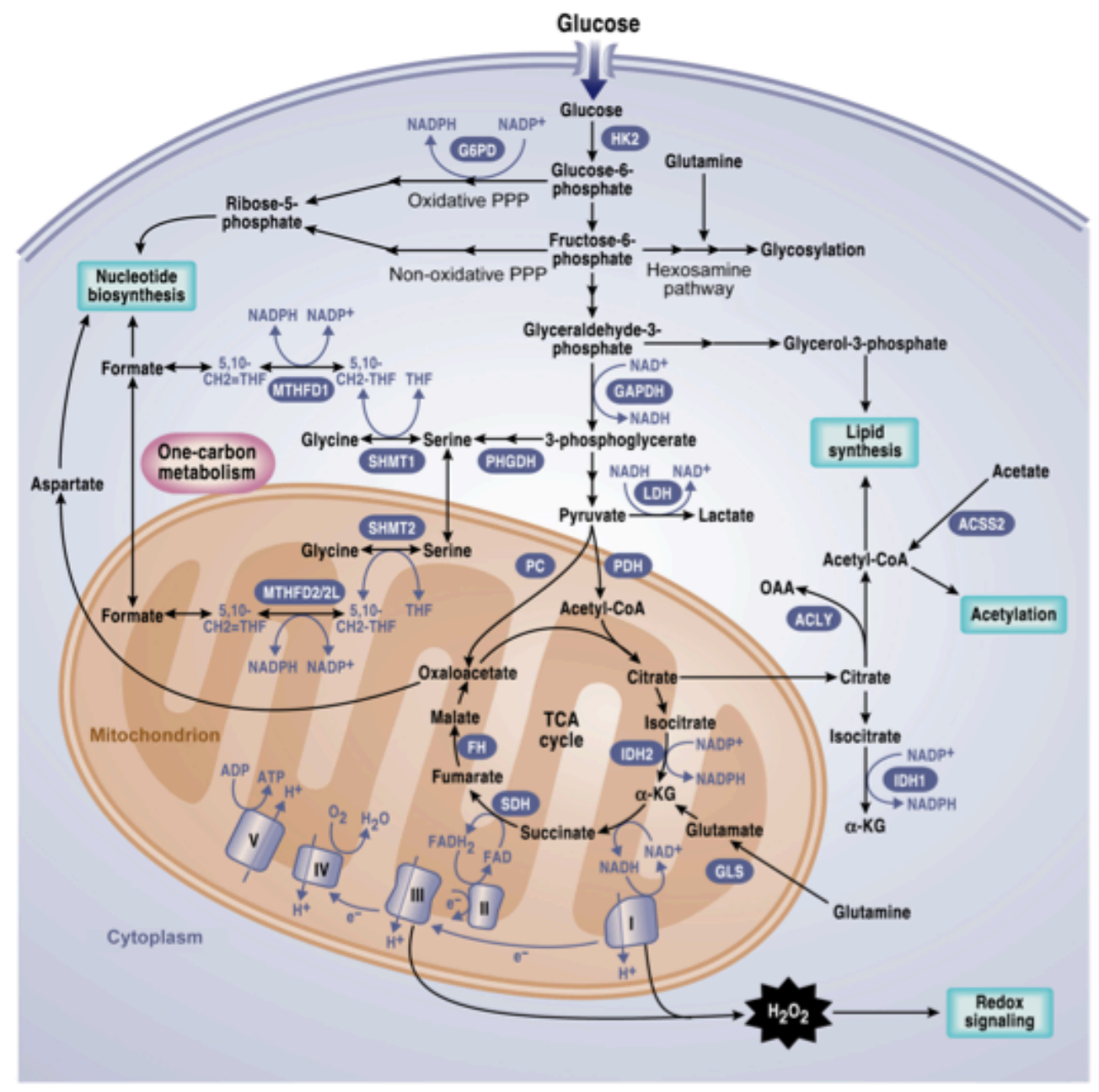

Figure 3. Anabolic pathways support cancer cell growth. Increased glycolytic flux in cancer cells generates intermediates that serve as substrates for anabolic pathways such as nucleotide biosynthesis, lipid synthesis, and one-carbon metabolism to sustain cell growth. From [DeBerardinis, R. J., and Chandel, N. S. (2016) Fundamentals of cancer metabolism. Sci Adv 2, e1600200]. Reprinted with permission from AAAS. 


\section{Lactate Metabolism}

In normal cells, pyruvate is converted to acetyl-CoA to fuel the TCA cycle, yet cancer cells have been found to preferentially generate lactate from pyruvate. This is in part due to the upregulation of lactate dehydrogenase A (LDHA), which catalyzes pyruvate to lactate. This reaction provides several selective advantages to cancer cells $(39,48)$. Converting pyruvate to lactate regenerates NAD+ to allow for continued glycolytic activity through glyceraldehyde-3-phosphate dehydrogenase (GAPDH). Moreover, excretion of lactate into the tumor microenvironment lowers extracellular $\mathrm{pH}$ and increases the activity of metalloproteases, aiding in the degradation of the extracellular matrix and inducing cancer metastasis (49,50). Likewise, extracellular lactate promotes an immunosuppressive tumor microenvironment (51-53).

Lactate is trafficked in and out of the cell by monocarboxylate transporters, MCT1 (import) and MCT4 (export). While cancer cells upregulate MCT4 and primarily export lactate (54), recent studies have reported circulating lactate can be imported through MCT1 and utilized as a TCA cycle carbon source in both mouse models of lung cancer as well as in NSCLC patients $(37,55,56)$. The symbiosis of excreting and oxidizing imported lactate is postulated to allow glucose to supply other anabolic pathways for cell growth while sustaining the bioenergetic demands of rapid proliferation $(43,57)$.

\section{Glutaminolysis}

In addition to glycolysis, cancer cells rely heavily on glutaminolysis to meet their bioenergetic needs for cellular growth and proliferation (37). Glutamine is the 
most abundant amino acid in the plasma and is consumed at significantly higher rates in cancer cells compared to normal tissue $(47,58)$. Glutamine plays several key roles in cancer metabolism as a nitrogen donor for nucleotide and protein synthesis, a carbon source for lipid biosynthesis and energy production, and as a precursor for the production of glutathione (Figure 4) (58-60). Increased expression and activity of glutamine metabolizing enzymes and transporters have been reported in multiple cancers $(42,61)$. Additionally, targeting glutamine utilization via glutamine depletion or inhibition of glutaminolytic enzymes has shown efficacy against glutamine-dependent cancer types in vitro and in vivo $(47,61)$.

Glutaminolysis is a series of biochemical reactions that initiates when glutamine is transported into the cytoplasm and is further metabolized through deamination reactions catalyzed by mitochondrial or cytosolic glutaminases to generate glutamate. In the cytoplasm, glutamine is used as a nitrogen donor for biosynthesis of purine and pyrimidine nucleotides, or as a carbon source through the conversion of glutamate for the antioxidant glutathione and nonessential amino acids (42). Many cancer cells require de novo lipid biosynthesis which diverts citrate from the TCA cycle to supply a source of lipogenic acetyl-CoA. Diminished availability of citrate to the TCA cycle as a consequence of the Warburg effect results in the need for anaplerotic replenishment of the TCA cycle, which can be provided by glutaminolysis (47). In the mitochondria, glutamate serves as a source of carbon for the TCA cycle, through production of alpha-ketoglutarate by glutamate dehydrogenase (GLUD1) or various transaminases, such as aspartate 


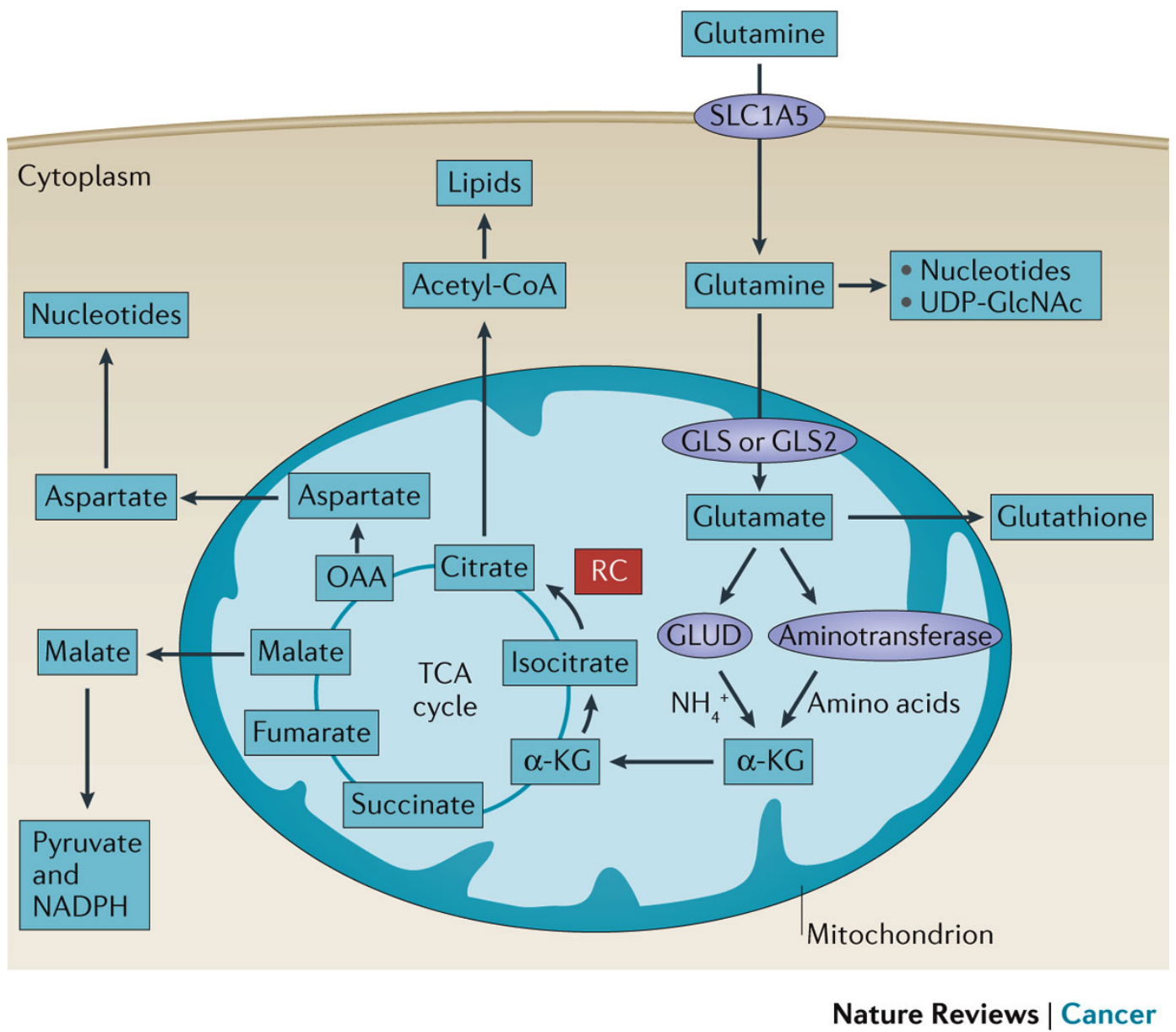

Figure 4. Major metabolic and biosynthetic fates of glutamine. Glutamine plays several key roles in cancer metabolism as a nitrogen donor for nucleotide synthesis, a carbon source for lipid biosynthesis and energy production, and as a precursor for glutathione biosynthesis. Abbreviations: glutamine transporter (SLC1A5), glutaminase (GLS/GLS2), glutamate dehydrogenase (GLUD), reductive carboxylation $(\mathrm{RC})$. Reprinted with permission from [Springer Nature] : [Nature] [NATURE REVIEWS CANCER] (From Krebs to clinic: glutamine metabolism to cancer therapy), (Brain J. Altman, Zachary E. Stine, and Chi V. Dang), [@MACMILLIAN PUBLISHERS LIMITED] (2016). 
aminotransferase (AAT), alanine aminotransferase (ALT), or phosphoserine aminotransferase (PSAT). Oxidative metabolism of glutamine through the TCA cycle also produces $\mathrm{NADH}$ and $\mathrm{FADH}_{2}$ for mitochondrial OXPHOS (oxidative phosphorylation) to generate ATP necessary to sustain cellular bioenergetics. Additionally, glutaminolysis allows cancer cells to mitigate oxidative stress associated with rapid cell proliferation. Glutamine carbons exiting the TCA cycle as malate are converted to pyruvate by malic enzyme, a reaction which generates reduced nicotinamide adenine dinucleotide phosphate (NADPH) (62). NADPH is required for the generation of reduced glutathione, a reactive oxygen species scavenger that protects against oxidative stress.

In addition to serving as a source of anaplerotic carbon for the TCA cycle, glutamine can also contribute to the production of acetyl-CoA for lipogenesis via reductive carboxylation. Acetyl-CoA production from glutamine occurs via two distinct mechanisms. First, the addition of $\mathrm{CO}_{2}$ to glutamine-derived $\alpha$ ketoglutarate via isocitrate dehydrogenase 1 (IDH1) produces citrate, which is transported to the cytosol to generate lipogenic acetyl-CoA (63). Likewise, glutamine-derived malate can be converted to pyruvate by malic enzyme, which can be further metabolized to lipogenic acetyl-CoA via citrate (47). Primarily observed under hypoxic conditions, reductive carboxylation of $\alpha$-ketoglutarate provides a source of acetyl-CoA for lipogenesis that is independent of glucose, allowing cells to divert glucose carbons into other anabolic pathways for growth (64).

Pentose Phosphate Pathway 
Pentose phosphate pathway (PPP) is one of the major metabolic pathways that promotes tumor cell proliferation by generating the substrates necessary for nucleic acid synthesis to support DNA replication and RNA production. DNA and RNA are polymers composed of varying combinations of nucleotides, made up of an organic base (pyrimidines including cytosine, thymine, and uracil, and purines which include adenine and guanine), one or more phosphate groups, and a pentose sugar (ribose for RNA or deoxyribose for DNA). The major functions of the PPP are to generate ribose-5-phosphate, the pentose phosphate moiety for nucleotides, and generate NADPH through activity of glucose-6-phosphate dehydrogenase (G6PD) (37).

PPP is comprised of two branches. In the oxidative arm, the glycolytic intermediate glucose-6-phosphate is irreversibly converted to ribulose-5phosphate, yielding two molecules of NADPH. The non-oxidative arm is a reversible pathway comprised of carbon-exchanging reactions beginning with ribulose-5-phosphate and producing a final product of the glycolytic intermediates fructose-6-phosphate and glyceraldehyde-3-phosphate, which can participate in downstream metabolic pathways. Additionally, the non-oxidative arm produces ribose-5-phosphate (R5P) as an intermediate which is used in nucleotide synthesis. The regulatory enzymes that control the PPP include G6PD (oxidative branch) and transketolase (non-oxidative branch).

Rapidly proliferating cells have a high demand for nucleotides and other substrates for biosynthesis, therefore by providing NADPH and R5P for nucleotide synthesis, the PPP is essential for tumor cells to mitigate oxidative stress while 
sustaining their anabolic demands $(65,66)$. In proliferating tumor cells, G6PD activity increases (67), and several PPP enzymes are reported to be upregulated in multiple cancer subtypes $(68,69)$. Recent studies suggest that in addition to its proliferative role, the PPP has an important role in other aspects of cancer such as drug resistance, apoptosis, invasion, and metastasis (68), making the PPP a potential metabolic target for anti-cancer therapies.

One-Carbon Metabolism

One-carbon (1C) metabolism supports multiple physiological processes including the production of $1 \mathrm{C}$ units for nucleotide synthesis, methylation reactions, and the generation of reduced cofactors for redox homeostasis (70). $1 \mathrm{C}$ units are largely derived from serine and glycine, both non-essential amino acids which can be obtained exogenously or synthesized from other carbon sources (71). Serine can be synthesized de novo from glucose through a series of enzymatic reactions which convert 3-phosphoglycerate into serine, and glycine can be produced from serine or threonine. Upregulation of enzymes within serine synthesis as well as "serine addiction" has been observed in several human cancers (72). These substrates are utilized by two primary $1 \mathrm{C}$ metabolism pathways: the folate cycle and the methionine cycle (70). The folate cycle produces $1 \mathrm{C}$ units for nucleotide synthesis as well as NADPH for maintaining redox balance, and has been the target of many anti-cancer therapies (70). Conversely, the methionine cycle produces methyl groups for methylation reactions and epigenetic modifications. Lipid Metabolism 
Lipids are a broad category of hydrophobic or amphipathic molecules. These are comprised of triacylglycerides that primarily serve as energy storage, and phosphoglycerides, sterols, and sphingolipids, which are the major structural components of plasma membranes. The main constituents of triacylglycerides and phosphoglycerides are fatty acids, which consist of long hydrocarbon chains with a carboxy-terminal group. To sustain their high proliferative rate, tumor cells increase de novo lipid biosynthesis to supply the building blocks for membrane formation $(73,74)$. Oncogenes specifically enhance lipogenesis through the upregulation of lipogenic enzymes such as ATP citrate lyase (ACLY), fatty acid synthase (FASN), and acetyl-CoA carboxylase (ACC), as well as by increasing the production of substrates for fatty acid synthesis (75-77). While tumor metabolic reprogramming involves an increase in lipogenesis, recent studies have highlighted a role for fatty acid oxidation in tumorigenesis (78). Fatty acids are a rich energy source as their degradation produces acetyl-CoA which can undergo mitochondrial oxidation, yielding large amounts of ATP through the TCA cycle and mitochondrial respiration $(73,74)$.

As stated previously, metabolic reprogramming is a hallmark of cancer that is characterized by upregulation of multiple pathways including glycolysis, glutaminolysis, PPP, one-carbon metabolism, and lipid metabolism. These specific pathways not only aid in meeting the energy demands of rapid proliferating tumor cells but supply the substrates to sustain large-scale biosynthesis. Additionally, the majority of key oncogenic or tumor suppressor pathways observed in human cancers contribute to the metabolic adaptations of tumor cells, which confer a 
selective advantage. Elucidating the unique metabolic phenotype of cancer cells and the genetic drivers thereof allows for identification of new targets for the potential development of novel therapies to improve patient outcome.

\section{Metabolic Functions of pRb}

Advances in our understanding of $p R b$ function have highlighted roles that extend beyond the cell cycle. Specifically, recent studies demonstrate a direct role for $\mathrm{pRb}$ in controlling cellular metabolism in both normal and transformed cells. The results of these studies are discussed below.

\section{Glucose Metabolism}

The earliest studies to highlight a role for $\mathrm{pRb}$ in controlling glucose metabolism reported elevated expression and activity of hexokinase II (HK2), a rate limiting enzyme in glycolysis, in retinoblastomas compared to normal retina (79). Activation of $\mathrm{pRb}$ has also been shown to increase expression of several glycolytic genes in oncogene-induced senescent cells, promoting both glycolysis and OXPHOS (80). Notably, both glycolysis and OXPHOS were abolished upon knockdown of $R B 1$, highlighting a direct role for $\mathrm{pRb}$ in glycolytic activation. In addition, genetic deletion of $R B 1$ in retinal pigment epithelial cells decreases glucose oxidation (81).

Several studies using transgenic mouse models to modulate $\mathrm{pRb} / \mathrm{E} 2 \mathrm{~F}$ pathway activity in vivo have demonstrated a role for $\mathrm{pRb} / \mathrm{E} 2 \mathrm{~F}$ proteins in regulating glucose tolerance. Deletion of E2F1 in adipocytes results in resistance to diet-induced obesity (82), while loss of $R b 1$ in the hypothalamus leads to glucose intolerance and obesity (83). Additionally, glucose uptake has been shown 
to promote $\mathrm{pRb}$ phosphorylation, thus increasing E2F activity in non-transformed tissues $(84,85)$. Conversely, glucose deprivation promotes the accumulation of hypophosphorylated pRb in cultured mesangial cells (84). These data suggest that $\mathrm{pRb}$ itself can be regulated in part by changes in glucose levels.

Nucleotide Synthesis

Among the first direct E2F-regulated targets to be described included genes involved in nucleotide synthesis, such as dihydrofolate reductase (DHFR), thymidylate synthase (TS), ribonucleotide reductase (RNR), and thymidine kinase (TK1) $(86,87)$. In the absence of $p R b$, the transcription of each of these genes increases suggesting regulation by an pRb/E2F complex (88). Additionally, E2Fregulation of these targets is conserved during evolution, highlighting the significance of this pathway in regulating nucleotide synthesis (89-91). Several studies have shown a potential link between $\mathrm{pRb}$-mediated control of nucleotide synthesis and cell cycle regulation. Expression of a constitutively active $\mathrm{pRb}$ protein results in both an increase in $\mathrm{G}_{1}$ cell population and a concomitant decrease in dNTP pools (88). Likewise, pRb, but not p107 or p130, was found to repress expression of RNR and DHFR in cells that had undergone oncogeneinduced senescence (92). Notably, knockdown of $R B 1$ in these cells rescued the changes in gene expression and allowed the cells to reenter the cell cycle.

\section{Lipogenesis}

Targets of the $\mathrm{pRb} / \mathrm{E} 2 \mathrm{~F}$ pathway are often regulated by additional DNAbinding proteins which modulate their gene expression. One study identified a genetic interaction between $\mathrm{pRb}$ and the sterol regulatory element-binding protein 
(SREBP) transcription factors (93). SREBPs are master regulators of lipogenic and steroidogenic genes (94), thus demonstrating a new role for $\mathrm{pRb}$ in regulating lipid metabolism. pRb was reported to target many of the genes encoding enzymes within fatty acid and cholesterol biosynthesis (93). Moreover, the authors noted these genes possess either E2F-consensus sequences, sterol regulatory elements (SREs), or both. Lipidomic profiling coupled with transcriptomic analysis of mouse embryonic fibroblasts (MEFs) revealed loss of $R b 1$ induces significant alterations in their lipid composition and increases tumorigenic potential (95).

The TCA Cycle and Oxidative Metabolism

The $\mathrm{pRb} / \mathrm{E} 2 \mathrm{~F}$ complex directly regulates mitochondrial activity by suppressing the expression of enzymes that regulate mitochondrial pyruvate oxidation $(96,97)$. Specifically, pyruvate dehydrogenase kinase (PDK4) is a direct target of $\mathrm{pRb} / \mathrm{E} 2 \mathrm{~F}$, and when activated, inhibits pyruvate dehydrogenase $(\mathrm{PDH})$ activity, resulting in decreased glucose oxidation within the TCA cycle. Contrary to these findings, acute deletion of $R b 1$ in mice has been reported to increase mitochondrial pyruvate oxidation from glucose in both the lung and colon (81). Additionally, RB1 deficiency in triple negative breast cancers increases both OXPHOS and mitochondrial protein translation (98).

In addition to glucose, cancer cells oxidize glutamine-derived carbon to fuel the TCA cycle $(58,59,99)$. Increased glutaminolysis and glutathione production has been observed in pRb-deficient mammalian cells and Drosophila $(91,100)$. Specifically, loss of $R b 1$ increases expression of the glutamine transporter ASCT2 and the activity of glutaminase in MEFs (100). Notably, glutamine withdrawal 
significantly increased ROS in these cells, suggesting pRb-deficient cells may be susceptible to oxidative stress upon glutaminase inhibition.

While the mechanism by which $\mathrm{pRb}$ mediates metabolic changes has not been fully elucidated, several studies has reported that E2F and pRb proteins bind directly to promoters of genes that regulate metabolic flux (101). Moreover, $\mathrm{pRb}$ can also exert its metabolic function through directly decreasing expression of oncogenic signaling pathways that converge on metabolism, such as Ras or c-Myc (86). An important gap in the evidence for a model by which $\mathrm{pRb}$ directly regulates metabolism is that the majority of these studies were performed in non-transformed cells or tissues. To date, there is no published study that directly assesses the metabolic phenotype resulting from $\mathrm{pRb}$ dysfunction in lung cancer; particularly in vivo. Based on the growing body of evidence that $\mathrm{pRb}$ plays a role in regulating the metabolic state of the cell $(86,87,95,102)$, we hypothesize that $\mathrm{pRb}$ modulates metabolism in lung cancer through control of specific genes within pathways that support cancer growth. This hypothesis will be examined by the following aims:

- Specific Aim 1: Define the metabolic changes resulting from pRb activation in NSCLC in vitro. This aim will be evaluated in A549 lung adenocarcinoma cells and will implement several in vitro metabolic assays. $\mathrm{pRb}$ activation will be achieved pharmacologically using an FDA-approved CDK4/6 inhibitor.

- Specific Aims 2 and 3: Characterize the changes in glucose utilization (Aim 2) and metabolism of other TCA nutrient substrates (Aim 3) resulting from $R b 1$ deletion in mouse lung tumors in vivo. These aims 
will be evaluated using a combination of steady-state and stable-isotope labeled metabolomics to assess global changes in either glucose, glutamine, or lactate metabolism resulting from $R b 1$ loss in Kras-driven lung tumors in vivo. 


\section{CHAPTER 2: PALBOCICLIB TREATMENT ALTERS NUCLEOTIDE BIOSYNTHESIS AND GLUTAMINE DEPENDENCY IN A549 CELLS}

\section{Introduction}

Lung cancer is among the most frequently diagnosed cancers and is the leading cause of cancer-related death worldwide, with an estimated 1.6 million deaths each year (1-3). Of its subtypes, non-small cell lung cancer (NSCLC) accounts for $85 \%$ of all lung cancer diagnoses (2). One of the hallmark events in NSCLC pathogenesis is deregulation of the cell cycle $(18,103)$. Transition from $\mathrm{G}_{1}$ to $S$ phase during cell cycle progression is tightly regulated by phosphorylation of the retinoblastoma protein tumor suppressor $(\mathrm{pRb})$ by the CDK4/6-Cyclin $\mathrm{D}$ complex. Activity of the CDK4/6-Cyclin D complex is strongly inhibited by $\mathrm{p} 16$ which induces cell cycle arrest. In the majority of NSCLC cases, p16 is mutated, deleted, or epigenetically silenced, resulting in constitutive phosphorylation of $p R b$ and uncontrolled cell cycle progression $(18,103)$. Pharmacologically, CDK4/6 inhibition phenocopies p16 activity $(104,105)$.

Highly selective and potent small-molecule CDK4/6 inhibitors have shown anti-tumor activity both in vitro and in vivo $(104,105)$. Among these inhibitors, palbociclib (PD-0332991) has been FDA-approved for the treatment of women with breast cancer (21). Recently, palbociclib has shown efficacy either alone or as combination therapy in preclinical studies of NSCLC (22-26). Mechanistically, the 
functional consequences of CDK4/6 inhibition apart from cell cycle arrest in NSCLC are largely unknown; yet metabolic reprogramming in response to palbociclib has revealed unique targetable vulnerabilities in several cancers including pancreatic, colorectal, and leukemia (106-108). As such, we aimed to characterize the metabolic phenotype induced by palbociclib in NSCLC.

Herein, we report that palbociclib treatment decreases nucleotide biosynthesis and increases glutaminolysis without altering glycolysis in A549 lung adenocarcinoma cells. Specifically, palbociclib-induced glutamine dependency sensitizes A549 cells to glutaminase inhibition. Together, these data expand our knowledge of understanding of the metabolic consequences of CDK4/6 inhibition in NSCLC. 


\section{Materials and Methods}

\section{Cell culture}

The A549 lung adenocarcinoma cells were obtained from ATCC and cultured in DMEM (Gibco) supplemented with 10\% fetal bovine serum (Hyclone) and $50 \mu \mathrm{g} / \mathrm{ml}$ gentamicin sulfate (Gibco). Cells were maintained at $5 \% \mathrm{CO}_{2}$ at $37^{\circ} \mathrm{C}$. Palbociclib (PD-0332991) and CB-839 were purchased from Selleck Chemicals.

\section{Cell transfections}

Using Lipofectamine RNAiMAX reagent (Invitrogen), A549 cells were transiently transfected with control siRNA (Silencer Select Negative Control \#2, Cat. No. 4390826, Ambion) or siRNA targeted to RB1 (Silencer Select s523, Cat. No. 4390824 , Ambion) for 24 hours prior to palbociclib treatment.

\section{Cell proliferation and viability}

A549 cells were seeded at 120,000 in 6-well plates (Corning), followed by transfection and treatment with $1 \mu \mathrm{M}$ palbociclib or vehicle control. For glutaminase inhibition studies, cells were seeded at 25,000 in 24-well plates (Corning), followed by $25 \mathrm{nM}$ CB-839 treatment. Forty-eight hours post-treatment, cell number was determined by trypan blue exclusion and enumeration using a hemocytometer.

\section{Glucose uptake}

A549 cells were seeded at 120,000 in 6 -well plates (Corning). Cells were transfected and treated with $1 \mu \mathrm{M}$ palbociclib or vehicle control for 48 hours prior to performing the assay. Cells were then incubated in glucose-free DMEM for $30 \mathrm{~min}$, followed by incubation with $5 \mu \mathrm{L}$ of $2-\left[{ }^{14} \mathrm{C}\right]$-deoxyglucose $(0.25 \mu \mathrm{Ci} / \mathrm{ml}$; Perkin Elmer $)$ and three subsequent washes with ice-cold glucose-free DMEM. Lysates were 
collected in $500 \mu \mathrm{L}$ of $0.1 \%$ SDS and scintillation counts (counts/min) were measured using $350 \mu \mathrm{L}$ of cell lysate on a Tri-Carb 2910 liquid scintillation analyzer (Perkin Elmer Life Sciences). Protein concentration was determined using the BCA assay (Pierce) according to the manufacturer's protocol. Counts were normalized to $\mu \mathrm{g}$ of protein.

\section{${ }^{3} \mathrm{H}_{2} \mathrm{O}$-Glycolysis Assay}

A549 cells were seeded at 120,000 in 6 -well plates (Corning). Cells were transfected and treated with $1 \mu \mathrm{M}$ palbociclib or vehicle control for 48 hours prior to performing the assay. All cells were then incubated with $500 \mu \mathrm{L}$ of complete medium containing $2 \mu \mathrm{L}$ of $1 \mu \mathrm{Ci}$ of $5-\left[{ }^{3} \mathrm{H}\right]$-glucose for $60 \mathrm{~min}$. Medium was then collected and centrifuged for 5 min at $8,000 \mathrm{rpm}$ to pellet cell debris. To isolate ${ }^{3} \mathrm{H}_{2} \mathrm{O}$ generated via enolase activity from the $5-\left[{ }^{3} \mathrm{H}\right]$-glucose added to the medium, $150 \mu \mathrm{L}$ of radiolabeled medium was added to open microcentrifuge tubes that were placed in airtight scintillation vials containing $1 \mathrm{~mL}$ of $\mathrm{H}_{2} \mathrm{O}$. Vials were parafilm sealed, and ${ }^{3} \mathrm{H}_{2} \mathrm{O}$ from the medium was allowed to equilibrate with the $\mathrm{H}_{2} \mathrm{O}$ in the scintillation vials for 48 hours at $37^{\circ} \mathrm{C} .{ }^{3} \mathrm{H}_{2} \mathrm{O}$ that has diffused into the $\mathrm{H}_{2} \mathrm{O}$ was measured on a Tri-Carb 2910 liquid scintillation analyzer (Perkin Elmer Life Sciences). Protein concentration was determined using the BCA assay (Pierce) according to the manufacturer's protocol. Counts were normalized to $\mu \mathrm{g}$ of protein.

\section{Mito stress test}

A549 cells were seeded at 120,000 in 6 -well plates (Corning). Cells were transfected and treated with $1 \mu \mathrm{M}$ palbociclib or vehicle control for 48 hours prior to performing the assay. OCR measurements were conducted using a Seahorse 
XFe96 analyzer according to manufacturer's protocol. One day prior to preforming the assay, cells were reseeded at 35,000 in XFe96 cell culture plates and incubated in $5 \% \mathrm{CO}_{2}$ at $37^{\circ} \mathrm{C}$. One hour prior to analysis, growth medium was replaced with assay medium (DMEM minus phenol red and sodium bicarbonate that is supplemented with $1 \mathrm{mM}$ pyruvate, $2 \mathrm{mM}$ L-glutamine, and 10mM glucose, $\mathrm{pH} 7.4$ ) and incubated in a non- $\mathrm{CO}_{2}$ incubator. During assay, $1 \mu \mathrm{M}$ oligomycin (Sigma), $2 \mu \mathrm{M}$ FCCP (Sigma), and $1 \mu \mathrm{M}$ rotenone/antimycin A (Sigma) were sequentially injected into each well in accordance with standard protocols. Absolute rates (pmoles/min) were normalized to $\mu \mathrm{g}$ of protein.

\section{Mito fuel flexibility assay}

A549 cells were seeded at 120,000 in 6 -well plates (Corning). Cells were transfected and treated with $1 \mu \mathrm{M}$ palbociclib or vehicle control for 48 hours prior to performing the assay. OCR measurements were conducted using a Seahorse XFe96 analyzer according to manufacturer's protocol. One day prior to preforming the assay, cells were reseeded at 35,000 in XFe96 cell culture plates and incubated $5 \% \mathrm{CO}_{2}$ at $37^{\circ} \mathrm{C}$. One hour prior to analysis, growth medium was replaced with assay medium (DMEM minus phenol red and sodium bicarbonate that is supplemented with $1 \mathrm{mM}$ pyruvate, $2 \mathrm{mM}$ L-glutamine, and $10 \mathrm{mM}$ glucose, $\mathrm{pH} 7.4$ ) and incubated in a non- $\mathrm{CO}_{2}$ incubator. Capacity and dependency for fatty acid, glutamine, and glucose oxidation were determined through injections of the following inhibitors in accordance with standard protocols: $4 \mu \mathrm{M}$ etomoxir (inhibits long chain fatty acid oxidation), $3 \mu \mathrm{M}$ BPTES (inhibits glutamine oxidation), and $2 \mu \mathrm{M}$ UK5099 (inhibits glucose oxidation). The percent capacity for each fuel source was 
determined by dividing the OCR following inhibiting the two other pathways by the OCR observed when all pathways are inhibited. The percent dependency for each fuel source was determined by dividing the OCR observed when that specific pathway is inhibited by the OCR observed when all pathways are inhibited. Absolute rates (pmoles/min) were normalized to $\mu \mathrm{g}$ of protein.

\section{Glycolysis stress test}

A549 cells were seeded at 120,000 in 6 -well plates (Corning). Cells were transfected and treated with $1 \mu \mathrm{M}$ palbociclib or vehicle control for 48 hours prior to performing the assay. ECAR measurements were conducted using a Seahorse XFe96 analyzer according to manufacturer's protocol. One day prior to preforming the assay, cells were reseeded at 35,000 in XFe96 cell culture plates and incubated $5 \% \mathrm{CO}_{2}$ at $37^{\circ} \mathrm{C}$. One hour prior to analysis, growth medium was replaced with assay medium (DMEM minus phenol red and sodium bicarbonate that is supplemented with $2 \mathrm{mM}$ L-glutamine, $\mathrm{pH} 7.4$ ) and incubated in a non- $\mathrm{CO}_{2}$ incubator. During assay, $10 \mathrm{mM}$ glucose (Sigma), $1 \mu \mathrm{M}$ oligomycin (Sigma), and 50mM 2-deoxyglucose (Sigma) were sequentially injected into each well in accordance with standard protocols. Absolute rates $(\mathrm{mpH} / \mathrm{min})$ were normalized to $\mu \mathrm{g}$ of protein.

\section{Glucose 6-phosphate dehydrogenase activity assay}

A549 cells were seeded at 120,000 in 6 -well plates (Corning). Cells were transfected and treated with $1 \mu \mathrm{M}$ palbociclib or vehicle control for 48 hours prior to performing the assay. The activity of G6PD from cell lysates was measured following 
the manufacturer's protocol using the Glucose-6-Phosphate Dehydrogenase Activity Assay Kit (Sigma, Cat. No. MAK015-1KT) and normalized to $\mu$ g of protein.

\section{$\left[\mathrm{U}-{ }^{13} \mathrm{C}\right]$-glucose tracer studies}

Cells were seeded at $1 \times 10^{6}$ cells in $10 \mathrm{~cm}$ dishes (Corning) and treated with palbociclib or vehicle control for 48 hours. Cells were then labeled for six hours with DMEM supplemented with $1 \mathrm{~g} / \mathrm{L}\left[\mathrm{U}-{ }^{13} \mathrm{C}\right]$-glucose and $10 \%$ dialyzed fetal bovine serum (Gibco). Cells were washed three times in ice-cold 1x PBS and quenched with acetonitrile. Metabolites were extracted in acetonitrile:water:chloroform $(2 \mathrm{ml}: 1 \mathrm{~mL}: 740 \mu \mathrm{L})$. Samples were centrifuged at $3,000 \times \mathrm{xg}$ for 20 minutes at $4^{\circ} \mathrm{C}$ to separate the polar, lipid, and cell debris layers. The remaining cell debris was reextracted with $500 \mu \mathrm{L}$ chloroform:methanol:butylated hydroxytoluene $(2: 1: 1 \mathrm{mM})$ and centrifuged at $22,000 \times \mathrm{xg}$ for 20 minutes at $4^{\circ} \mathrm{C}$. The residual polar and lipid fractions were combined with their respective fractions from the first extraction. The polar fraction was vacuum-dried by lyophilization. The dried sample was dissolved in $100 \mu \mathrm{L} \mathrm{50 \%}$ acetonitrile and vigorously vortex-mixed for 3 minutes. After centrifugation at $14,000 \mathrm{rpm}$ and $4^{\circ} \mathrm{C}$ for $20 \mathrm{~min}, 80 \mu \mathrm{L}$ of supernatant was collected for 2DLC-MS/MS analysis.

\section{DLC-MS/MS analysis and data processing}

All samples were randomly analyzed on a Thermo Q Exactive HF Hybrid Quadrupole-Orbitrap Mass Spectrometer coupled with a Thermo DIONEX UltiMate 3000 HPLC system (Thermo Fisher Scientific, Waltham, MA, USA). The UltiMate 3000 HPLC system was equipped with a reverse phase chromatography (RPC) column and a hydrophilic interaction chromatography (HILIC) column that 
wwas configured in parallel to form a parallel 2DLC-MS system (109). To obtain full MS data, every sample was analyzed by the parallel 2DLC-MS in positive mode $(+)$ and negative mode (-), respectively. For metabolite identification, one unlabeled sample in each sample group was analyzed by 2DLC-MS/MS in positive mode (+) and negative mode (-) to acquire MS/MS spectra at three collision energies (20, 40 and $60 \mathrm{eV})$.

\section{Data analysis for 2DLC-MS/MS}

Full MS .raw files were first converted to .mzML format with msConvert tool, a part of an open-source ProteoWizard suite, described in detail by Adusumilli and Mallick (110). Isotopologue peak deconvolution and assignments were performed using EI-MAVEN (111). Peaks were assigned using a metabolite list generated and verified using full scan MS and MS/MS spectra of unlabeled samples, as described previously (112-114). The metabolite list contained metabolite names and corresponding molecular formulae used to generate theoretical $\mathrm{m} / \mathrm{z}$ values for all possible isotopologues, and retention times for each metabolite. El-MAVEN parameters for compound library matching were as follows: EIC Extraction Window \pm 7 ppm; Match Retention Time \pm 0.60 min. For ${ }^{13} \mathrm{C}$ isotopologue peak detection, the software criteria were set as follows: Minimum Isotope-parent correlation 0.20; Isotope is within 5 scans of parent; Abundance threshold 1.0; Maximum Error To Natural Abundance $100 \%$. All assignments were visually inspected and compared to unlabeled samples for reference. The peak list with corresponding abundances was exported to a comma-separated (CSV) file and uploaded to the Polly workflow for natural abundance correction and calculation of total pool size for each 
metabolite (by summing peak areas of each detected isotopologue) using Polly Isocorrect module. Finally, the data were downloaded and plotted using Microsoft Excel and GraphPad Prism software.

\section{Real time-PCR}

Total RNA was isolated from cell pellets using the RNeasy Mini Kit (Qiagen) according to the manufacturer's protocol. The resulting total RNA $(1 \mu \mathrm{g})$ was converted to cDNA using the High-Capacity RNA-to cDNA kit (applied biosystems). Gene expression was determined by qPCR using the following Taqman Gene Expression Assays: RB1 (Hs01078066_m1), RRM1 (Hs01040698_m1), RRM2 (Hs00357247_g1), PRPS2 (Hs00267624_m1), G6PD (Hs0166169_m1), ASCT2 (Hs01056542_m1), GLS (Hs01014020_m1), and GLUD1 (Hs01632647_g1). $\beta$ actin (Hs01060665_g1) was used as an internal control. Data are reported as the $\log$ (base 2) of the fold change with respect to siNeg treated with vehicle control.

\section{Immunoblotting}

Whole-cell lysates were prepared in RIPA lysis buffer (Pierce) containing protease and phosphatase inhibitors. $20 \mu \mathrm{g}$ of protein was separated on $10 \%$ Bolt Bis-Tris gels (Invitrogen) and transferred to PVDF membrane. Membranes were blocked with 5\% BSA in TBS-T and probed with 1:1000 dilution of anti-phospho-Rb (Cell Signaling, \#3590S) overnight at $4^{\circ} \mathrm{C}$. Membranes were washed and incubated with HRP-conjugated anti-rabbit $(1: 5,000)$ secondary antibodies for one hour. Protein detection was performed by ECL chemiluminescent reagent (Amersham) exposure. 1:20,000 dilution of anti- $\beta$-actin antibody (Sigma, A2228) was used to assess protein loading. 


\section{Statistical analysis}

Statistical analyses were carried out using GraphPad Prism. All numerical data are reported as mean \pm SEM. For each experiment, statistical analysis, replicates, and $p$ values are described in their respective figure legends. 


\section{Results}

\section{Palbociclib treatment does not alter glycolysis in A549 cells}

To assess the role of CDK4/6 inhibition on metabolism in NSCLC, we utilized A549 lung adenocarcinoma cells. While these cells express wild-type pRb, they harbor a p16 INK4A deletion that results in constitutive $\mathrm{pRb}$ hyperphosphorylation and inactivation. Our prior studies have demonstrated treatment with palbociclib inhibits the phosphorylation of $\mathrm{pRb}$ and results in decreased cell proliferation (Figure 5A,B) (115). Recent studies have demonstrated palbociclib alters glucose metabolism in multiple cancer subtypes (116-118). To monitor the effect of palbociclib on glucose uptake, we performed radiolabeled glucose uptake assay using $2-\left[{ }^{14} \mathrm{C}\right]$-deoxyglucose in A549 cells. As CDK4/6 inhibition can have metabolic effects independent of $p R b$, these studies were performed following palbociclib treatment with simultaneous knockdown of RB1 (Figure 5C). We observed no significant change in glucose uptake upon palbociclib treatment in A549 cells (Figure 6A). We next examined, as a measurement of glycolytic activity, the release of ${ }^{3} \mathrm{H}_{2} \mathrm{O}$ from $5-\left[{ }^{3} \mathrm{H}\right]$-glucose via enolase activity. We found that palbociclib decreases ${ }^{3} \mathrm{H}_{2} \mathrm{O}$ production in an $\mathrm{pRb}-$ dependent manner (Figure 6B). However, it has been reported that the use of 5$\left[{ }^{3} \mathrm{H}\right]$-glucose to measure glycolysis can overestimate glycolytic rate, as both the pentose phosphate pathway (PPP) and glycolysis generate the substrate for enolase (119). To better assess glycolytic function in response to palbociclib treatment, we performed a glycolysis stress test using a Seahorse XFe96 analyzer. Interestingly, we observed no difference in the extracellular acidification rate (ECAR) 


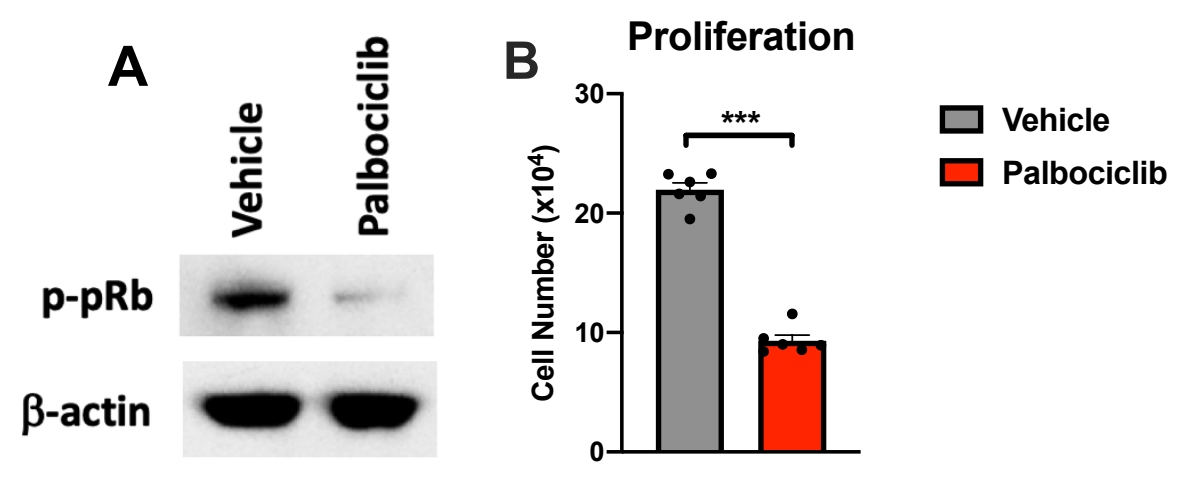

C RB1 Expression

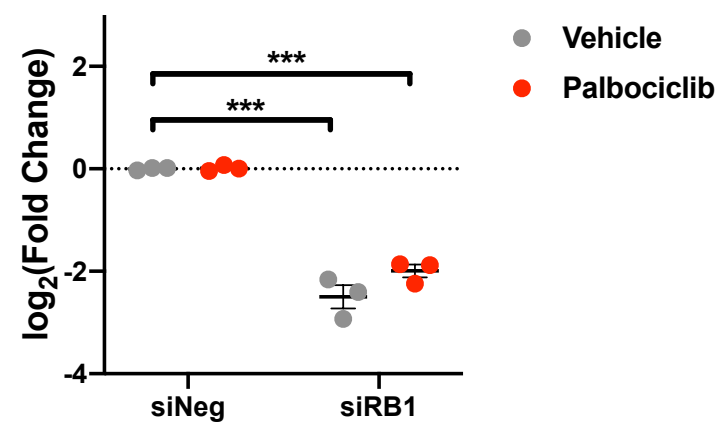

Figure 5. Palbociclib decreases $\mathrm{pRb}$ phosphorylation and proliferation of A549 lung cancer cells. (A) Western blot analysis phosho-pRb ( $p-p R b)$ levels and (B) cell proliferation A549 cells following 48 -hour $1 \mu \mathrm{M}$ palbociclib treatment. (C) Confirmation of $p R b$ knockdown by siRNA by $q P C R$. For $(\mathbf{A}, \mathbf{C}) \beta$-actin was used as a loading and internal control, respectively. For $(\mathbf{B}, \mathbf{C})$ values represent mean \pm SEM, analyzed by unpaired t-test ( $n=5$, independent experiments) (B) and twoway ANOVA with Sidak's post-hoc multiple comparisons $(n=3$, independent experiments) (C). Statistical significances between each group are as follows: ${ }^{* * *} p<0.001$. 
A Glucose Uptake Assay
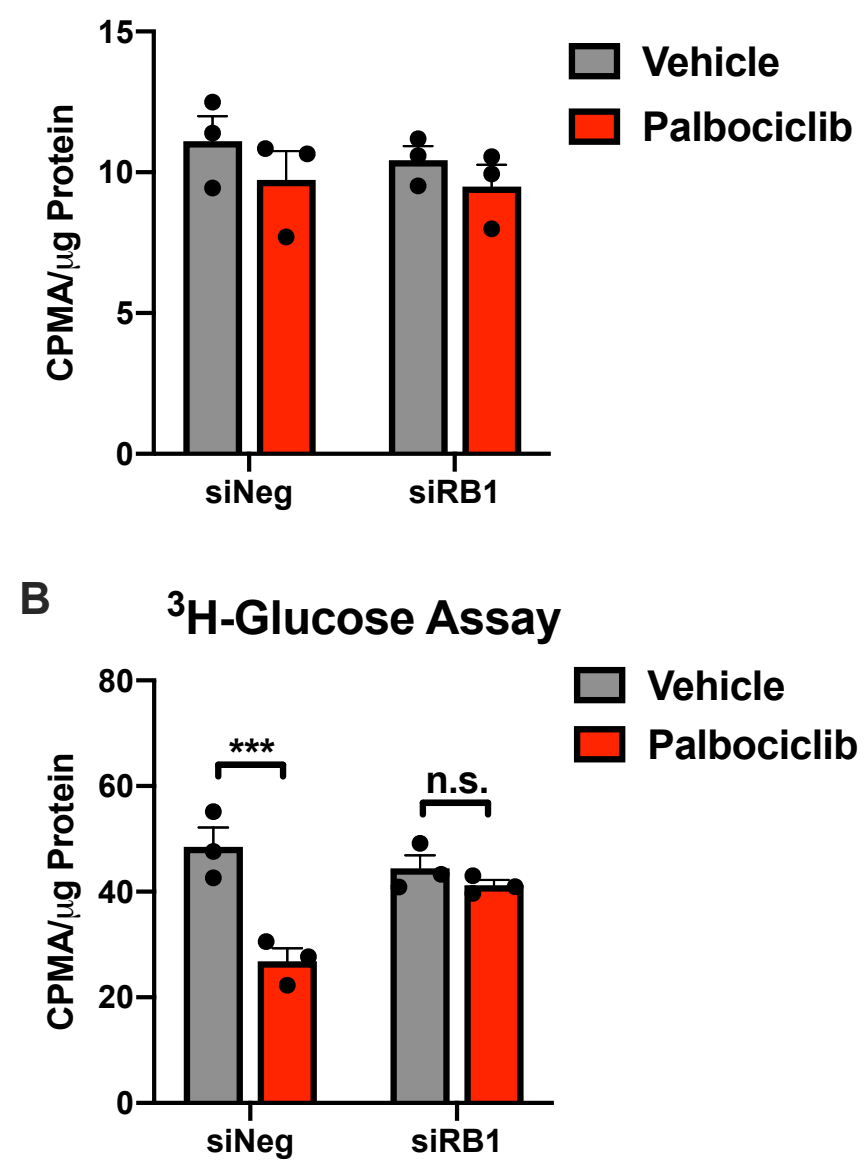

Figure 6. Palbociclib has no effect on glucose uptake but decreases ${ }^{3} \mathrm{H}_{2} \mathrm{O}$ production in an pRb-dependent manner. (A) Glucose uptake assessed by intracellular 2-[14C]-deoxyglucose, and (B) Enolase activity measured by ${ }^{3} \mathrm{H}_{2} \mathrm{O}$ production in A549 cells following knockdown of $\mathrm{pRb}$ and 48-hour treatment with $1 \mu \mathrm{M}$ palbociclib. Values represent mean \pm SEM, analyzed by two-way ANOVA with Sidak's post-hoc multiple comparisons $(n=3$, independent experiments). Statistical significances between each group are as follows: ${ }^{* * *} p<0.001$. 
upon palbociclib treatment (Figure 7), suggesting palbociclib does not alter glycolysis in A549 cells.

To define global changes in glucose utilization resulting from palbociclib treatment, we performed $\left[\mathrm{U}-{ }^{13} \mathrm{C}\right]$-glucose tracer studies. Utilization of ubiquitously labeled glucose results in the intracellular generation of ${ }^{13} \mathrm{C}$ labeling of the hexose and triose sugar intermediates within the glycolytic pathway; leading to fully labeled pyruvate $(m+3)$ and lactate $(m+3)$ (Figure 8). Palbociclib has been shown to increase glycolytic flux in both breast and pancreatic cancers $(106,117,118)$; however, consistent with our glycolysis stress test findings, palbociclib does not alter glucose carbon incorporation into glycolytic intermediates in A549 cells (Figure 9). Our data suggest that the palbociclib-mediated effects on glycolysis may be tissue-specific.

\section{CDK4/6 inhibition decreases glucose flux through the PPP}

Given we observed a decrease in ${ }^{3} \mathrm{H}_{2} \mathrm{O}$ production as measured from radiolabeled 5-[3H]-glucose, but did not observe a corresponding decrease in ECAR or glucose carbon incorporation into glycolytic intermediates from our [U-13 $\mathrm{C}]-$ glucose tracer studies, we hypothesized palbociclib may alter PPP activity. We observed decreased glucose carbon incorporation into sedoheptulose 7phosphate, an intermediate in the PPP. Treatment also decreased $m+5$ labeling of several nucleotides, which is indicative of a fully labeled ribose moiety derived from PPP activity (Figure 10,11). Together, these data suggest palbociclib decreases glucose metabolism through the PPP. Consistent with our labeling data, palbociclib 

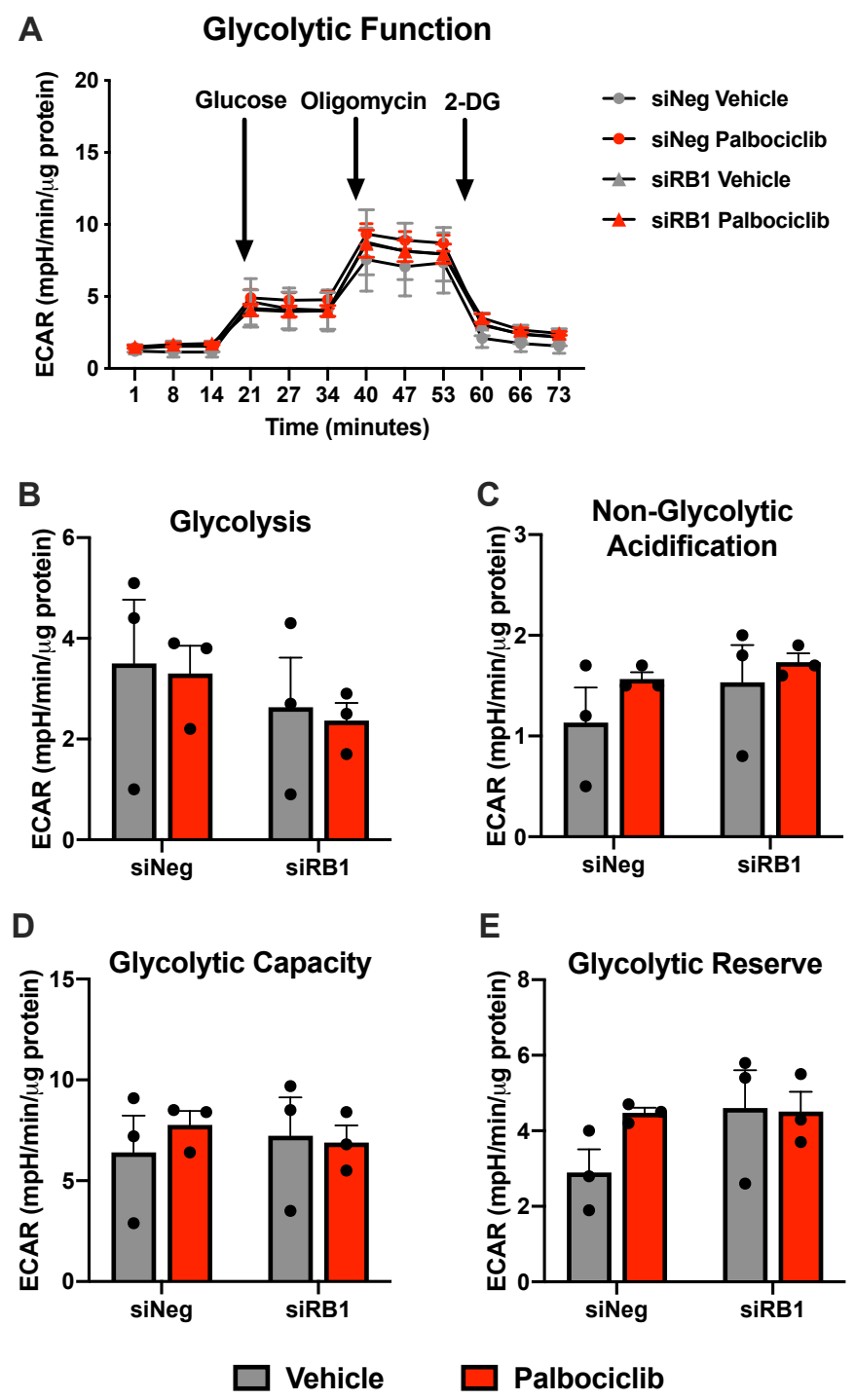

E

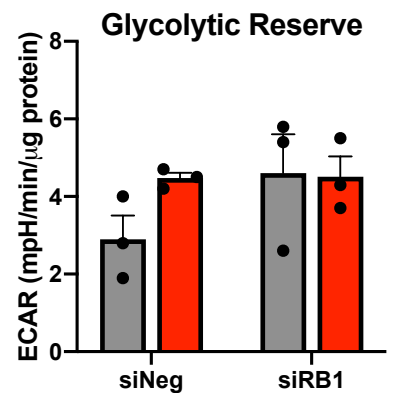

Figure 7. Palbociclib does not alter glycolytic function in vitro. (A) Glycolysis stress test measured in A549 cells following knockdown of pRb and 48-hour treatment with $1 \mu \mathrm{M}$ palbociclib. (B-E) ECAR assessment of (B) glycolysis, (C) nonglycolytic acidification, (D) glycolytic capacity, and (E) glycolytic reserve. Values represent mean \pm SEM, analyzed by two-way ANOVA with Sidak's post-hoc multiple comparisons ( $n=3$, independent experiments). 


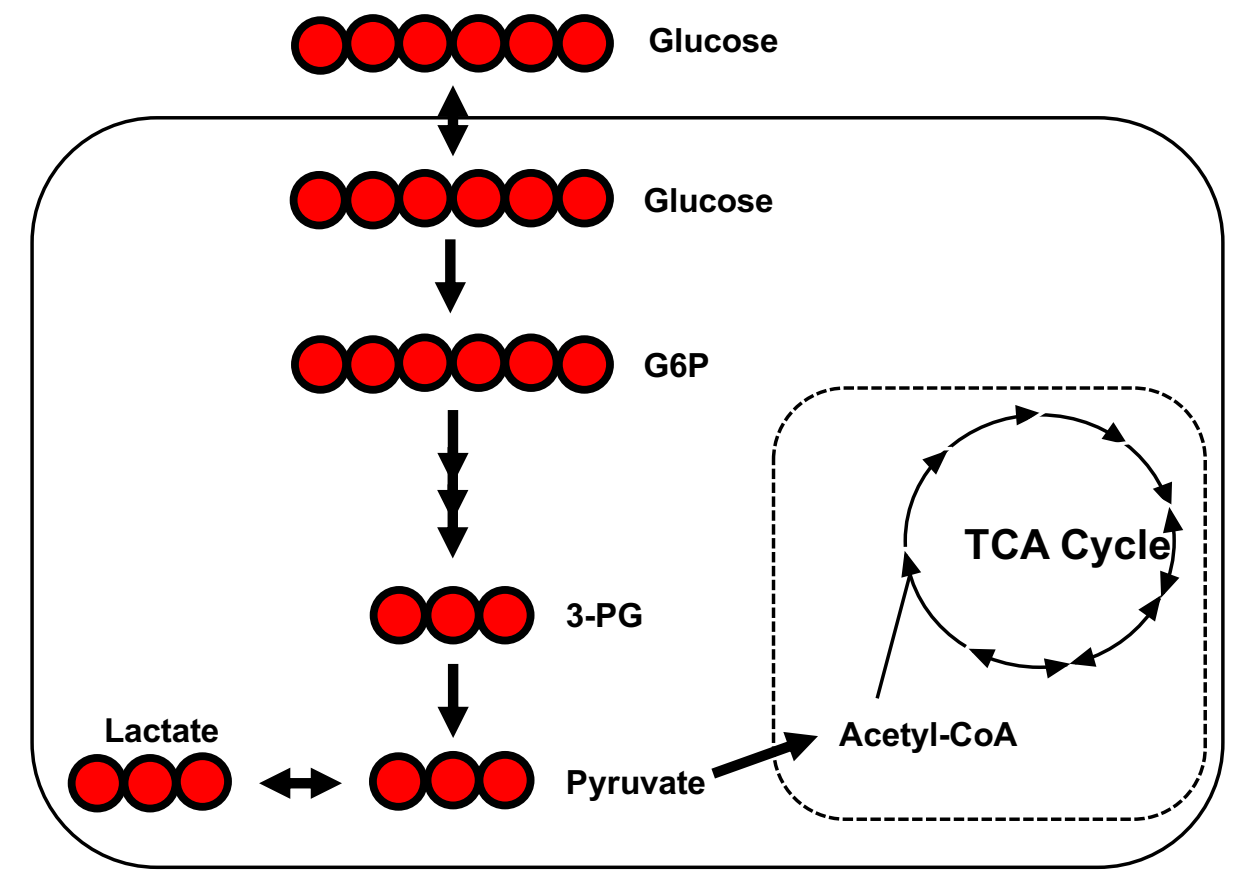

Figure 8. Cartoon of $\left[\mathrm{U}-{ }^{13} \mathrm{C}\right]$-glucose fate mapping though glycolysis. Red circles indicate ${ }^{13} \mathrm{C}$. 

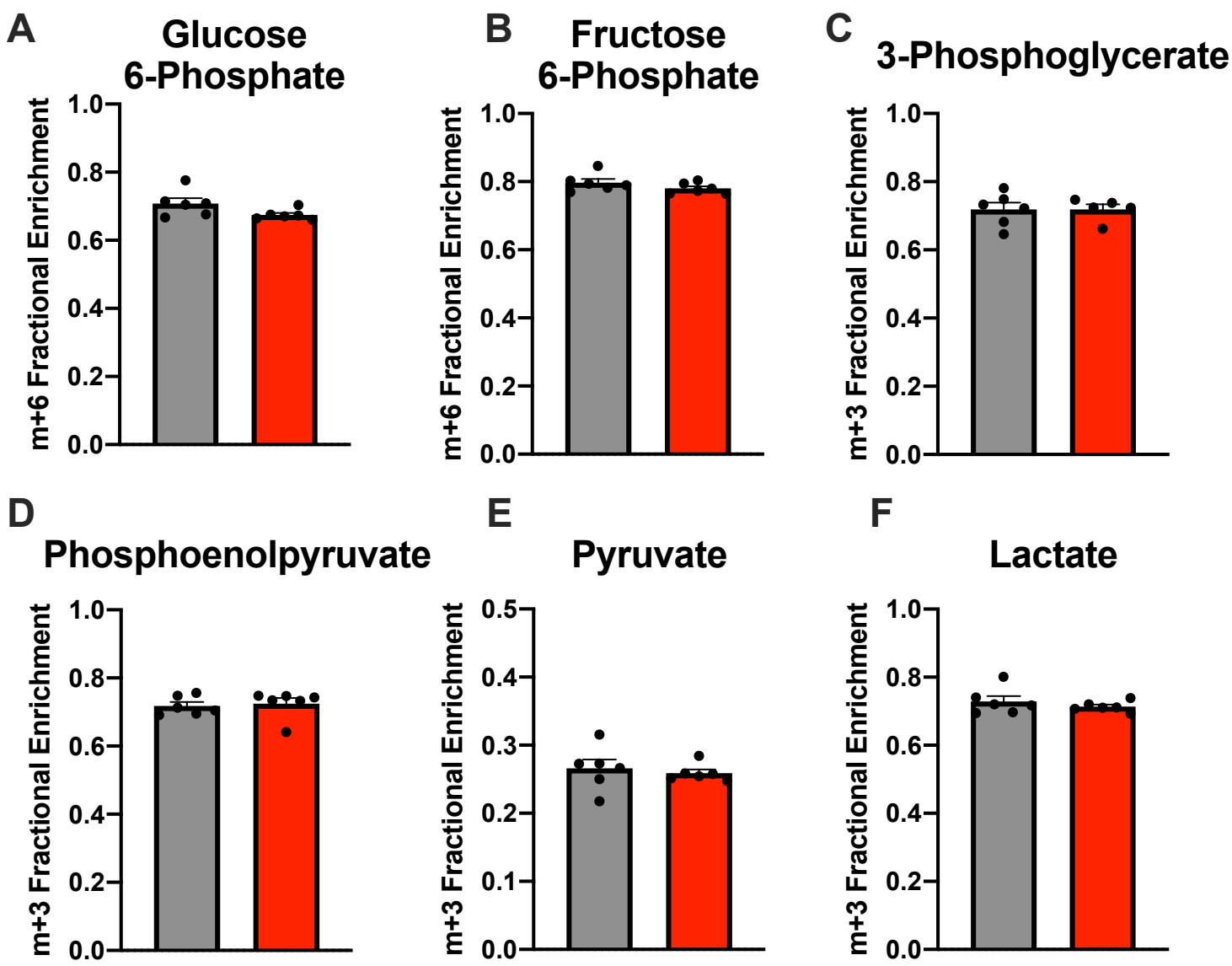

$\square$ Vehicle $\square$ Palbociclib

Figure 9. Palbociclib does not alter glucose carbon incorporation into glycolytic intermediates in A549 cells. (A-F) Fractional enrichment of $m+6$ labeled glucose 6-phosphate (A) and fructose 6-phosphate (B), and $m+3$ labeled 3-phosphoglycerate (C), phosphoenolpyruvate (D), pyruvate (E), and lactate (F) following 48 -hour treatment with $1 \mu \mathrm{M}$ palbociclib. Values represent mean $\pm \mathrm{SEM}$, analyzed by unpaired student's t-test ( $n=6$, technical replicates). 


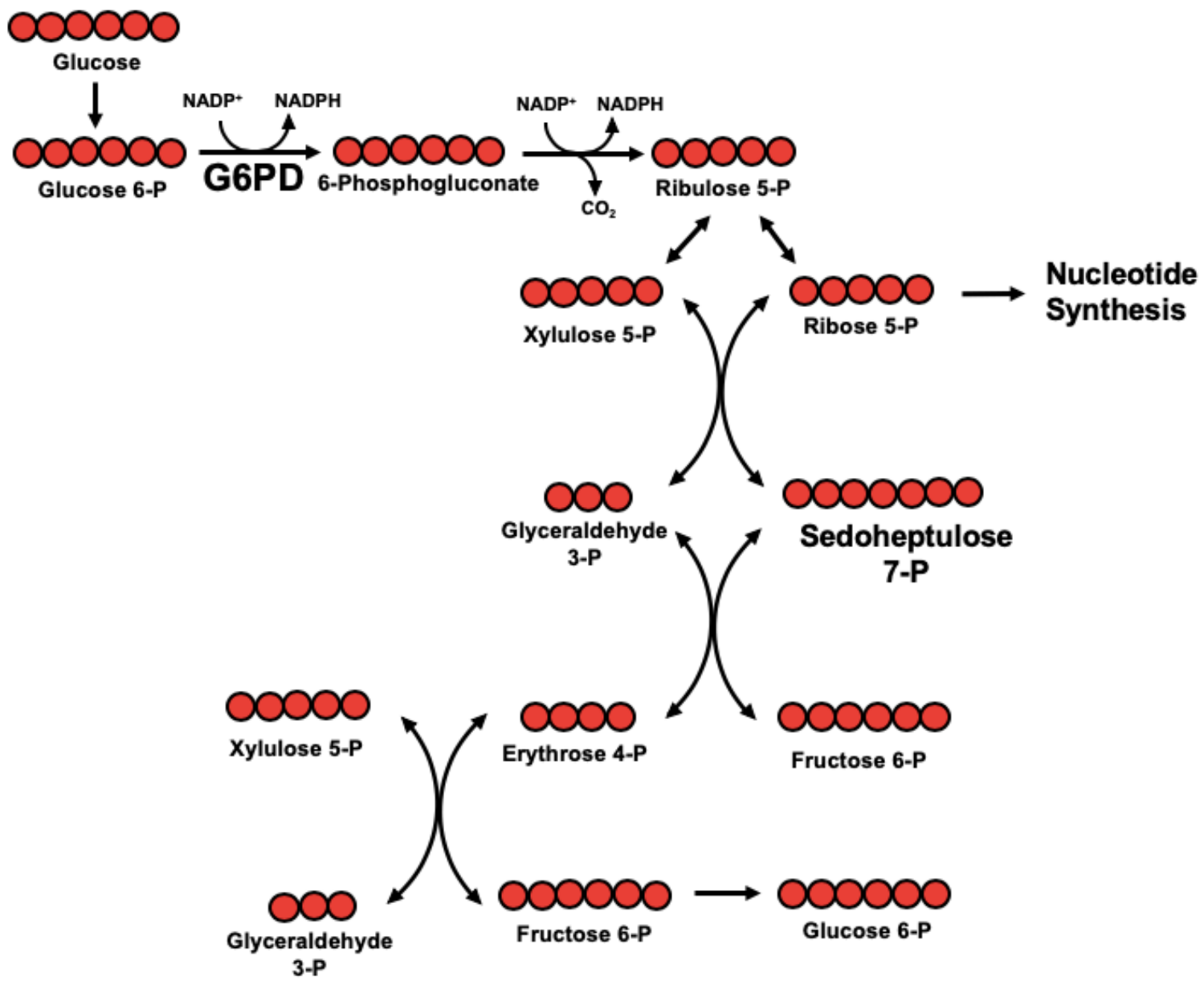

Figure 10. Cartoon of $\left[\mathrm{U}-{ }^{13} \mathrm{C}\right]$-glucose fate mapping though the pentose phosphate pathway. Red circles indicate ${ }^{13} \mathrm{C}$. 

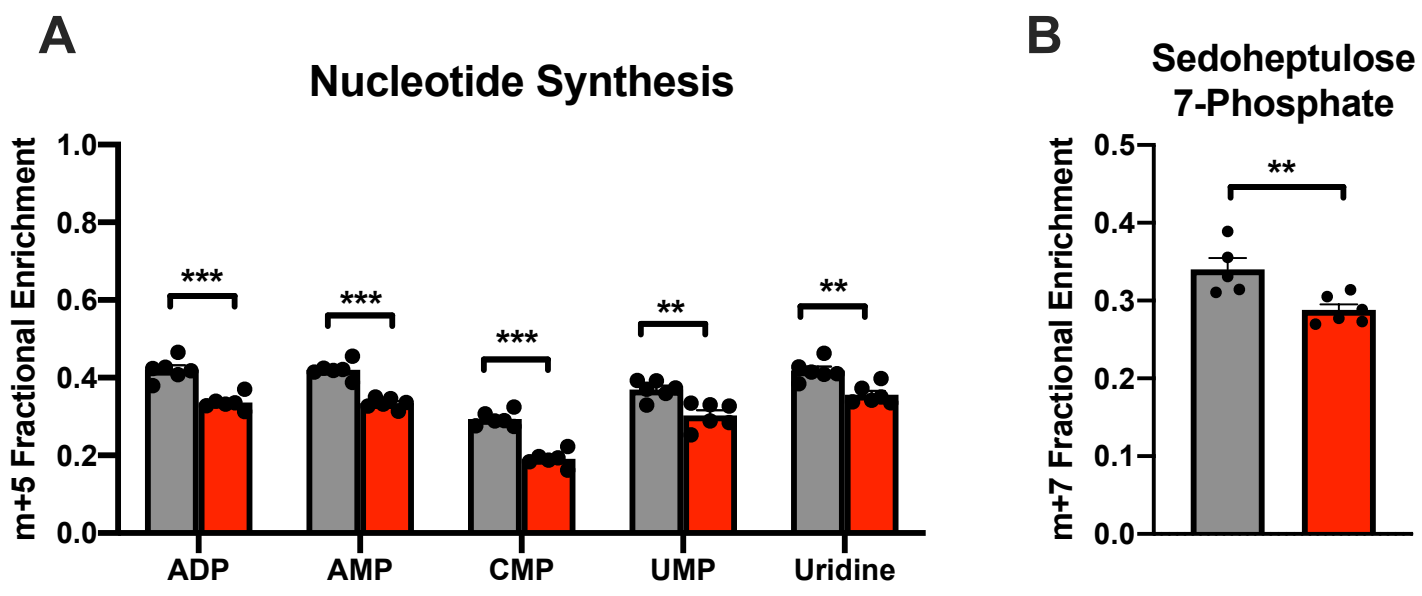

\section{$\square$ Vehicle $\square$ Palbociclib}

Figure 11. Palbociclib decreases glucose carbon incorporation into the PPP in A549 cells. (A) Fractional enrichment of $m+5$ labeled nucleotides and nucleosides, and (B) m+7 sedoheptulose 7-phosphate following 48-hour treatment with $1 \mu \mathrm{M}$ palbociclib. Values represent mean \pm SEM, analyzed by unpaired student's t-test ( $n=6$, technical replicates). Statistical significances between each group are as follows: ${ }^{* *} p<0.01$ and ${ }^{* *} p<0.001$. 
decreased glucose 6-phosphate dehydrogenase (G6PD) activity in an pRbdependent manner (Figure 12A). Additionally, we measured expression of G6PD and other genes within nucleotide synthesis including phosphoribosyl pyrophosphate synthetase 2 (PRPS2) and ribonucleotide reductase 1/2 (RRM1/2). Palbociclib decreased expression of RRM2 in an pRb-dependent manner but does not significantly alter expression of other genes within nucleotide synthesis (Figure 12B-E).

\section{Palbociclib increases oxygen consumption in A549 cells}

CDK4/6 inhibition has been reported to increase both mitochondrial mass and oxygen consumption in pancreatic cancer (106). As such, we assessed mitochondrial activity by measurement of the oxygen consumption rate (OCR) in A549 cells following palbociclib treatment. Consistent with other cancer types $(106,107)$, we observed a significant increase in several parameters of mitochondrial activity including basal $(\mathrm{p}=0.0019)$ and non-mitochondrial respiration $(p=0.0115)$ (Figure 13$)$. While two-way ANOVA revealed no interaction between palbociclib treatment and pRb status $(p=0.113)$, palbociclib increased basal OCR 1.4-fold, which was reduced to 1.2-fold in the absence of pRb.

To determine if the increase in basal oxygen consumption upon palbociclib treatment is the result of increased glucose oxidation, we measured TCA cycle metabolites following $\left[\mathrm{U}-{ }^{13} \mathrm{C}\right]-$ glucose labeling in A549 cells. Pyruvate $(\mathrm{m}+3)$ generated from glycolysis can be metabolized to lactate by lactate dehydrogenase $(\mathrm{LDH})$ or oxidized in the TCA cycle through pyruvate dehydrogenase $(\mathrm{PDH})$ or 

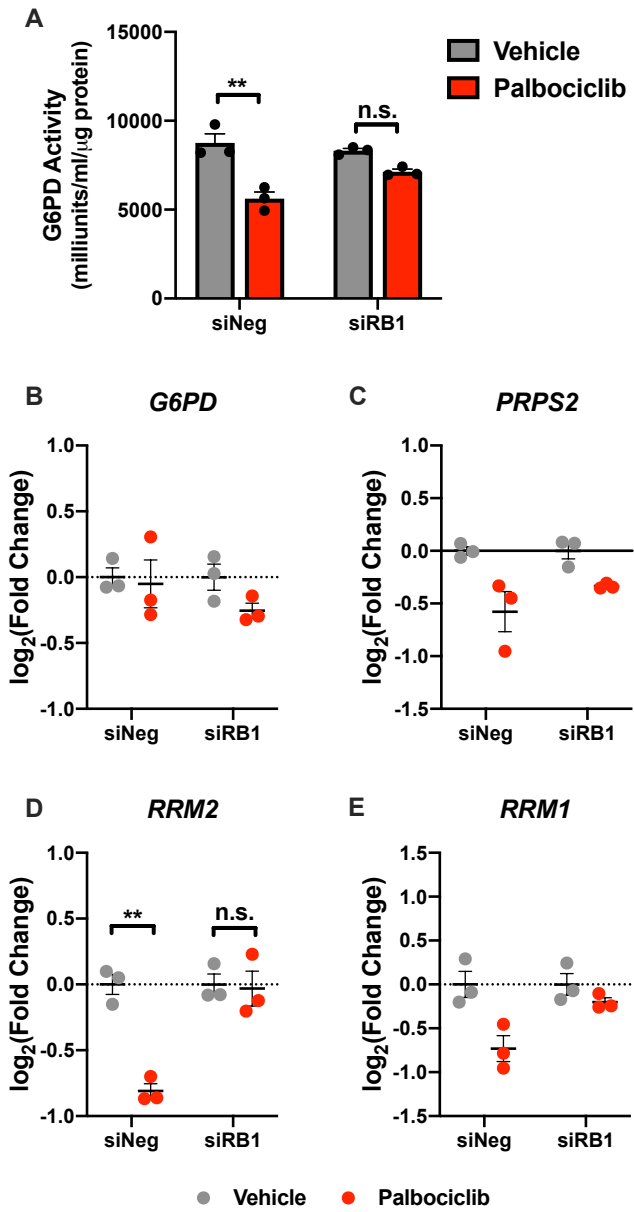

Figure 12. Palbociclib decreases G6PD activity and RRM2 transcript levels in A549 cells. (A) G6PD activity assessed in A549 cells following knockdown of $\mathrm{pRb}$ and 48-hour treatment with $1 \mu \mathrm{M}$ palbociclib. (B-E) qPCR analysis of glucose 6-phosphate dehydrogenase (G6PD), phosphoribosyl pyrophosphate synthetase 2 (PRPS2), and ribonucleotide reductase $1 / 2(R R M 1 / 2)$ in A549 cells following knockdown of $\mathrm{pRb}$ and 48 -hour treatment with $1 \mu \mathrm{M}$ palbociclib. Values represent mean \pm SEM, analyzed by two-way ANOVA with Sidak's post-hoc multiple comparisons ( $n=3$, independent experiments). Statistical significances between each group are as follows: ${ }^{* *} p<0.001$. 
A Mitochondrial Respiration

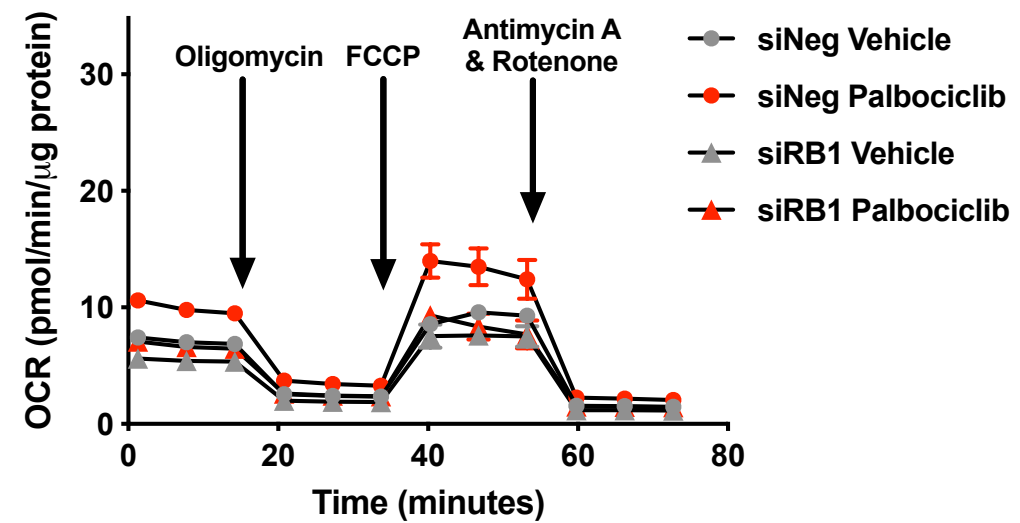

B

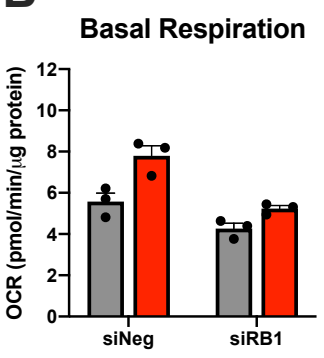

C

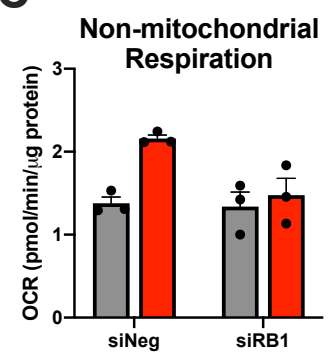

D

E $\mathbf{F}$
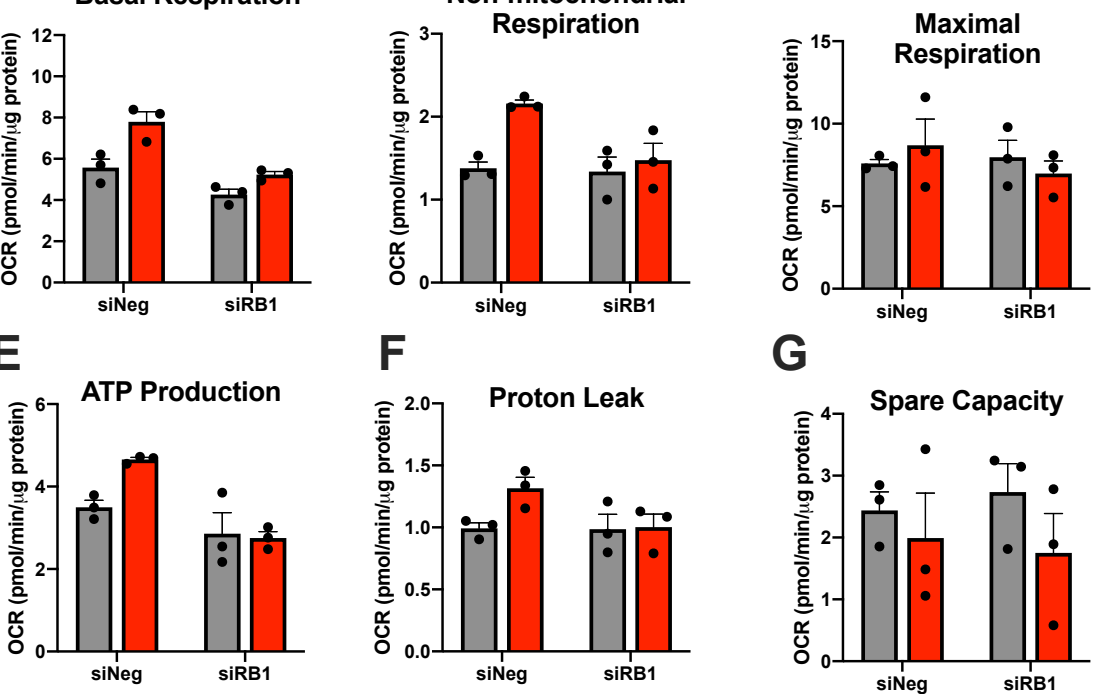

G

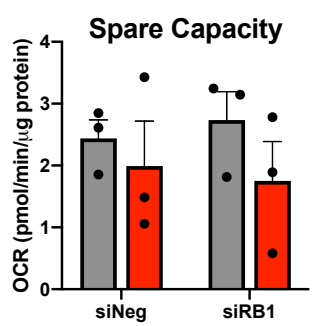

Vehicle

Palbociclib

Figure 13. Palbociclib increases mitochondrial respiration in A549 cells. (A) Oxygen consumption rate (OCR) measured in A549 cells following knockdown of pRb and 48-hour treatment with $1 \mu \mathrm{M}$ palbociclib. (B-G) OCR assessment of (B) basal respiration, (C) non-mitochondrial respiration, (D) maximal respiration (E) ATP production, (F) proton leak, and (G) spare capacity. Values represent mean \pm SEM, analyzed by two-way ANOVA ( $\mathrm{n}=3$, independent experiments). 
pyruvate carboxylase (PC). PDH entry of pyruvate carbon is indicated by $m+2\left(1^{\text {st }}\right.$ turn) $/ m+4$ ( $2^{\text {nd }}$ turn) isotopologues, while PC activity is observed by $m+3$ isotopologue labeling of TCA intermediates. (Figure 14). While there was no consistent effect on PDH-mediated pyruvate carbon entry $(m+2 / m+4)$, we found that palbociclib increased $m+3$ labeling of several TCA metabolites, suggesting palbociclib increases PC activity for anaplerosis in A549 cells (Figure 15).

\section{Palbociclib sensitizes A549 cells to glutaminase inhibition in an pRb- dependent manner}

We next sought to determine whether palbociclib alters the capacity to metabolize or the dependency on specific TCA fuels such as glucose, glutamine, or fatty acids for mitochondrial function. We performed the Mito Fuel Flex assay using a Seahorse XFe96 analyzer to assess the contributions of glucose, glutamine, and fatty acids as fuel sources to maintain basal mitochondrial respiration. Palbociclib had no effect on the overall capacity of A549 cells to utilize glucose, but did decrease the cells' dependency on glucose to maintain basal respiration, indicating glucose is not the sole fuel source for the TCA cycle in palbociclib treated cells (Figure 16A,D). While palbociclib increases the capacity to oxidize fatty acids, it has no effect on the cells' dependency for fatty acid oxidation, suggesting that inhibition of fatty acid oxidation would have no effect on the viability of palbociclib treated cells (Figure 16B,E). Notably, we observed an increase in both glutamine capacity and dependency in A549 cells upon palbociclib treatment (Figure 16C,F). 


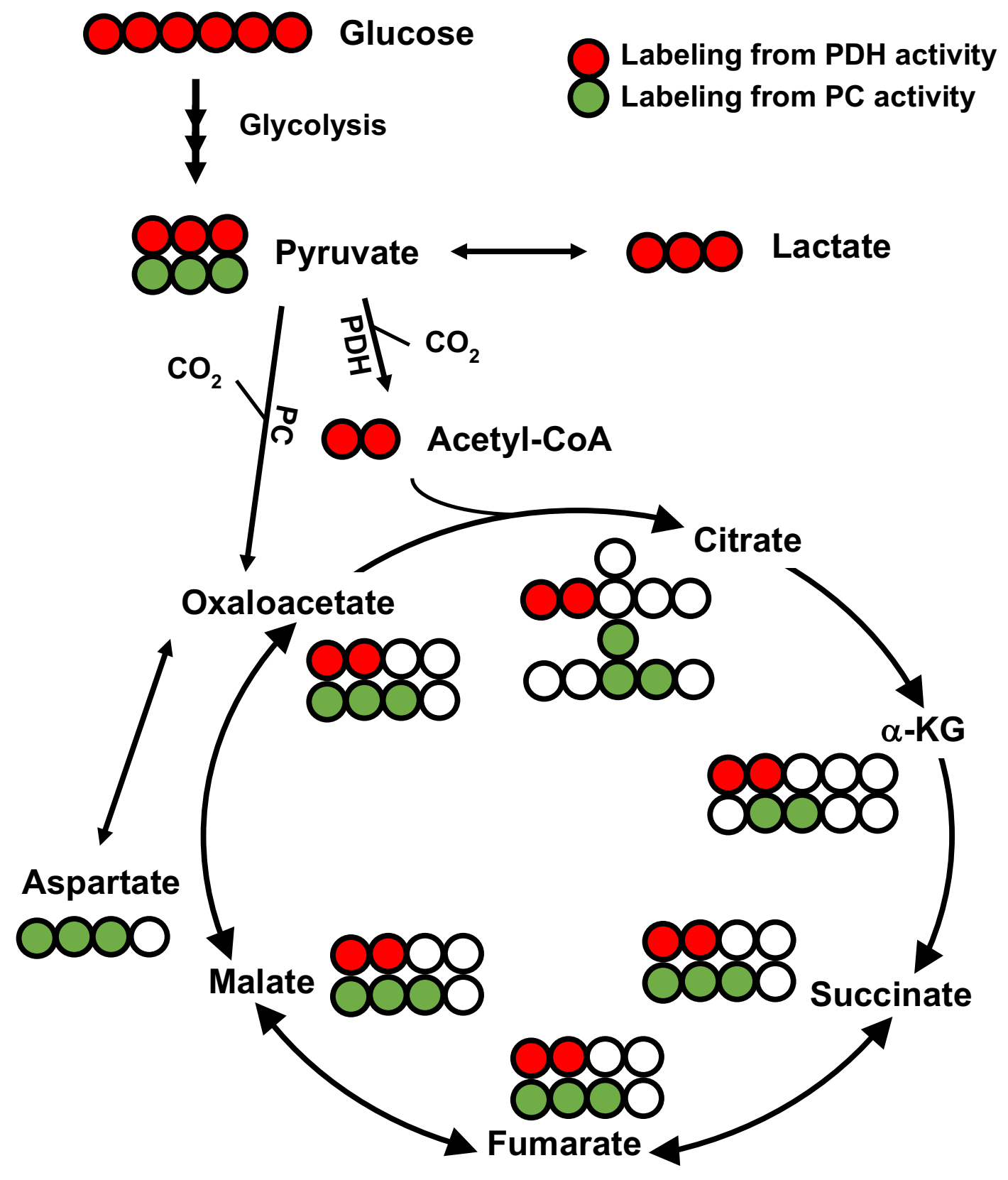

Figure 14. Cartoon of $\left[\mathrm{U}-{ }^{13} \mathrm{C}\right]$-glucose fate mapping through the $1^{\text {st }}$ turn of the TCA cycle. Red circles are ${ }^{13} \mathrm{C}$ labeling indicative of pyruvate dehydrogenase activity, green circles are ${ }^{13} \mathrm{C}$ labeling indicative of pyruvate carboxylase activity, and white circles are unlabeled ${ }^{12} \mathrm{C}$. 

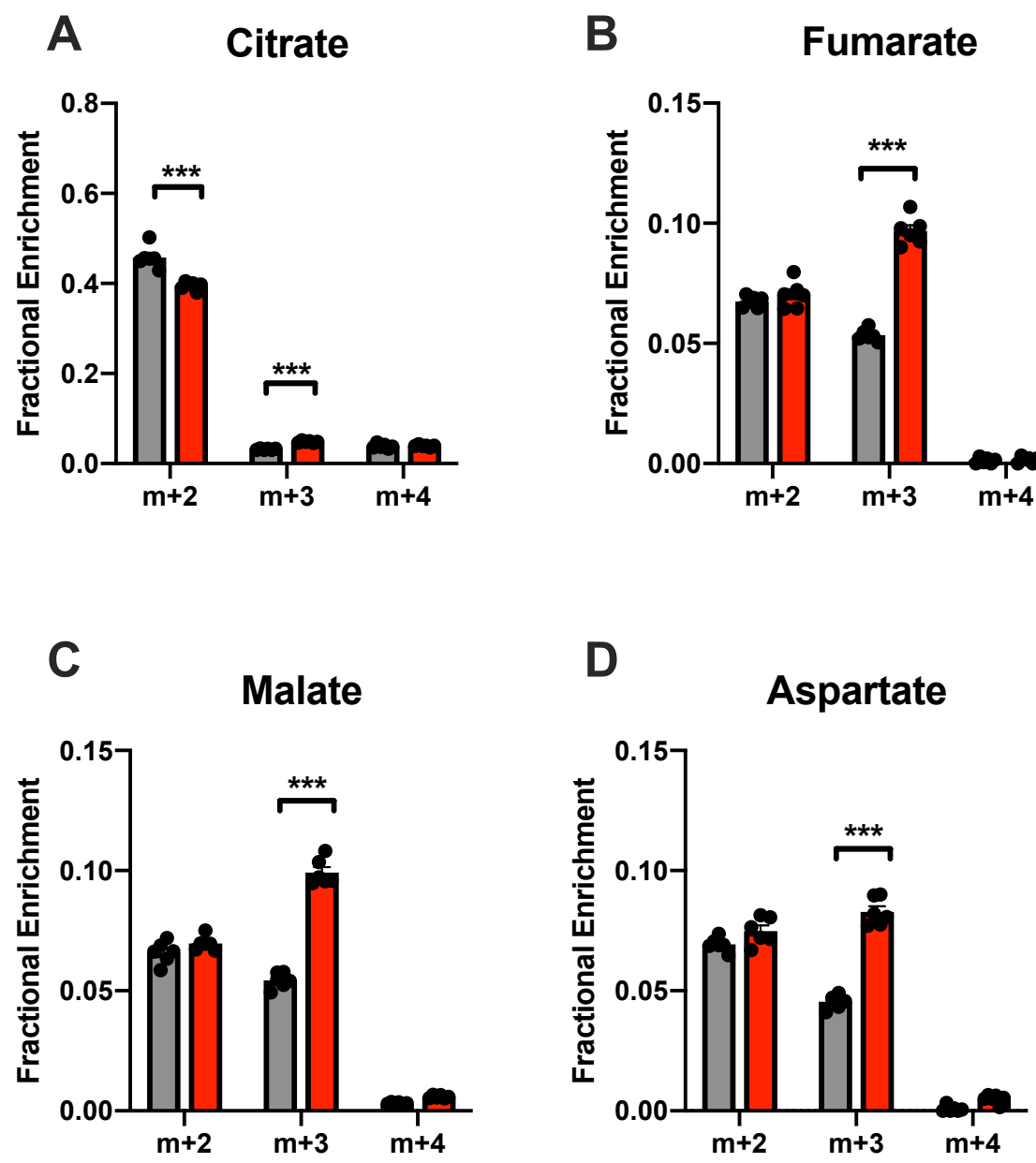

\section{$\square$ Vehicle $\square$ Palbociclib}

Figure 15. Palbociclib increases PC-mediated anaplerosis in A549 cells. (AD) Fractional enrichment of the TCA metabolites (A) citrate, (B) fumarate, (C) malate, and (D) aspartate in A549 cells following 48-hour treatment with $1 \mu \mathrm{M}$ palbociclib. Values represent mean \pm SEM, analyzed by unpaired student's t-test for each metabolite isotopologue (vehicle vs. palbociclib) ( $n=6$, technical replicates). Statistical significances between each group are as follows: ${ }^{* * *} p<0.001$ 
A

Capacity

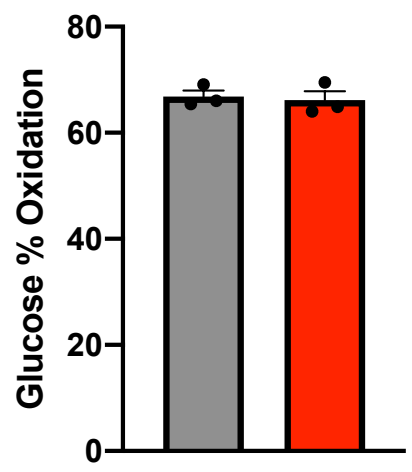

D Dependency

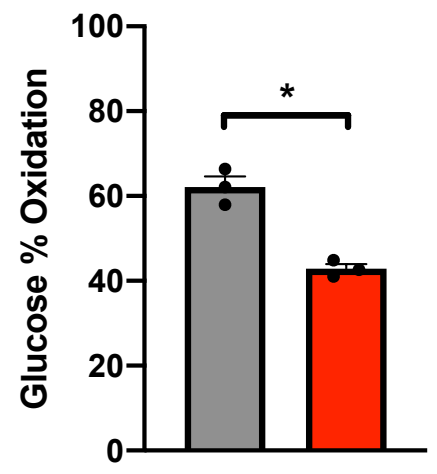

B

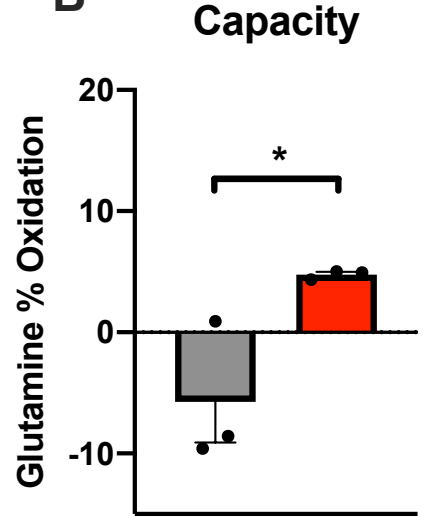

E Dependency

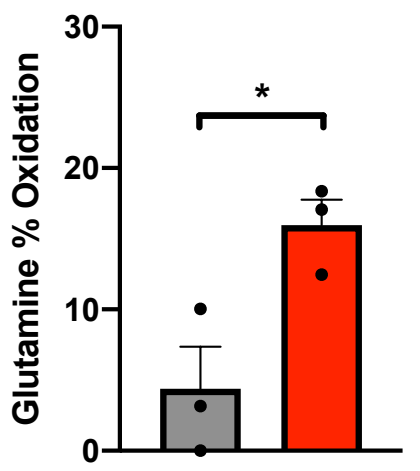

C Capacity

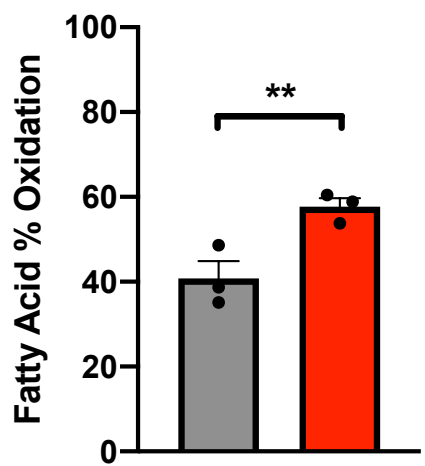

F Dependency

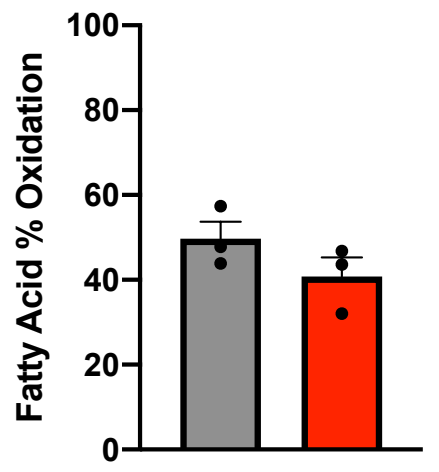

$\square$ Vehicle $\square$ Palbociclib

Figure 16. Palbociclib increases glutamine dependency in A549 cells. (A) glucose, (B) glutamine, and (C) fatty acid capacity, and (D) glucose, (E) glutamine, and (F) fatty acid dependency measured by the Mito Fuel Flex assay in A549 cells following 48 -hour treatment with $1 \mu \mathrm{M}$ palbociclib. Values represent mean $\pm \mathrm{SEM}$, analyzed by unpaired student's t-test ( $n=3$, independent experiments). Statistical significances between each group are as follows: ${ }^{*} p<0.05$ and ${ }^{* *} p<0.01$. 
The enzyme glutaminase converts glutamine to glutamate and is highly expressed in cancer cells $(58,59,62)$. CB-839 is a highly potent glutaminase inhibitor that has shown anti-tumor activity in both in vitro and in vivo models of lung cancer (120). We hypothesized that the observed increase in glutamine dependency may sensitize palbociclib treated cells to glutaminase inhibition. Although palbociclib does not significantly alter expression of genes within glutamine utilization, including the glutamine transporter, ACTS2, glutaminase (GLS), or glutamine dehydrogenase (GLUD1) (Figure 17), we observed a significant decrease in proliferation in cells treated with CB-839 and palbociclib, than with palbociclib or CB-839 alone (Figure 18). Additionally, statistical analysis found a significant interaction between inhibitor sensitivity and pRb status $(p<$ $0.0001)$, suggesting $p R b$ expression is necessary for palbociclib to exert its effect on glutamine dependency. Together, our data highlight that palbociclib-induced metabolic adaptations have the potential to be therapeutically exploited. 

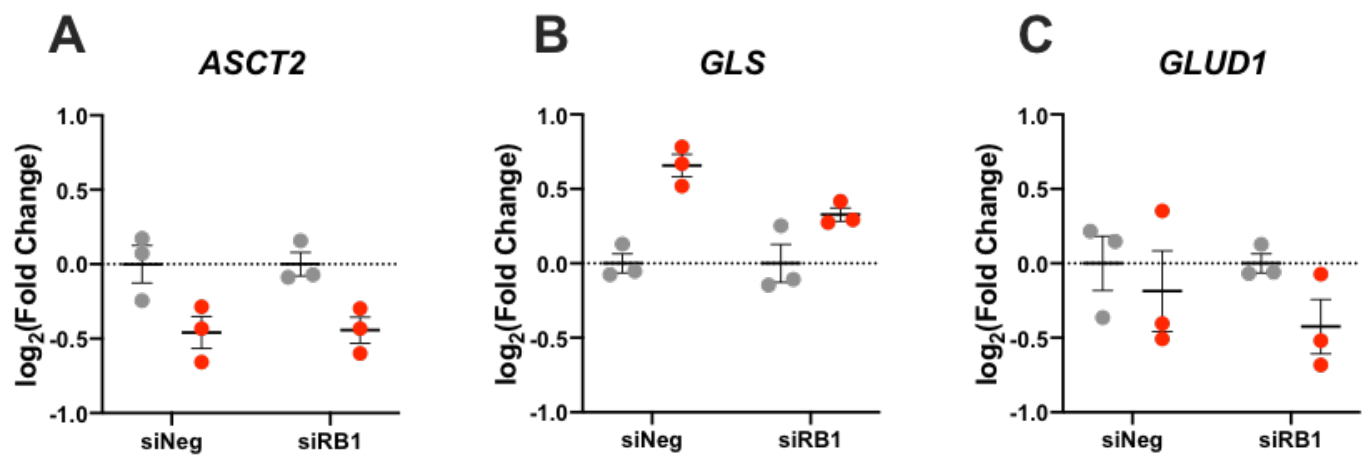

- Vehicle Palbociclib

Figure 17. Palbociclib does not alter expression of genes within glutamine utilization. qPCR analysis of the glutamine transporter ASCT2, glutaminase (GLS), and glutamate dehydrogenase (GLUD1) in A549 cells following knockdown of $\mathrm{pRb}$ and 48 -hour treatment with $1 \mu \mathrm{M}$ palbociclib. Values represent mean $\pm \mathrm{SEM}$, analyzed by two-way ANOVA ( $\mathrm{n}=3$, independent experiments). 


\section{Proliferation}

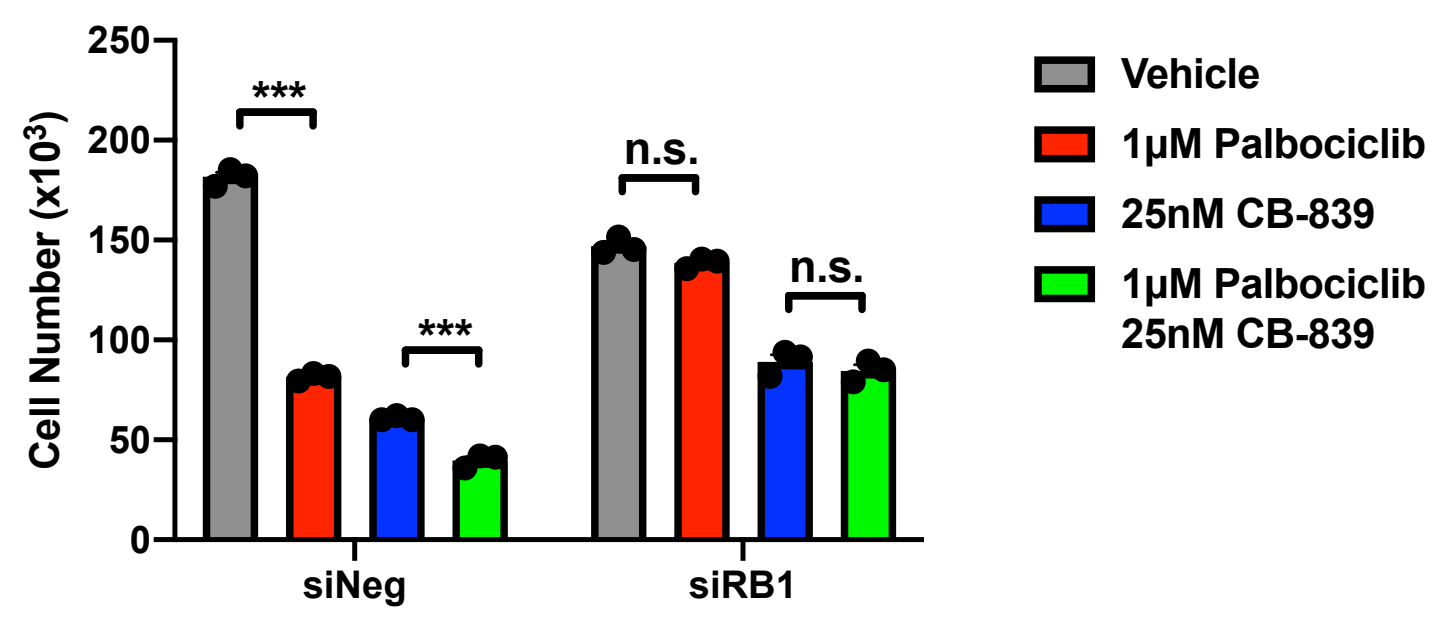

Figure 18. Palbociclib sensitizes A549 cells to glutaminase inhibition. Cell proliferation following knockdown of $\mathrm{pRb}$ and 48-hour treatment with $1 \mu \mathrm{M}$ palbociclib and/or 25nM CB-839. Values represent mean \pm SEM, analyzed by twoway ANOVA with Sidak's post-hoc multiple comparisons $(n=3$, independent experiments). Statistical significances between each group are as follows: ${ }^{* * *} p<0.001$. 


\section{Discussion}

While cancer metabolism as a target for therapeutic intervention has been extensively studied $(35,38,42,48,61)$, there is a growing appreciation for cell cycle proteins that display metabolic regulatory functions $(33,86,96,104,121)$. Additionally, with the increase in utilization of CDK4/6 inhibitors in the clinic, there is a need for better understanding of the metabolic consequences of CDK4/6 inhibition. In the current study, we report that activation of $\mathrm{pRb}$ via treatment with the CDK4/6 inhibitor palbociclib in A549 lung adenocarcinoma cells results in a metabolic shift wherein palbociclib alters glucose and glutamine utilization. Specifically, palbociclib decreases glucose metabolism through the PPP via inhibition of G6PD activity (Figure 12A), while increasing glutaminolysis to maintain basal mitochondrial function (Figure 16B,E). Moreover, both changes observed were rescued upon knockdown of $\mathrm{pRb}$, suggesting the metabolic consequences of CDK4/6 inhibition in A549 cells with respect to these metabolic processes are $\mathrm{pRb}$-dependent.

Recently, it has been demonstrated that CDKs can directly regulate metabolism via phosphorylation of metabolic enzymes. Specifically, the cyclin D3/CDK6 kinase complex can phosphorylate pyruvate kinase M2 and 6phosphofructokinase (108). The authors report that this results in shunting of glycolytic intermediates into the PPP and the serine synthesis pathways. Treatment with palbociclib reduces this flux, resulting in NADPH and glutathione

depletion and inducing apoptosis. Consistent with these findings, we observed a decrease in glucose carbon incorporation into nucleotides (Figure 11A). This was 
in part due to decreased activity of the rate limiting enzyme in the PPP, G6PD (Figure 12A). As A549 cells express both CDK4 and CDK6, it remains unclear whether the observed decrease in G6PD activity is due the effects of the cyclin D3/CDK6 kinase complex inhibition.

As previously described, palbociclib increases mitochondrial activity in vitro $(106,107)$. Specifically, CDK4/6 inhibition increases glutamine utilization and sensitivity to glutaminase inhibition in breast and colorectal cancer cells (107). The authors reported that the increase in glutaminolysis was a result of enhanced MYC signaling in response to CDK4/6 inhibition. We did observe a modest increase in basal oxygen consumption upon palbociclib treatment (Figure 13B), which is driven, in part, by enhanced glutaminolysis (Figure 16B,E). We postulate that this, in turn, sensitized A549 cells to treatment with CB-839 (Figure 18). MYC exerts its effect on glutaminolysis specifically via upregulation of the glutamine transporter ASCT2 and GLS $(122,123)$. As we did not observe significant upregulation of these genes (Figure 17), our data suggest the enhanced glutaminolysis in this context may be independent of MYC signaling.

While other studies have reported enhanced glycolysis upon CDK4/6 inhibition or deletion, or direct activation of pRb itself $(80,106,107)$, our [U-13 $C$ ]glucose and ECAR studies revealed no significant changes in glycolytic function upon palbociclib treatment (Figure $6,7,9$ ). One possible explanation for this discrepancy is the acute treatment duration for our studies (48 hours compared to 120 hours). Prolonged CDK4/6 inhibition (96 hours to two weeks) has been reported to induce both senescence and autophagy in vitro $(106,107,124,125)$. 
Many of the reported metabolic consequences of palbociclib treatment are also metabolic hallmarks of these cellular processes. Senescent cells exhibit elevated glycolysis and mitochondrial metabolism, resulting in increased mitochondrial mass and production of reactive oxygen species (ROS) $(126,127)$. This triggers autophagy and protein degradation to mitigate the cellular stress induced by senescence (128). In addition to enhanced glycolysis, palbociclib treatment has been reported to increase amino acid catabolism, mitochondrial abundance and activity, and ROS production $(106,107)$. Our studies are unique in that we have identified potential senescence-independent metabolic consequences of CDK4/6 inhibition.

Given the recent use of palbociclib in clinical trials for NSCLC patients, understanding the noncanonical functions CDK4/6 inhibition in cancer cell metabolism are important for identifying potential combination therapies to improve patient outcome. Our studies demonstrate that palbociclib treatment increases glutamine dependency and sensitizes cells to the glutaminase inhibitor, CB-839. While the precise mechanism by which palbociclib mediates increased glutaminolysis remains unclear, $\mathrm{pRb}$ expression is required for palbociclib to exert its function in this context. Together, our data highlight the metabolic changes upon palbociclib treatment in A549 cells and may support the of targeting CDK4/6 inhibition in combination with glutaminase inhibitors in NSCLC patients with $\mathrm{pRb}$ proficient tumors. 


\section{CHAPTER 3: LOSS OF RB1 ENHANCES GLYCOLYTIC METABOLISM IN KRAS-DRIVEN LUNG TUMORS IN VIVO \\ Introduction}

Lung cancer is the leading cause of cancer-related deaths for both men and women worldwide, with the 5-year survival rate being less than $18 \%(1)$. Of its subtypes, non-small cell lung cancer (NSCLC) accounts for $85 \%$ of all lung cancer diagnoses (2). Deregulation of the cell cycle is a major driver of tumorigenesis, and aberrant expression of cell cycle proteins in the retinoblastoma protein, E2F factor (pRb-E2F) pathway have been found to play a key role in the pathogenesis of NSCLC $(18,103)$. pRb is a tumor suppressor that is reported to be dysfunctional in the majority of human cancers. Canonically, $\mathrm{pRb}$ functions to regulate cell cycle progression by repressing the transcriptional activity of the E2F family of transcription factors, inhibiting S phase entry (129). In most NSCLC cases, pRb inactivation occurs via hyperphosphorylation; however, in $15-30 \%$ of cases, $R b 1$, the gene encoding $\mathrm{pRb}$, is mutated, which correlates to poorer overall survival for these patients $(33,130)$.

Advances in our understanding of $\mathrm{pRb}$ function have highlighted additional biochemical pathways under $\mathrm{pRb}$ regulation beyond cell cycle progression. Emerging evidence supports a direct role for $\mathrm{pRb}$ in regulating metabolic pathways such as glycolysis, glutaminolysis, lipogenesis, mitochondrial oxidative 
phosphorylation, and reactive oxygen species metabolism $(86,87,95,102)$. pRb can exert its metabolic function via interaction with the E2F family of transcription factors and altering expression of metabolic enzymes and transporters $(81,96,97)$. Additionally, acute loss of $R b 1$ increases mitochondrial pyruvate oxidation in normal lung tissue; however, the metabolic effects of $\mathrm{pRb}$ loss during lung cancer development are largely unknown.

Herein, we report that loss of $R b 1$ in an in vivo mutant Kras-driven model of lung cancer enhances glycolytic metabolism without altering mitochondrial pyruvate oxidation. Moreover, loss of $R b 1$ has no significant effect on TCA anaplerosis or utilization of alternative nutrient sources apart from glucose. These data expand our knowledge of understanding of the metabolic phenotype resulting from $\mathrm{pRb}$ dysfunction in a widely used model of lung cancer. 


\section{Materials and Methods}

\section{Mouse model and adenoviral infection}

All animal studies were approved by the University of Louisville's Institutional Animal Care and Use Committee. Kras ${ }^{L S L / G 12 D / R b 1^{+/+}}$and

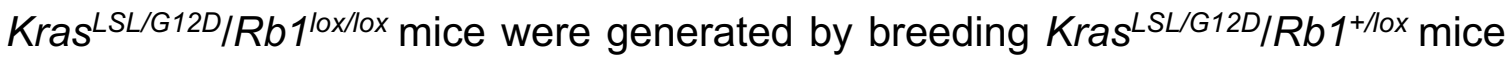
as described in (131). Lung tumors were induced in 8-week old $K r a s^{L S L / G 12 D / R b 1^{+/+}}$

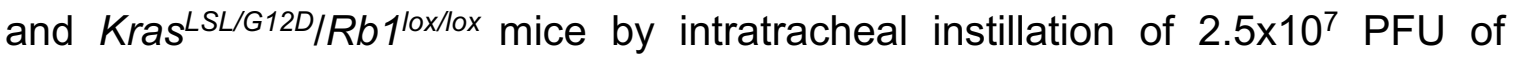
adenovirus expressing Cre-recombinase (Vector Development Lab, Baylor College of Medicine). For all studies, age-matched non-instilled

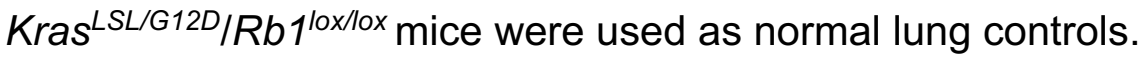

\section{Kaplan-Meier analysis}

Eight-weeks post-surgery, $K r a s^{L S L / G 12 D / R b 1^{+/+}}$and $K r a s^{L S L / G 12 D / R b 1^{1 /-} \text { mice }}$ were examined twice weekly. Mice were sacrificed upon visible signs of advanced morbidity such as lethargy, weight loss $(>15 \%)$, hunching, and distressed rapid breathing. The logrank $P$ value and hazard ratio $(H R)$ was calculated using KaplanMeier survival analysis in GraphPad Prism software.

\section{$\left[\mathrm{U}-{ }^{13} \mathrm{C}\right]$-glucose, $\left[\mathrm{U}-{ }^{13} \mathrm{C},{ }^{15} \mathrm{~N}\right]$-glutamine, and $\left[\mathrm{U}-{ }^{13} \mathrm{C}\right]$-lactate tracer studies}

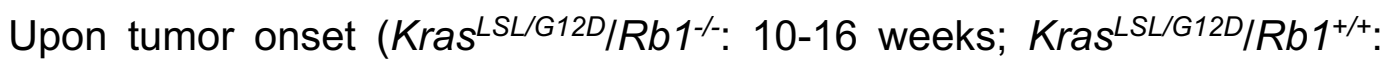
15-20 weeks; determined by symptomatic observation of labored breathing) mice were injected via the tail vein with either $80 \mu \mathrm{L} 25 \% \mathrm{w} / \mathrm{v}\left[\mathrm{U}-{ }^{13} \mathrm{C}\right]-$ glucose or $200 \mu \mathrm{L}$ of $36.2 \mathrm{mg} / \mathrm{ml}\left[\mathrm{U}-{ }^{13} \mathrm{C},{ }^{15} \mathrm{~N}\right]$-glutamine, three times, 15 minutes apart as described in $(132,133) \cdot\left[\mathrm{U}-{ }^{13} \mathrm{C}\right]$-lactate studies were performed following the same protocol using $100 \mu \mathrm{L}$ of $300 \mathrm{mM}\left[\mathrm{U}-{ }^{13} \mathrm{C}\right]$-lactate. At 15 minutes after the last injection, mice 
were sacrificed by cervical dislocation, blood collected, and lung tumors or normal lung were excised and flash frozen in liquid nitrogen. Number of animals per group (normal lung, $R b 1^{+/+}$, and $R b 1^{-/}$lung tumors) for each labeled nutrient is depicted within their respective figure legends.

\section{Plasma $\left[\mathrm{U}-{ }^{13} \mathrm{C}\right]$-glucose, $\left[\mathrm{U}-{ }^{13} \mathrm{C},{ }^{15} \mathrm{~N}\right]$-glutamine, and $\left[\mathrm{U}-{ }^{13} \mathrm{C}\right]$-lactate analysis}

Blood was collected from mice by cardiac puncture following euthanasia and processed as described in (133). Up to $150 \mu \mathrm{L}$ of blood was collected in $\mathrm{K}_{2^{-}}$ EDTA microtubes and incubated at room temperature for 5 minutes, then placed on ice. Plasma was separated from blood cells by centrifugation at $3,500 \mathrm{xg}$ for 15 minutes at $4^{\circ} \mathrm{C}$. For $\left[\mathrm{U}-{ }^{13} \mathrm{C}\right]$-glucose and $\left[\mathrm{U}-{ }^{13} \mathrm{C}\right]$-lactate studies, plasma was deproteinized by trichloroacetic acid (TCA) extraction by adding $300 \mu \mathrm{L}$ of 1:10 TCA dilution to $30 \mu \mathrm{L}$ plasma. Samples were centrifuged at $15,000 \mathrm{rpm}$ for 30 minutes at $4^{\circ} \mathrm{C}$ and the supernatant was vacuum dried by lyophilization. Samples were redissolved in $650 \mu \mathrm{L} \mathrm{D}_{2} \mathrm{O}$ and analyzed by $2 \mathrm{D}-\mathrm{NMR}$. For $\left[\mathrm{U}-{ }^{13}-\mathrm{C},{ }^{15} \mathrm{~N}\right]$-glutamine studies, metabolites were extracted from plasma by adding $130 \mu \mathrm{L}$ methanol:water $(80: 20)$ to $10 \mu \mathrm{L}$ plasma. Samples were vortexed for 10 seconds, incubated for 10 minutes at $4^{\circ} \mathrm{C}$, followed by centrifugation at $16,000 \times$ for 10 minutes at $4^{\circ} \mathrm{C}$. The supernatant was vacuum dried by SpeedVac, followed by 2DLC-MS/MS analysis.

\section{Metabolite tissue sample preparation for tracer studies}

To extract metabolites from tissue samples, up to $20 \mathrm{mg}$ of pulverized frozen tissue was extracted for polar and lipid metabolites as described in (132) with minor modifications. In brief, metabolites were extracted in acetonitrile:water:chloroform $(1 \mathrm{ml}: 750 \mu \mathrm{L}: 500 \mu \mathrm{L})$. Samples were centrifuged at $3,000 \mathrm{xg}$ for 20 minutes at $4^{\circ} \mathrm{C}$ to 
separate the polar, lipid, and tissue debris layers. The remaining tissue debris was re-extracted with $500 \mu \mathrm{L}$ chloroform:methanol:butylated hydroxytoluene $(2: 1: 1 \mathrm{mM})$ and centrifuged at $22,000 \times \mathrm{xg}$ for 20 minutes at $4^{\circ} \mathrm{C}$. The residual polar and lipid fractions were combined with their respective fractions from the first extraction. The polar fraction was vacuum-dried by lyophylization. The dried sample was dissolved in $100 \mu \mathrm{L} \mathrm{50 \%}$ acetonitrile and vigorously vortex-mixed for 3 minutes. After centrifugation at $14,000 \mathrm{rpm}$ and $4^{\circ} \mathrm{C}$ for $20 \mathrm{~min}, 80 \mu \mathrm{L}$ of supernatant was collected for 2DLC-MS/MS analysis.

\section{Sample preparation and derivatization for steady-state metabolomics}

Up to $20 \mathrm{mg}$ of pulverized frozen tissue was extracted in $1 \mathrm{ml}$ of $50 \%$

methanol and separated into polar (aqueous layer), and protein/DNA/RNA/glycogen pellet. The polar fraction was dried at $10^{-3} \mathrm{mBar}$ using a SpeedVac (Thermo) followed by derivatization. The protein/DNA/RNA/glycogen pellet was washed 4 times with $50 \%$ methanol and once with $100 \%$ methanol. Samples were centrifuged at 15,000rpm for 10 minutes between washes. Hydrolysis of the protein/DNA/RNA/glycogen pellet was performed by first resuspending the dried pellet in $\mathrm{diH}_{2} \mathrm{O}$ followed by the addition of equal parts $2 \mathrm{~N}$ $\mathrm{HCl}$. Samples were vortexed thoroughly and incubated at $95^{\circ} \mathrm{C}$ for 2 hours. The reaction was quenched with $100 \%$ methanol with $40 \mu \mathrm{M} \mathrm{L-norvaline} \mathrm{(as} \mathrm{an} \mathrm{internal}$ control). The sample was incubated on ice for 30 minutes and the supernatant was collected by centrifugation at $15,000 \mathrm{rpm}$ at $4^{\circ} \mathrm{C}$ for 10 minutes. The collected supernatant was subsequently dried by vacuum centrifuge at $10^{-3} \mathrm{mBar}$. 
Dried polar and hydrolyzed pellet samples were derivatized by the addition of $50 \mu \mathrm{l}$ of $20 \mathrm{mg} / \mathrm{ml}$ methoxyamine in pyridine to the dried sample in the $1.5 \mathrm{ml}$ Eppendorf tube. Samples were incubated for 1 hour and 30 minutes at $30^{\circ} \mathrm{C}$. Tubes were then centrifuged at $15,000 \mathrm{rpm}$ for 10 minutes. Supernatant of each tube was transferred to v-shaped amber glass chromatography vial. Lastly, addition of 80ul N-methyl-trimethylsilyation (MSTFA) occurred with an incubation period at $37^{\circ} \mathrm{C}$ for 30 minutes. Derivatized samples were then analyzed by GCMS.

\section{GC-MS analysis and data processing}

GC-MS protocols were similar to those described previously $(134,135)$ except a modified temperature gradient was used for GC: Initial temperature was $130^{\circ} \mathrm{C}$, held for 4 minutes, rising at $6^{\circ} \mathrm{C} /$ minute to $243^{\circ} \mathrm{C}$, rising at $60^{\circ} \mathrm{C} /$ minute to $280^{\circ} \mathrm{C}$, held for 2 minutes. The electron ionization (EI) energy was set to $70 \mathrm{eV}$. Scan (m/z:50-800) and full scan mode were used for metabolomics analysis. Mass spectra were translated to relative metabolite abundance using the Automated Mass Spectral Deconvolution and Identification System (AMDIS) software matched to the FiehnLib metabolomics library (available through Agilent) for retention time and fragmentation pattern matching with a confidence score of $>80$ (136-138). Data was further analyzed using the Data Extraction for Stable Isotopelabelled Metabolites (DEXSI) software package (139). Relative abundance was corrected for recovery using the L-norvaline and adjusted to protein input. Rapid quantitation of derivatized protein/DNA/RNA/glycogen pellet is as described in (140). Unsupervised hierarchical clustering analysis of steady-state metabolite 
levels was performed using the online Morpheus software tool from the Broad Institute.

\section{DLC-MS/MS analysis and data processing}

All samples were randomly analyzed on a Thermo Q Exactive HF Hybrid Quadrupole-Orbitrap Mass Spectrometer coupled with a Thermo DIONEX UltiMate 3000 HPLC system (Thermo Fisher Scientific, Waltham, MA, USA). The UltiMate 3000 HPLC system was equipped with a reverse phase chromatography (RPC) column and a hydrophilic interaction chromatography (HILIC) column that was configured in parallel to form a parallel 2DLC-MS system (109). To obtain full MS data, every sample was analyzed by the parallel 2DLC-MS in positive mode $(+)$ and negative mode (-), respectively. For metabolite identification, one unlabeled sample in each sample group was analyzed by 2DLC-MS/MS in positive mode $(+)$ and negative mode $(-)$ to acquire MS/MS spectra at three collision energies (20, 40 and $60 \mathrm{eV})$.

\section{Data analysis for 2DLC-MS/MS}

Full MS .raw files were first converted to .mzML format with msConvert tool, a part of an open-source ProteoWizard suite, described in detail by Adusumilli and Mallick (110). Isotopologue peak deconvolution and assignments were performed using El-MAVEN (111). Peaks were assigned using a metabolite list generated and verified using full scan MS and MS/MS spectra of unlabeled samples, as described previously (112-114). The metabolite list contained metabolite names and corresponding molecular formulae used to generate theoretical $\mathrm{m} / \mathrm{z}$ values for all possible isotopologues, and retention times for each metabolite. EI-MAVEN 
parameters for compound library matching were as follows: EIC Extraction Window \pm 7 ppm; Match Retention Time \pm 0.60 min. For ${ }^{13} \mathrm{C}$ isotopologue peak detection, the software criteria were set as follows: Minimum Isotope-parent correlation 0.20; Isotope is within 5 scans of parent; Abundance threshold 1.0; Maximum Error To Natural Abundance $100 \%$. All assignments were visually inspected and compared to unlabeled samples for reference. The peak list with corresponding abundances was exported to a comma-separated (CSV) file and uploaded to the Polly workflow for natural abundance correction and calculation of total pool size for each metabolite (by summing peak areas of each detected isotopologue) using Polly Isocorrect module. Finally, the data were downloaded and plotted using Microsoft Excel and GraphPad Prism software.

\section{NMR analysis}

NMR spectra were recorded at $293 \mathrm{~K}$ at $14.1 \mathrm{~T}$ initially on a Varian Inova NMR spectrometer with a $5 \mathrm{~mm} \mathrm{HCN}$ cold probe and later on a Bruker Advance Neo NMR spectrometer equipped with a $5 \mathrm{~mm}$ Prodigy probe. Typically, presaturation at very low power was employed in a pulse sequence during the recycle

delay ( 3 seconds) to saturate any residual water (HOD) in the samples before acquiring for about 2 seconds. Generally, 256 scans were performed on each sample for signal averaging for better signal to noise ratio. Labelled and unlabeled lactate and glucose concentrations were measured by simple integration of the peak(s) areas of these metabolites relative to the known concentration of DSS (Sodium trimethylsilylpropanesulfonate as a sodium salt) that is added to each 
sample which serves as both chemical shift reference and metabolite quantifications.

\section{Real time-PCR}

Total RNA was isolated from up to $30 \mathrm{mg}$ of frozen pulverized tissue using the RNeasy Mini Kit (Qiagen) according to the manufacturer's protocol. The resulting total RNA $(1 \mu \mathrm{g})$ was converted to cDNA using the High-Capacity RNA-to cDNA kit (applied biosystems). Gene expression was determined by qPCR using the following Taqman Gene Expression Assays:), Cs (Mm00466043_m1), Idh2 (Mm00612429_m1), Ogdh (Mm01179923_m1), Suclg1 (Mm00451244_m1), Sdha (Mm01352366_m1), Fh1 (Mm01321349_m1), Mdh2 (Mm00725890_s1), Asct2 (Mm00436603_m1), Gls (Mm01257297_m1), Glud1 (Mm00492353_m1), Mct1 (Mm01306379_m1), and $\beta$-actin (Mm00607939_s1) $\beta$-actin was used as an internal control. Data are reported as the log (base 2) of the fold change.

\section{Immunohistochemistry}

Mice were sacrificed by cervical dislocation and lungs were harvested, fixed overnight in $4 \%$ paraformaldehyde, and paraffin embedded. Lung tissue sections were dewaxed and rehydrated, followed by antigen retrieval in Tris-EDTA buffer $(\mathrm{pH}$ 9.0). Sections were then blocked using $5 \%$ goat serum and incubated with 1:100 dilution of the following antibodies overnight at $4^{\circ} \mathrm{C}$ : Glut1 (ProteinTech Cat. No. 21829-1-AP), Hk2 (Cell Signaling Cat. No. 2867S), and Pkm2 (Cell Signaling Cat. No. 4053S). Sections were subsequently incubated with 1:500 dilution of HRPconjugated anti-rabbit antibody (Invitrogen Cat. No. 32260) for one hour at room temperature. Expression was detected using DAB stain (Vector Laboratories) and 
counterstained with hematoxylin. Hematoxylin and eosin staining was performed by the University of Louisville's Special Procedures Laboratory within the Department of Pathology. Imaging was performed using an Aperioscope digital slide scanner.

\section{Immunoblotting}

Protein lysate was generated from three distinct lung tumors from both the $\mathrm{Kras} / \mathrm{Rb}^{+/+}$and $\mathrm{Kras} / \mathrm{Rb}^{-/}$mice. $20 \mu \mathrm{g}$ of tumor or MCF-7 (positive control) protein lysate were separated by $10 \%$ SDS-PAGE followed by transfer to PVDF membrane. After transfer, membranes were cut between the $85 \mathrm{kDa}$ and $64 \mathrm{kDa}$ molecular weights for simultaneous assessment of either pRb, p107, and GAPDH using anti-RB (Cell Signaling \#9309, 1:1000), p107 (ProteinTech 13354-1-AP, 1:500), and GAPDH (Millipore ABS16, 1:500) antibodies, respectively. Proteins were visualized using 1:5000 dilution of either anti-mouse or -rabbit HRP-linked secondary antibody and ECL prime chemiluminescent reagent (Amersham).

\section{Statistical Analysis}

Statistical analyses were carried out using GraphPad Prism. All numerical data are reported as mean \pm SEM. Grouped analysis was performed using Oneway ANOVA with Tukey's post-hoc comparison. For each experiment, replicates and $p$ values for all results are listed in their respective figure legends. 


\section{RESULTS}

\section{Steady-state metabolomics highlights metabolic discrepencies in pRb- deficient tumors in vivo}

Loss of $R b 1$ accelerates lung tumor progression in mutant Kras-driven lung cancer in vivo resulting in the development of higher-grade adenocarcinomas and decreased overall survival (131). Based on the emerging evidence that $\mathrm{pRb}$ directly regulates metabolism, we hypothesized loss of $R b 1$ promotes a metabolic phenotype that supports tumor progression. We have utilized a combination of steady-state and stable-isotope labeled metabolomics to assess global changes in metabolism resulting from $\mathrm{pRb}$ dysfunction in Kras-driven lung tumors in vivo (Figure 19A).

Consistent with previous findings, loss of $R b 1$ significantly decreased overall survival and increased tumor burden in this Kras-driven lung cancer model (Figure 19B,C, 20). To identify potential pRb-dependent metabolic adaptations in these lung tumors, we performed steady-state metabolomics analysis to analyze the relative abundance of metabolites within major metabolic pathways. Hierarchical clustering demonstrated distinct metabolic patterns between normal lung, $R b 1^{+/+}$, and $R b 1^{-/-}$lung tumors (Figure 21). Interestingly, glucose-6phosphate, fructose-6-phsophate, glyceraldehyde-3-phosphate, and metabolites within the pentose phosphate pathway (ribose-5-phosphate) appear to be elevated in the $R b 1^{-/}$lung tumors. This suggests that $\mathrm{pRb}$ may regulate glucose utilization in Kras-driven lung tumors as many of the qualitative changes in metabolite 

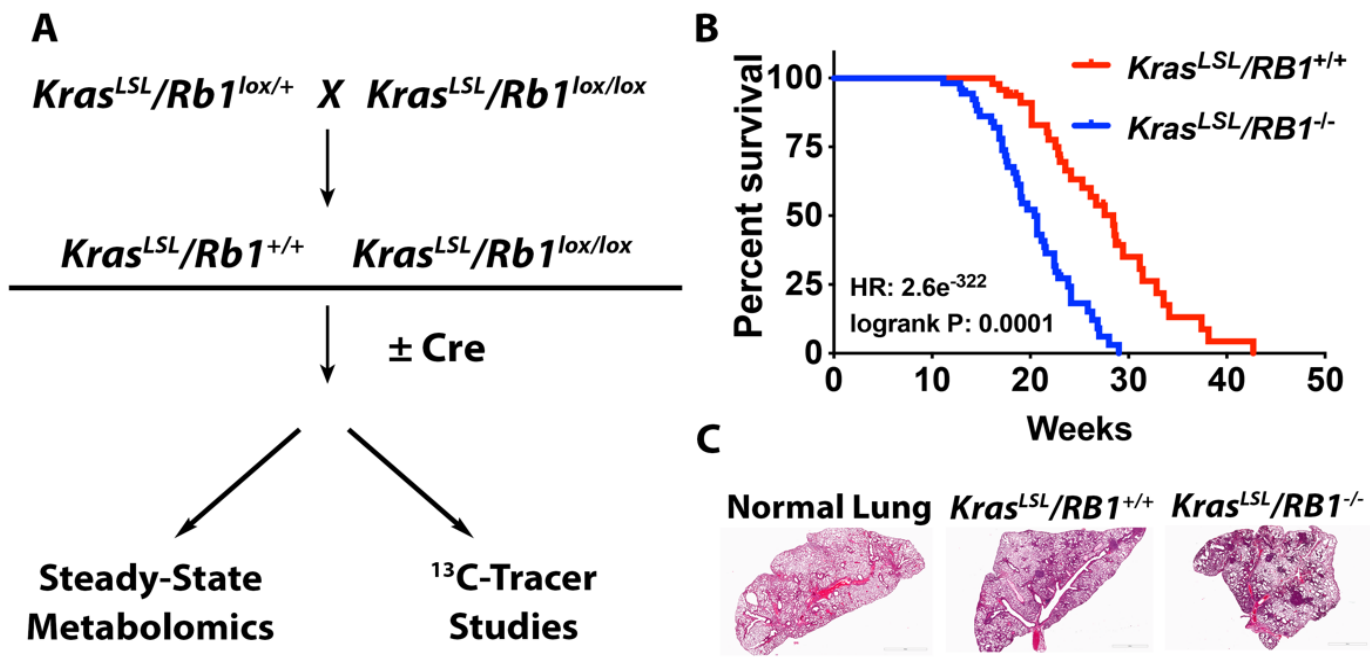

Figure 19. Loss of $R b 1$ accelerates lung cancer progression in a Kras-driven model of lung cancer. (A) Schematic of experimental design to assess the metabolic function of $\mathrm{pRb}$ in Kras-driven lung tumors in vivo. For all experiments, non-instilled $K r a s^{L S L} / R b 1^{10 x / 10 x}$ mice served as normal lung controls. (B) KaplanMeier survival analysis for $K r a s^{L S L}$ mice with wild-type $\left(R b 1^{+/+}\right)(n=53)$ or knockout $\left(R b 1^{-/}\right)(\mathrm{n}=47)$ of $\mathrm{Rb} 1 .(\mathrm{C})$ Representative H\&E staining of lung tissue from normal, $R b 1^{+/+}$, and $R b 1^{-/-}$mice (representative of $\mathrm{n}=3$ ). 


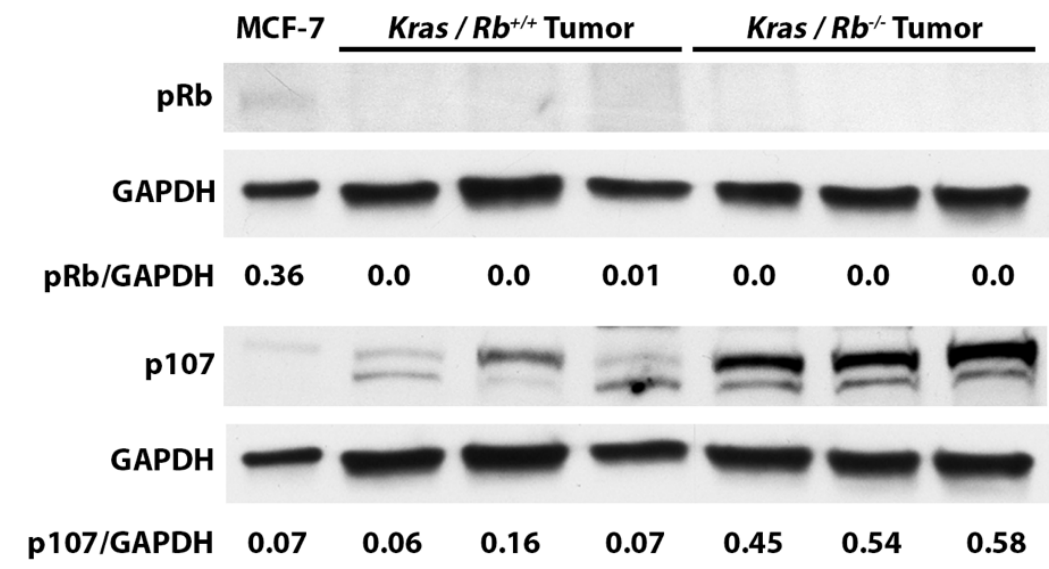

Figure 20. Confirmation of loss of $R b 1$ in resulting Kras-driven lung tumors. (A) Western blot analysis of $\mathrm{pRb}$ and $\mathrm{p} 107$ in three separate lung tumors after intratracheal instillation of $\mathrm{Ad}-\mathrm{Cre}$ in either the $\mathrm{Kras} / \mathrm{Rb} 1^{+/+}$or $\mathrm{Kras} / \mathrm{Rb} 1^{-/-}$mice. While $\mathrm{pRb}$ expression is relatively low in all developing lung tumors, elevated p107 confirms loss of $R b 1$ in the $K r a s / R b 1^{-/}$tumors as has been previously demonstrated for this model (15). MCF-7 cell lysate was used as a positive control for both $\mathrm{pRb}$ and $\mathrm{p} 107$ expression. 


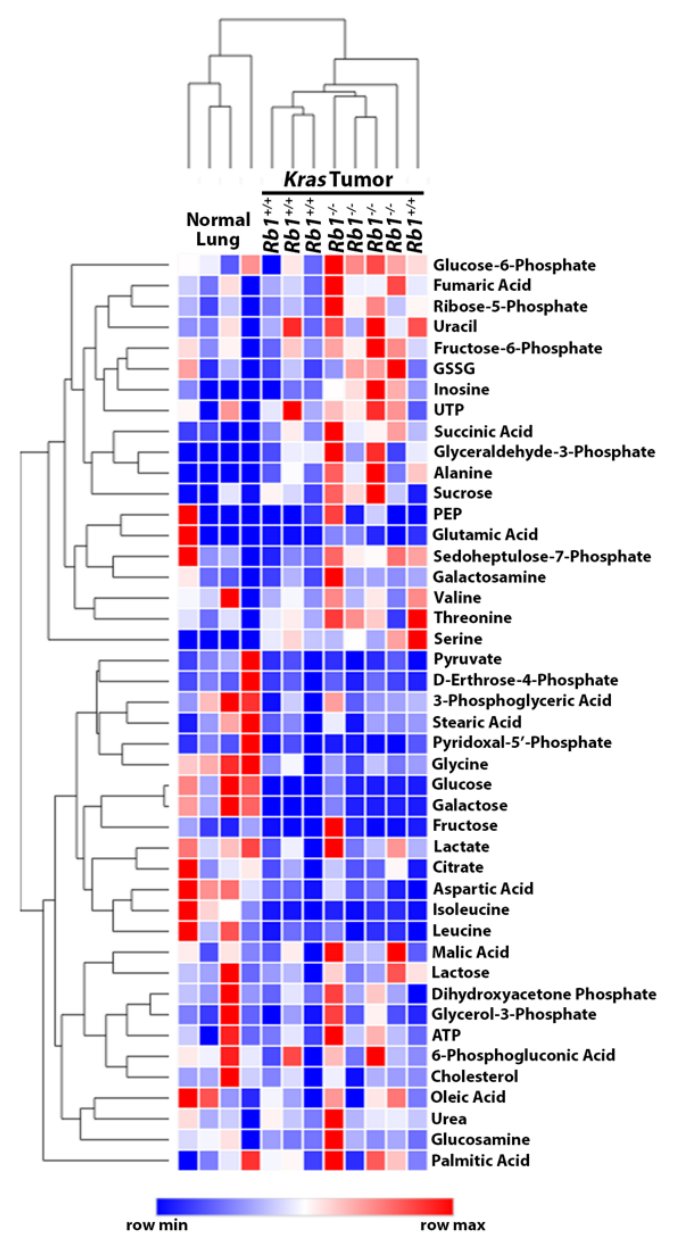

Figure 21. $R b 1$ loss qualitatively alters the steady state relative abundance of metabolites in Kras-driven lung tumors. Hierarchical clustering analysis depicts the relative abundance of metabolites in normal lung, $R b 1^{+/+}$, and $R b 1^{-/-}$ lung tumors $(n=4)$. Color coding indicates the row minimum or maximum for each metabolite from least (blue) to most (red) abundant. 
abundance were observed within glycolysis or metabolic pathways originating from glycolytic intermediates.

\section{Loss of $R b 1$ enhances glycolysis in Kras-driven lung tumors}

To examine differences in glucose utilization between $R b 1^{+/+}$and $R b 1^{-/-~ l u n g ~}$ tumors, we preformed $\left[\mathrm{U}-{ }^{13} \mathrm{C}\right]$-glucose tracer studies. Sufficient $\left[\mathrm{U}-{ }^{13} \mathrm{C}\right]$-glucose plasma enrichment was observed for both normal lung and tumor bearing mice (Figure 22A). Utilization of ubiquitously labeled glucose results in the intracellular generation of ${ }^{13} \mathrm{C}$ labeling of the hexose and triose sugar intermediates within the glycolytic pathway; resulting in fully labeled pyruvate $(m+3)$ (Figure 23). Pyruvate can then be metabolized to lactate by lactate dehydrogenase (LDH), transaminated to alanine by alanine aminotransferase (ALT), or enter TCA cycle through pyruvate dehydrogenase (PDH) or pyruvate carboxylase $(P C)$. It has been previously shown that Kras-driven lung tumors display similar labeling of pyruvate and lactate compared to adjacent lung (46). Consistent with these findings, labeling of glycolytic intermediates from glucose carbon did not significantly differ in $R b 1^{+/+}$tumors compared to normal lung tissue (Figure 24). Conversely, loss of $R b 1$ significantly increased glucose carbon incorporation into several glycolytic intermediates, including both pyruvate and lactate (Figure 24C,D).

We next sought to determine if the observed increase in carbon labeling of glycolytic intermediates in $R b 1^{-/}$lung tumors was due to changes in expression of rate-limiting enzymes in Kras-driven lung tumors. We performed immunohistochemitry analysis for glucose transporter 1 (Glut1), hexokinase 2 (Hk2), and pyruvate kinase M2 (Pkm2) in both normal and lung tumor tissue. We 

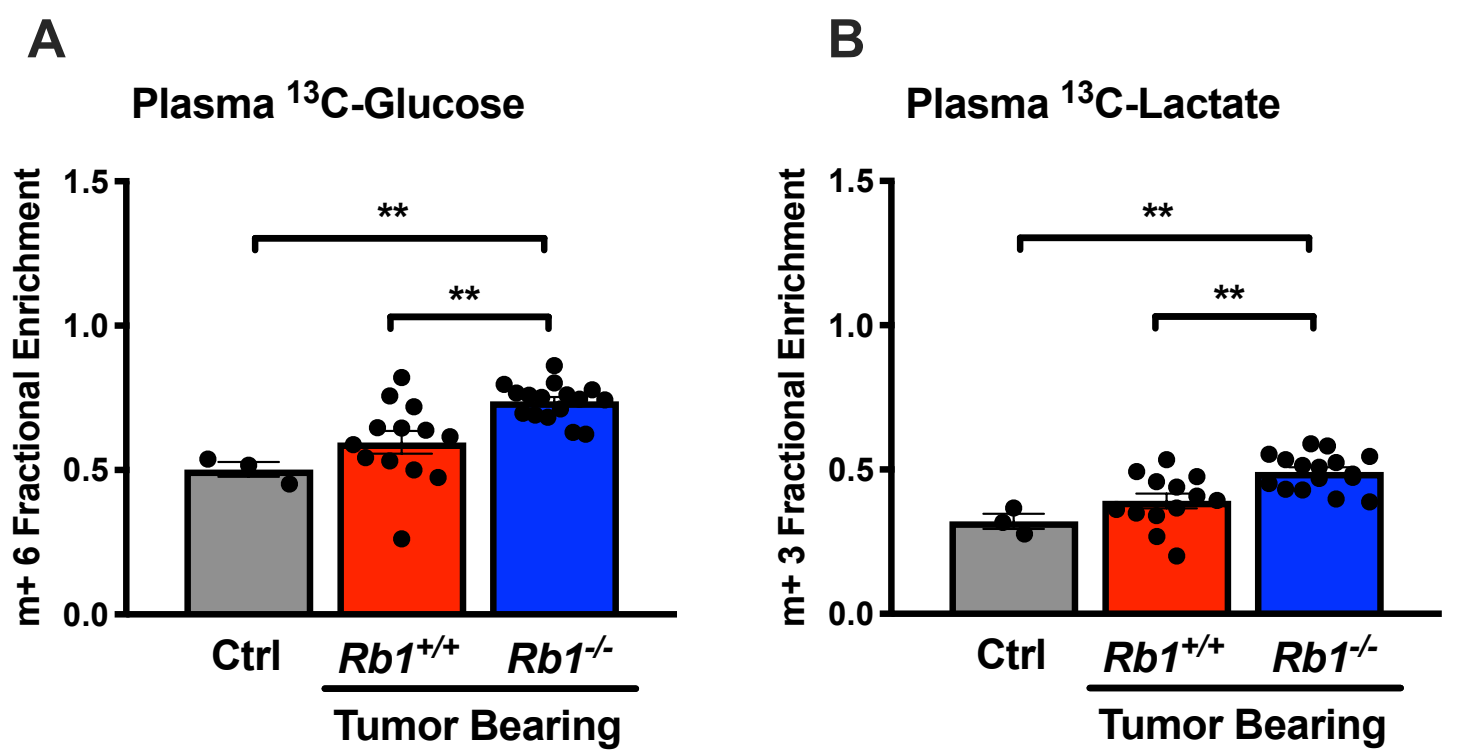

Figure 22. $R b 1^{-/}$mice exhibit increased labeled plasma glucose and lactate when administered $\left[\mathrm{U}-{ }^{13} \mathrm{C}\right]$-glucose. Fractional enrichment of fully labeled glucose $(\mathrm{m}+6)(\mathbf{A})$ and lactate $(\mathrm{m}+3)(\mathbf{B})$ in plasma from control, $R b 1^{+/+}$and $R b 1^{-/-}$ mice. For (A, B), values represent mean +/- SEM analyzed by one-way ANOVA with Tukey's post-hoc comparison (normal lung $\mathrm{n}=3, R b 1^{+/+} \mathrm{n}=12 ; R b 1^{-/-} \mathrm{n}=10$ ). Statistical significances between each group are as follows: ${ }^{* *} p<0.01$. 


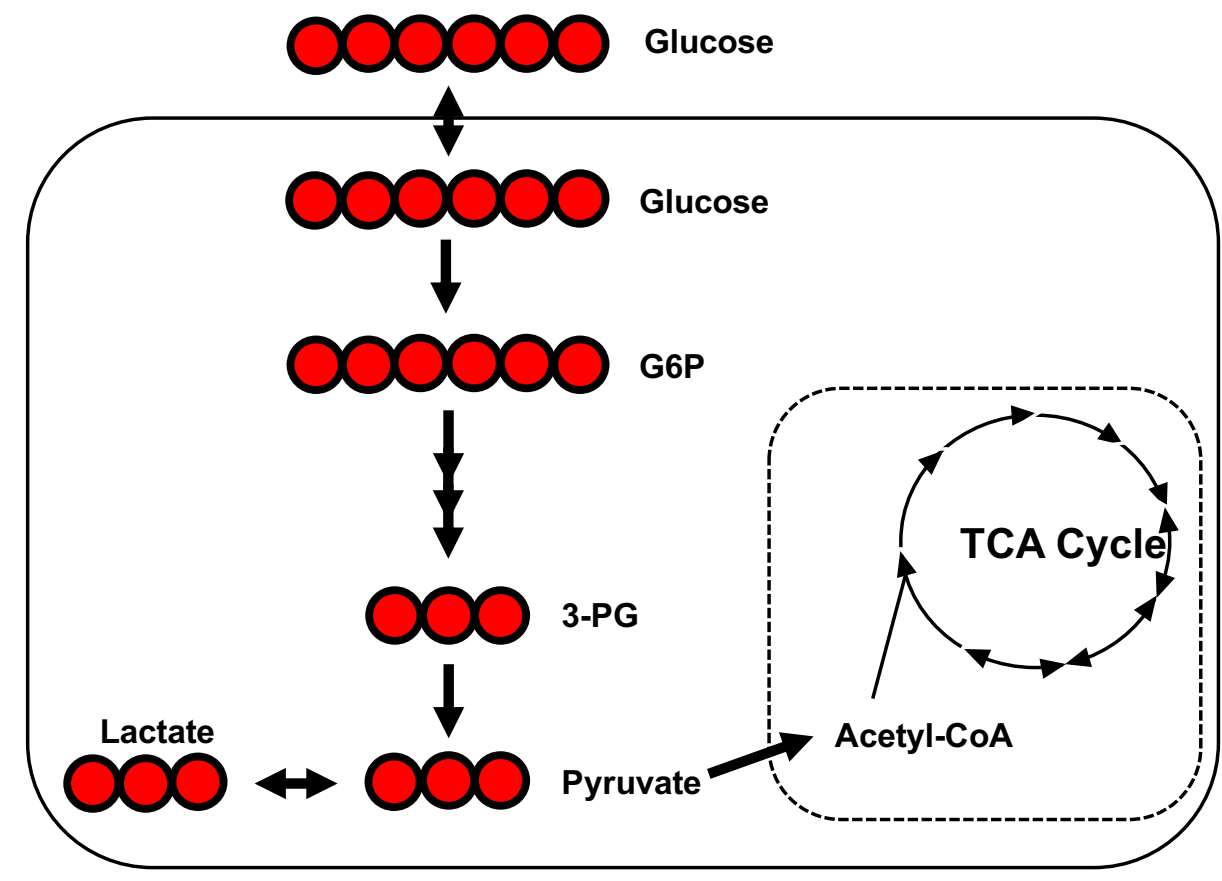

Figure 23. Cartoon of $\left[\mathrm{U}-{ }^{13} \mathrm{C}\right]-$ glucose fate mapping though glycolysis. Red circles indicate ${ }^{13} \mathrm{C}$. 
A

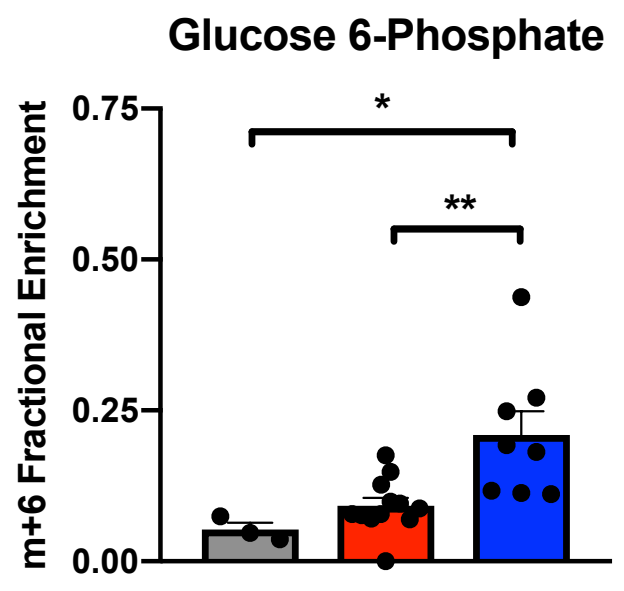

C

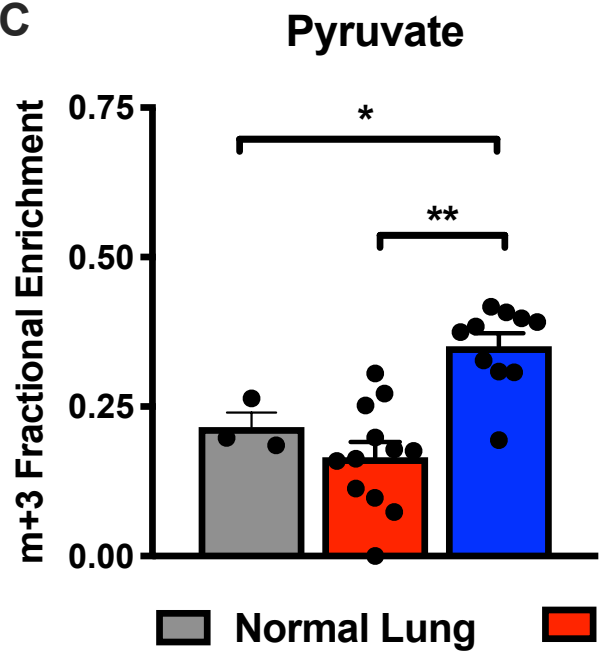

B
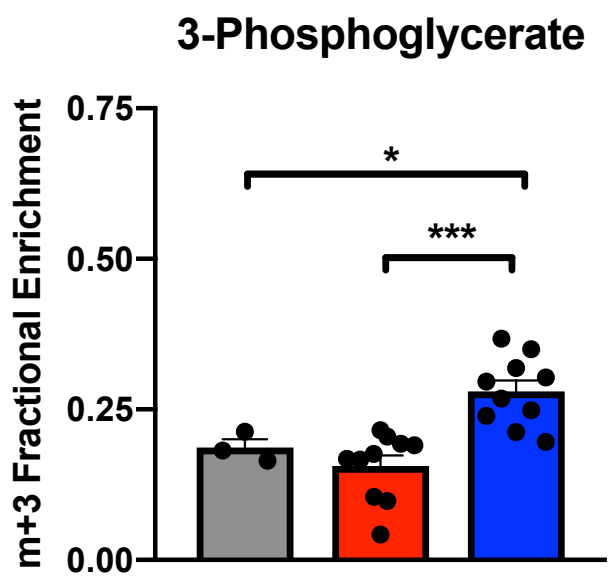

D Lactate

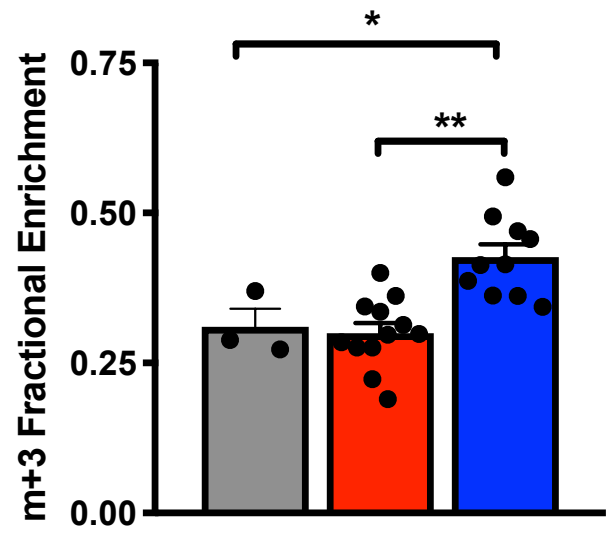

$R b 1^{+/+}$Tumor $\square R b 1^{-/-}$Tumor

Figure 24. Loss of $R b 1$ increases glucose carbon incorporation into glycolytic intermediates in vivo. (A-D) Fractional enrichment of $m+6$ labeled glucose 6-phosphate (A), and $m+3$ labeled 3-phosphoglycerate (B), pyruvate (C), and lactate (D) in normal lung, $R b 1^{+/+}$, and $R b 1^{-/-}$lung tumors following bolus [U${ }^{13} \mathrm{C}$-glucose injections. Values represent mean \pm SEM analyzed by one-way ANOVA with Tukey's post-hoc comparison (normal lung $\mathrm{n}=3, R b 1^{+/+} \mathrm{n}=12 ; R b 1^{-/-}$ $n=10$ ). Statistical significances between each group are as follows: ${ }^{*} p<0.05$, ${ }^{* *} p<0.01$, or ${ }^{* * *} p<0.001$ 
found that loss of $R b 1$ qualitatively increases Glut1, $\mathrm{Hk} 2$, and Pkm2 in Kras-driven lung tumors compared to those with intact $\mathrm{pRb}$ and normal lung tissue (Figure 25).These results indicate that $p R b$ enhances glycolysis, in part, via upregulation of glycolytic enzymes in Kras-driven lung tumors in vivo.

As stated earlier, pyruvate carbon can enter the TCA cycle via two distinct mechanisms. Pyruvate can enter the TCA cycle as acetyl-CoA generated from the pyruvate dehydrogenase complex (PDH), or via anaplerosis in which pyruvate enters the TCA cycle as oxaloacetate through the activity of pyruvate carboxylase (PC) (Figure 26). PDH entry of pyruvate carbon is indicated by $m+2\left(1^{\text {st }}\right.$ turn $) / m+4$ ( $2^{\text {nd }}$ turn) isotopologues, while PC activity is observed by $m+3$ isotopologue labeling of TCA intermediates. Kras-driven lung tumors utilize pyruvate as the primary source of TCA cycle carbon via PDH and exhibit elevated PC activity $(46,141)$. Consistent with these studies, we observed increased $m+2$ and $m+4$ carbon labeling in certain intermediates as well as $\mathrm{m}+3$ aspartate, malate, and fumarate in $R b 1^{+/+}$lung tumors compared to normal lung tissue (Figure 27). As several studies have demonstrated a role for the $\mathrm{pRb}-\mathrm{E} 2 \mathrm{~F}$ pathway in regulating oxidative metabolism $(81,96,97,142)$, we sought to define if loss of $R b 1$ further contributes to pyruvate oxidation in Kras-driven lung tumors. Interestingly, we observed no significant difference in both PDH or PC-mediated pyruvate carbon entry into the TCA cycle between $R b 1^{+/+}$and $R b 1^{-/}$lung tumors in vivo (Figure 27). Moreover, loss of $R b 1$ does not alter gene expression of TCA cycle enzymes (Figure 28). Taken together, analysis of $\left[\mathrm{U}-{ }^{13} \mathrm{C}\right]$-glucose labeling in pRb-deficient 


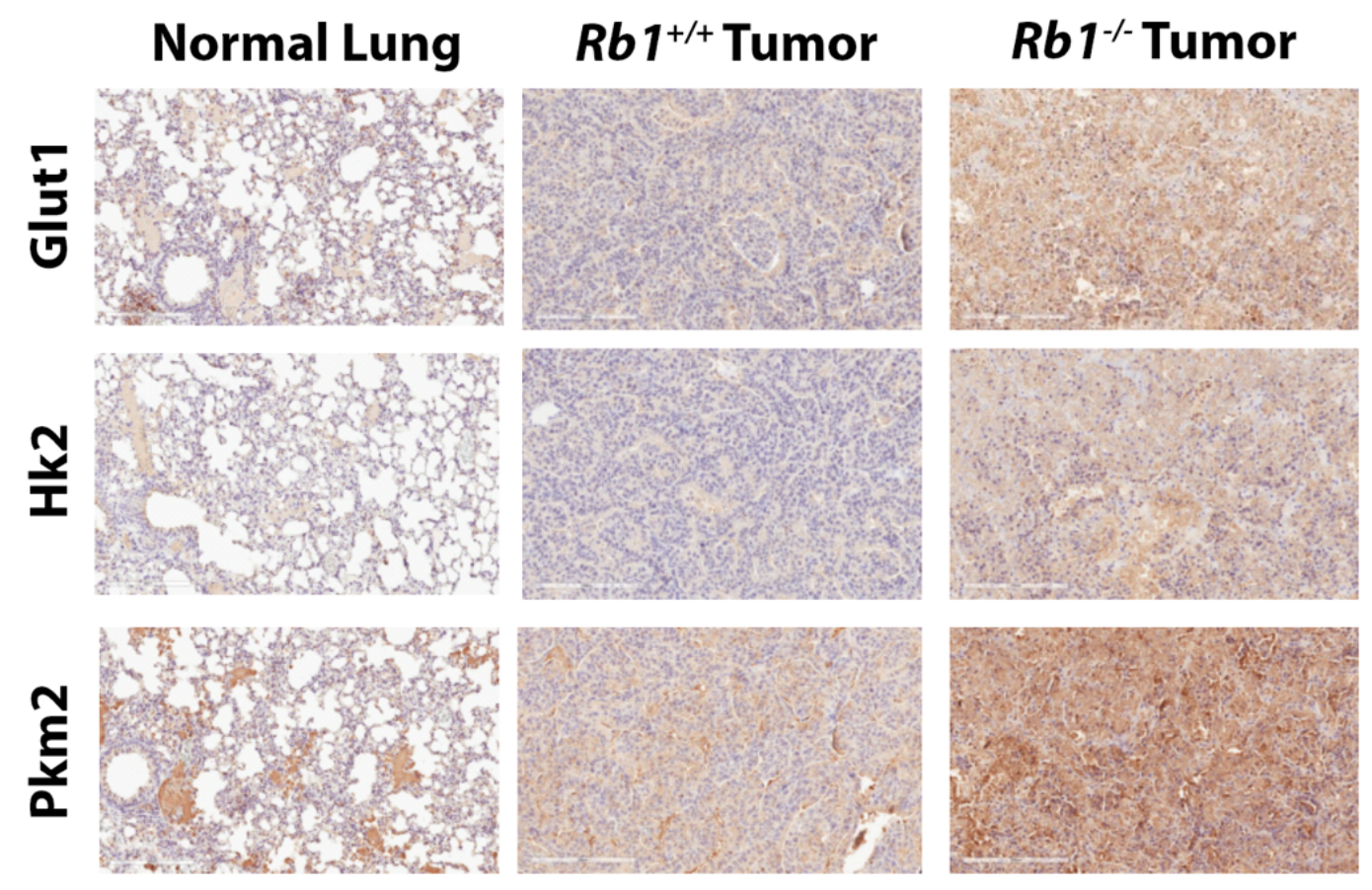

Figure 25. Loss of $R b 1$ increases expression of key glycolytic enzymes in Kras-driven lung tumors in vivo. Immunohistochemical staining examining glucose transporter 1 (Glut1), hexokinase 2 (Hk2), and pyruvate kinase M2 (Pkm2) expression in normal lung, $R b 1^{+/+}$, and $R b 1^{-/}$lung tumors. Images were taken under 20x magnification and the scale bar in the lower left corner of each image represents $200 \mu \mathrm{m}$. Staining is representative of $n=3$. 


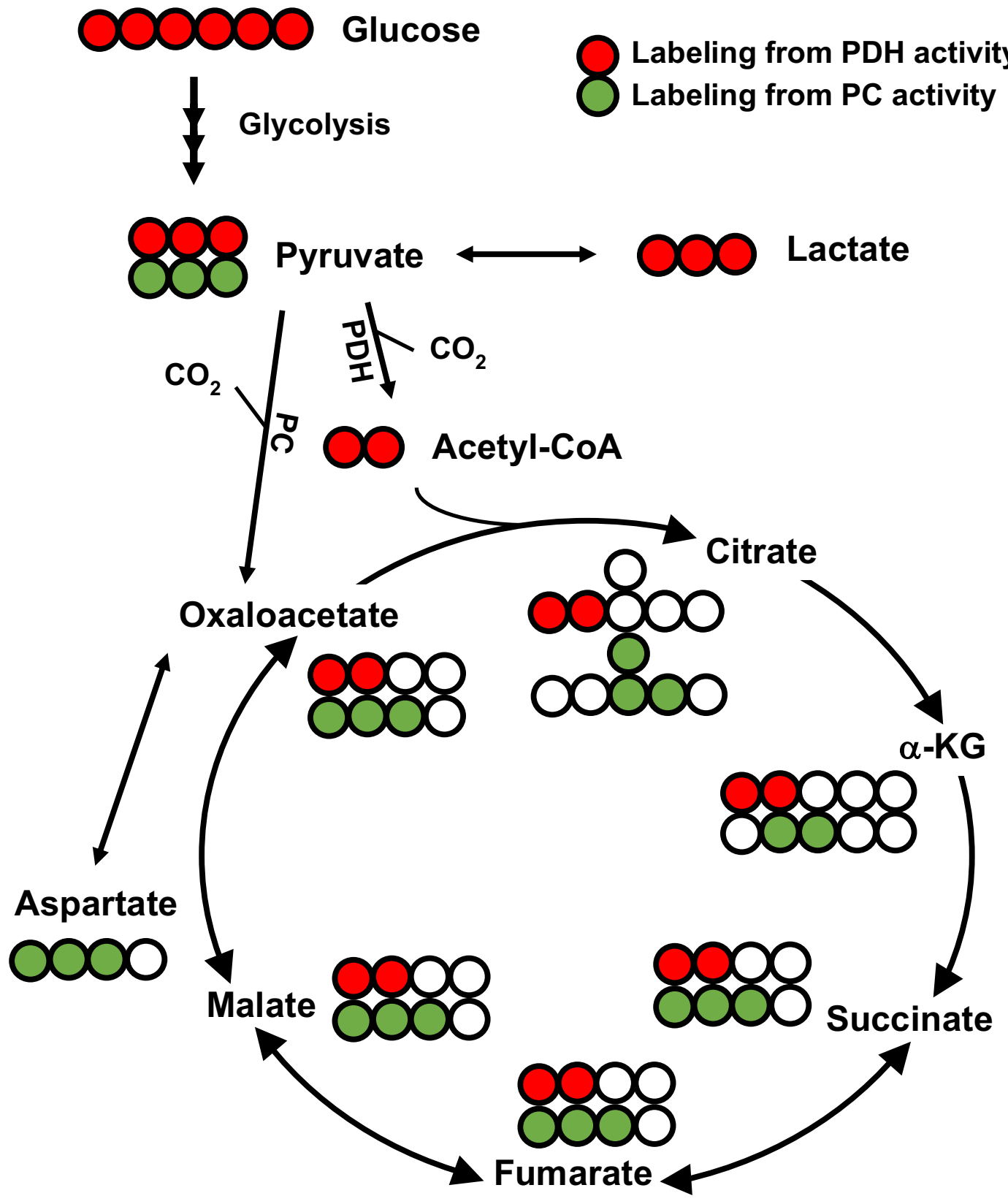

Figure 26. Cartoon of $\left[\mathrm{U}-{ }^{13} \mathrm{C}\right]$-glucose fate mapping through the $1^{\text {st }}$ turn of the TCA cycle. Red circles are ${ }^{13} \mathrm{C}$ labeling indicative of pyruvate dehydrogenase activity, green circles are ${ }^{13} \mathrm{C}$ labeling indicative of pyruvate carboxylase activity, and white circles are unlabeled ${ }^{12} \mathrm{C}$. 
A

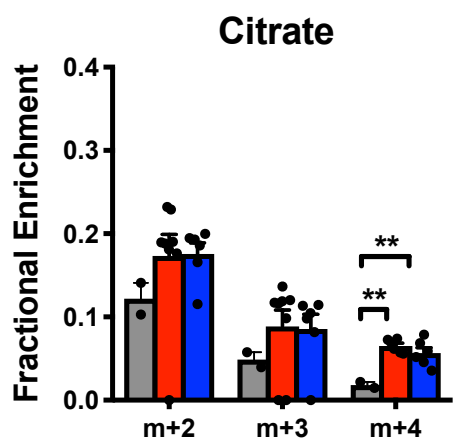

C

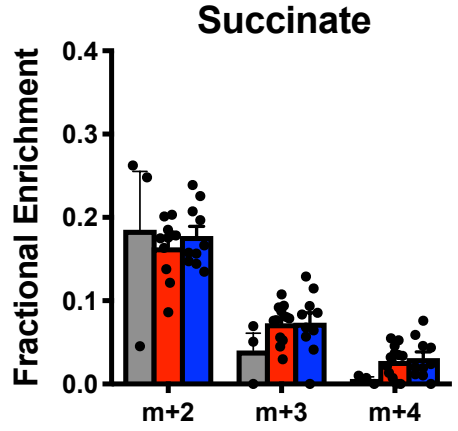

E

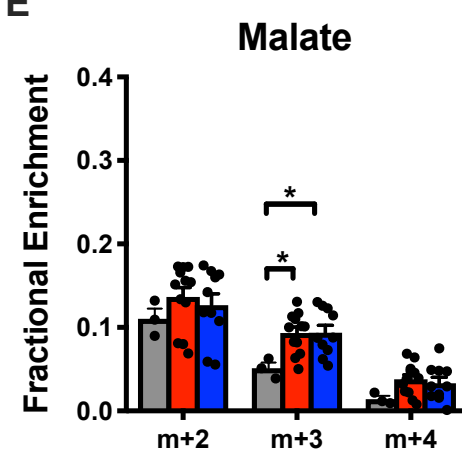

$\square$ Normal Lung
B
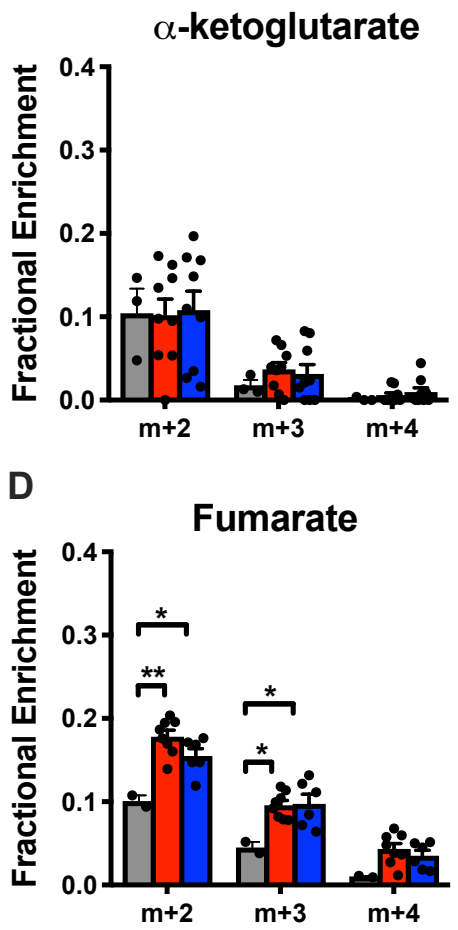

$\mathbf{F}$

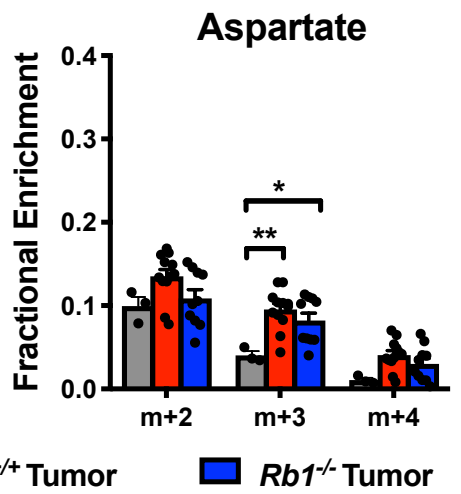

Figure 27. Loss of $R b 1$ does not affect pyruvate metabolism in Kras-driven lung tumors in vivo. (A-F) Fractional enrichment of TCA metabolites in normal lung, $R b 1^{+/+}$, and $R b 1^{-/}$lung tumors (normal lung $\mathrm{n}=3, R b 1^{+/+} \mathrm{n}=12 ; R b 1^{-/} \mathrm{n}=10$ ). Values represent mean +/- SEM analyzed by one-way ANOVA with Tukey's posthoc comparison. Statistical significances between each group are as follows: ${ }^{*} p<0.05$ or ${ }^{* *} p<0.01$ 
TCA Cycle

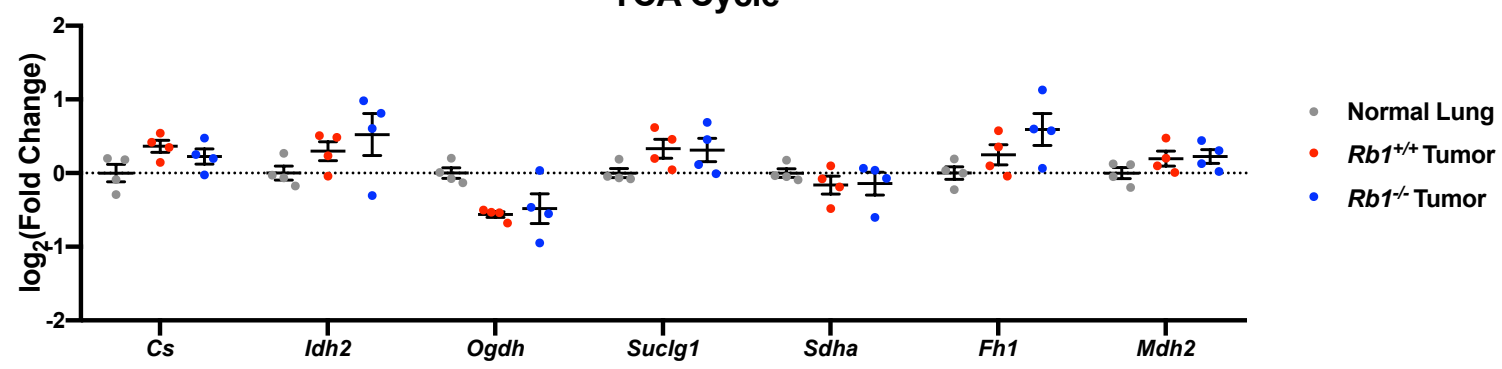

Figure 28. Loss of $R b 1$ does not affect gene expression of TCA cycle enzymes in Kras-driven lung tumors in vivo. qPCR analysis of the TCA cycle genes citrate synthase (Cs), isocitrate dehydrogenase 2 (Idh2), alphaketoglutarate dehydrogenase $(\mathrm{Ogdh})$, succinate-CoA ligase alpha subunit (Suclg1), succinate dehydrogenase complex, subunit a (Sdha), fumarate hydratase $1(F h 1)$, and malate dehydrogenase $2(M d h 2)$, in normal lung, $R b 1^{+/+}$, and $R b 1^{-/}$lung tumors $(\mathrm{n}=4)$. Expression was normalized to $\beta$-actin and reported as the log (base 2) of the fold change. Values represent mean +/- SEM analyzed by one-way ANOVA with Tukey's post-hoc comparison. 
lung tumors suggests loss of $R b 1$ enhances glycolysis without altering mitochondrial pyruvate oxidation in vivo.

\section{$\mathrm{pRb}$ does not regulate glutamine utilization in vivo}

Although it has been demonstrated that Kras-driven lung tumors do not utilize glutamine in vivo (46), loss of $R b 1$ has been shown to increase glutamine utilization as a source of anaplerotic carbon for the TCA cycle in mouse embryonic fibroblasts (MEFs) (100). As such, we sought to examine differences in glutamine utilization between $R b 1^{+/+}$and $R b 1^{-/}$lung tumors using $\left[\mathrm{U}-{ }^{13} \mathrm{C},{ }^{15} \mathrm{~N}\right]$-glutamine tracer studies (Figure 29). Under three sequential bolus doses, we observed low plasma $\left[\mathrm{U}-{ }^{13} \mathrm{C},{ }^{15} \mathrm{~N}\right]$-glutamine and intracellular labeled glutamine and glutamate for both normal lung and tumor bearing mice (Figure 30A,B). As has been previously reported for Kras-driven lung tumors (46), we found no significant increase in glutamine anaplerosis into TCA cycle intermediates compared to normal lung. Interestingly, pRb-deficient tumors did not exhibit significantly different labeling of TCA cycle intermediates compared to Kras-driven lung tumors or normal lung tissue (Figure $\mathbf{3 0 C}$ ). In addition to serving as a fuel source for the TCA cycle, cancer cells can metabolize glutamine via reductive carboxylation to citrate, producing acetyl-CoA via citrate lyase for lipogenesis (Figure 31A) $(64,143)$. We observed no significant difference in $m+5$ citrate generated from the fixation of unlabeled $\mathrm{CO}_{2}$ to $\alpha$-ketoglutarate (Figure 31B) (144), suggesting $\mathrm{pRb}$ function does not significantly contribute to reductive carboxylation of glutamine. Consistent with our labeling data, we did not observe any significant expression changes in genes 


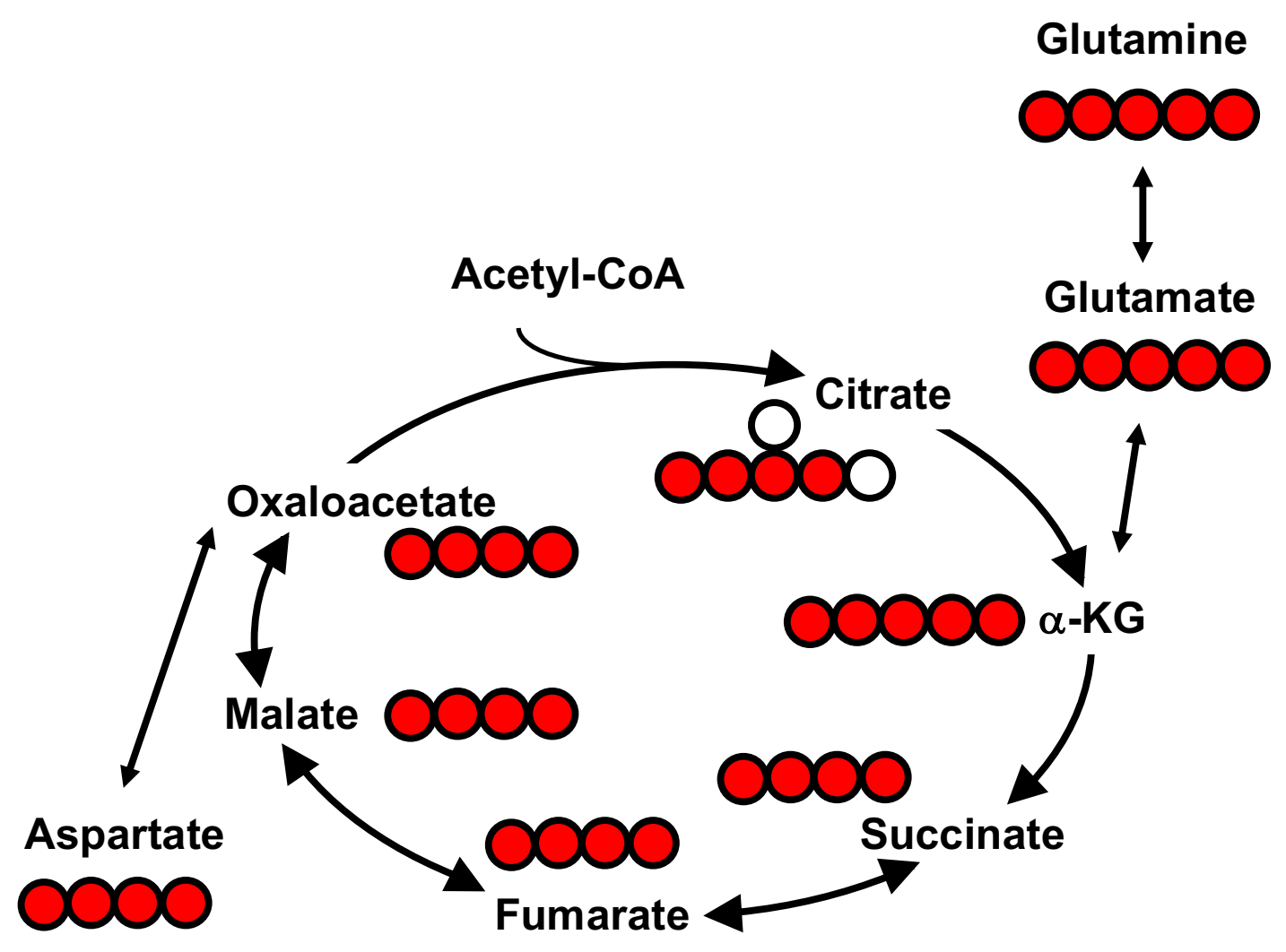

Figure 29. Cartoon of $\left[\mathrm{U}-{ }^{13} \mathrm{C},{ }^{15} \mathrm{~N}\right]$-glutamine fate mapping through the TCA cycle. Red circles indicate ${ }^{13} \mathrm{C}$ and white circles indicate unlabeled ${ }^{12} \mathrm{C}$. 


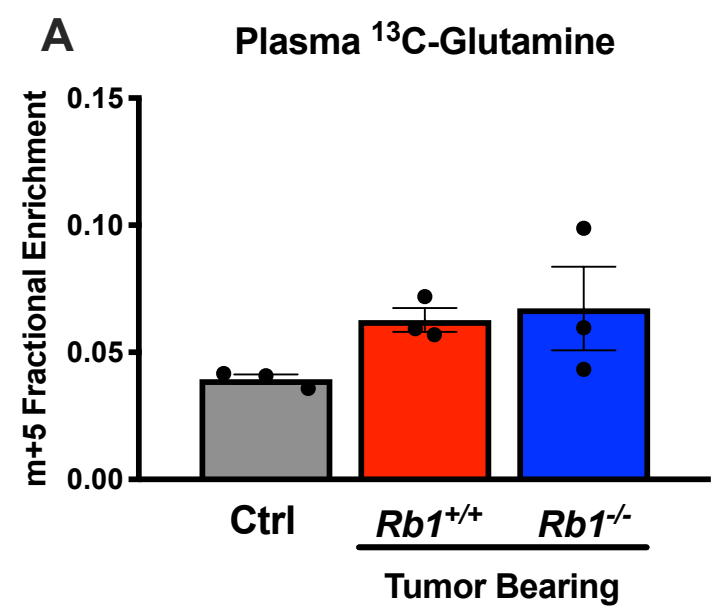

B
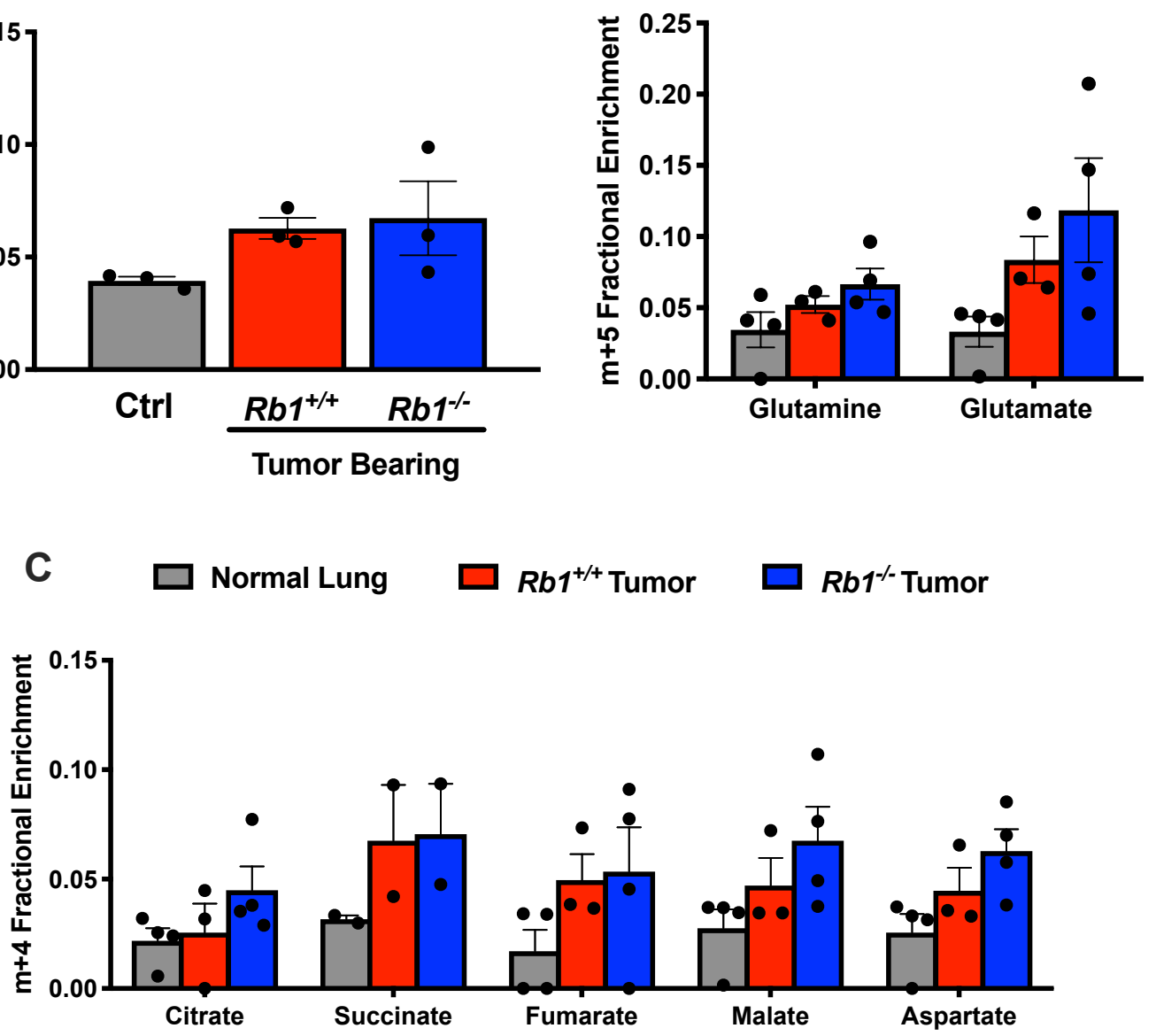

Figure 30. Loss of $R b 1$ does not influence glutaminolysis in vivo. (A) Fractional enrichment of fully labeled glutamine $(m+5)$ in plasma from control, $R b 1^{+/+}$and $R b 1^{-/}$mice. (B) Fractional enrichment of fully labeled glutamine $(m+5)$ and glutamate $(\mathrm{m}+5)$ in normal lung, $R b 1^{+/+}$, and $R b 1^{-/}$lung tumors following bolus $\left[\mathrm{U}-{ }^{13} \mathrm{C},{ }^{15} \mathrm{~N}\right]$-glutamine injections. (C) Fractional enrichment of $\mathrm{m}+4$ TCA metabolites in normal lung, $R b 1^{+/+}$, and $R b 1^{-/}$lung tumors. Values represent mean +/- SEM analyzed by analyzed by one-way ANOVA with Tukey's post-hoc comparison $(n=4)$. 

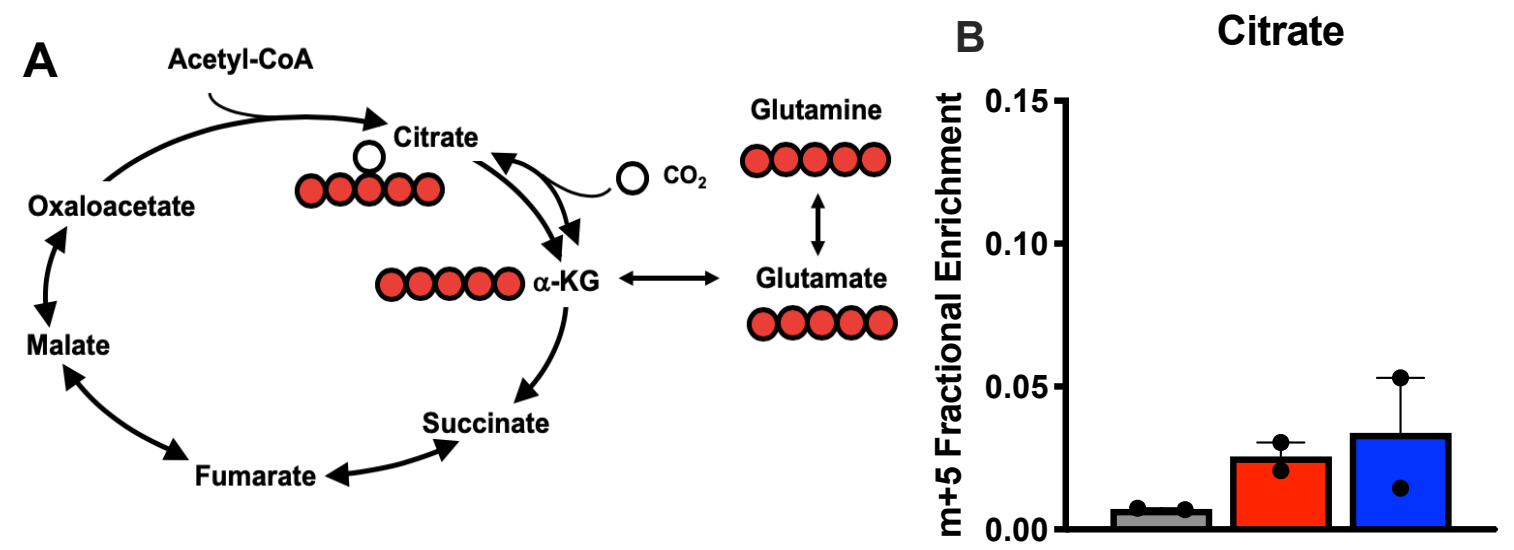

Figure 31. Loss of $R b 1$ does not influence reductive carboxylation in vivo. (A) Cartoon of $\left[\mathrm{U}-{ }^{13} \mathrm{C},{ }^{15} \mathrm{~N}\right]$-glutamine fate mapping through reductive carboxylation. Red circles are ${ }^{13} \mathrm{C}$ and white circle are unlabeled ${ }^{12} \mathrm{C}$. Fractional enrichment of $\mathrm{m}+5$ labeled citrate $(\mathrm{B})$ in normal lung, $R b 1^{+/+}$, and $R b 1^{-/}$lung tumors following bolus $\left[\mathrm{U}-{ }^{13} \mathrm{C},{ }^{15} \mathrm{~N}\right]$-glutamine injections. Values represent mean $+/-\mathrm{SEM}$ analyzed by analyzed by one-way ANOVA with Tukey's post-hoc comparison $(\mathrm{n}=)$. 
within glutamine utilization including the glutamine transporter (Asct2), glutaminase (G/s), or glutamate dehydrogenase (Glud1) (Figure 32). Together, our findings suggest Rb1 does not appear to influence glutamine utilization in the context of Kras-driven lung cancer in vivo.

\section{Loss of $R b 1$ does not alter lactate utilization in Kras-driven lung tumors}

Recent studies have reported circulating lactate can be utilized as a TCA cycle carbon source in both Kras-driven lung tumors in vivo as well as in NSCLC patients $(55,56)$. Given loss of $R b 1$ does not alter mitochondrial pyruvate oxidation in animals administered labeled glucose (Figure 27), we hypothesized loss of $R b 1$ may influence the utilization of circulating lactate. For these studies, we developed a labeling protocol using $\left[\mathrm{U}-{ }^{13} \mathrm{C}\right]$-lactate based on the method used for our [U-133 $\mathrm{C}-$ glucose and $\left[\mathrm{U}-{ }^{13} \mathrm{C},{ }^{15} \mathrm{~N}\right]$-glutamine tracer studies. In brief, three bolus doses of [U$\left.{ }^{13} \mathrm{C}\right]$-lactate were administered via tail vein injection, each 15 minutes apart. Fifteen minutes after the last injection, mice were euthanized and lung tumors or normal lung tissue was harvested for metabolite extraction followed by 2DLC-MS/MS analysis. Using this approach, plasma ${ }^{13} \mathrm{C}$-lactate was undetectable in both normal lung and tumor bearing mice when euthanized 15 minutes after the last injection. This is likely in part due to the high turnover rate for circulating lactate (56). To confirm $\left[\mathrm{U}-{ }^{13} \mathrm{C}\right]$-lactate was being rapidly turned over, we euthanized mice at 0,5 , or 10 minutes after the third dose of $\left[\mathrm{U}-{ }^{13} \mathrm{C}\right]$-lactate. When euthanized immediately, plasma ${ }^{13} \mathrm{C}$-lactate reached $\sim 15 \%$, then rapidly decreased by 5 and 10 minutes (Figure 33A). Even under these conditions, we were able to observe intracellular 


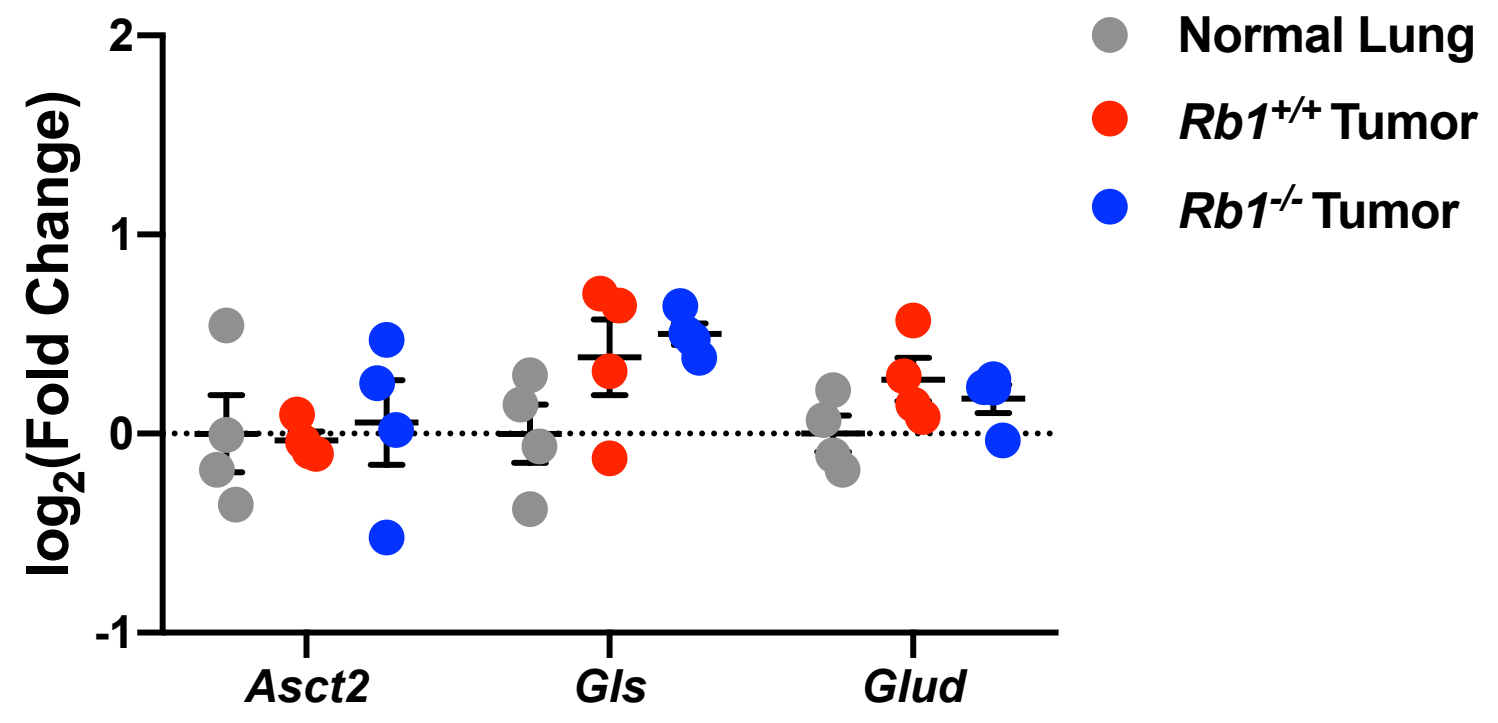

Figure 32. Genetic deletion of $R b 1$ does not regulate genes within glutamine utilization in vivo. qPCR analysis of glutamine transporter (Asct2), glutaminase (G/s), and glutamate dehydrogenase (Glud1) in normal lung, $R b 1^{+/+}$, and $R b 1^{-/-}$ tumors. Expression was normalized to $\beta$-actin and reported as the log (base 2) of the fold change. Values represent mean +/- SEM analyzed by analyzed by oneway ANOVA with Tukey's post-hoc comparison $(n=4)$. 
A

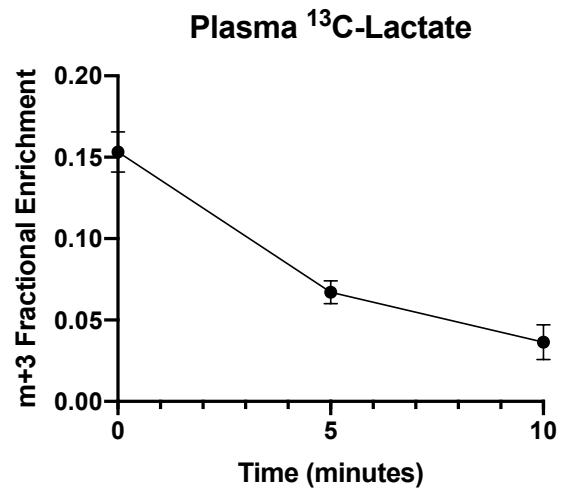

B

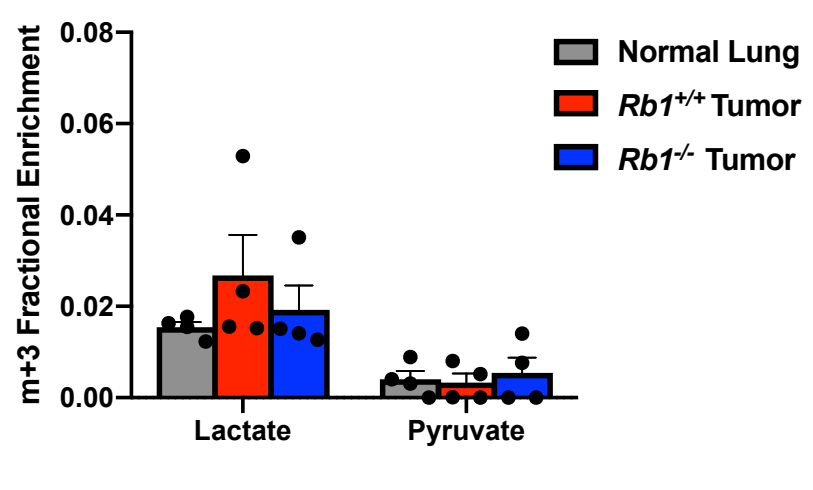

Figure 33. Rb1 deletion does not affect lactate carbon oxidation in Krasdriven lung tumors in vivo. (A) Fractional enrichment of fully labeled lactate $(\mathrm{m}+3)$ in plasma from control mice following bolus $\left[\mathrm{U}-{ }^{13} \mathrm{C}\right]$-lactate injections. Mice were euthanized immediately ( 0 minutes), 5 , or 10 minutes after the last injection ( $n=2$ for each time point). (B) Fractional enrichment of fully labeled lactate $(m+3)$ and pyruvate $(\mathrm{m}+3)$ in normal lung, $R b 1^{+/+}$, and $R b 1^{-/}$lung tumors following bolus $\left[\mathrm{U}-{ }^{13} \mathrm{C}\right]$-lactate injections $(n=4)$. Values represent mean $+/$ - SEM analyzed by analyzed by one-way ANOVA with Tukey's post-hoc comparison. 
labeling of lactate-derived metabolites (Figure 34, 33B). Although tumor bearing and normal lung mice exhibited similar levels of $m+3$ lactate and pyruvate (Figure 33B), we observed increased $m+2$ and $m+3$ labeling of several TCA cycle intermediates consistent with Kras-driven lung tumors exhibiting increased lactate utilization as a nutrient source for the TCA cycle (Figure 34, 35). However, loss of $R b 1$ did not significantly alter the extent of metabolite labeling. Consistent with our labeling data, while Kras-driven lung tumors exhibit elevated monocarboxylate transporter 1 (MCT1: lactate import), loss of $R b 1$ does not further alter expression of MCT1 (Figure 36). These data suggest that $\mathrm{pRb}$ does not contribute to the control of lactate metabolism within the mitochondria of Kras-driven lung tumors in vivo. 


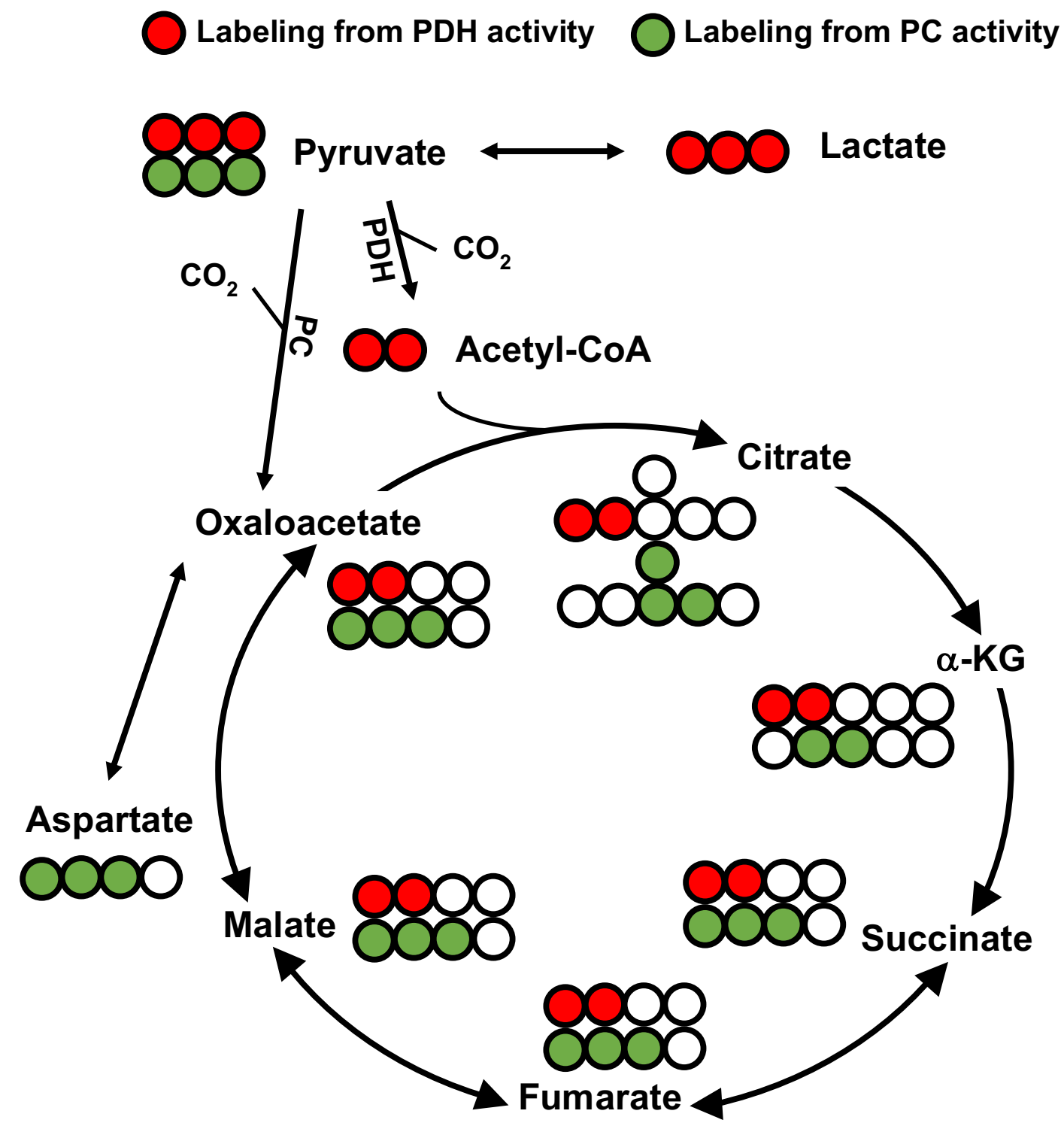

Figure 34. Cartoon of $\left[\mathrm{U}-{ }^{13} \mathrm{C}\right]$-lactate fate mapping through the $1^{\text {st }}$ turn of the TCA cycle. Red circles are ${ }^{13} \mathrm{C}$ labeling indicative of pyruvate dehydrogenase activity, green circles are ${ }^{13} \mathrm{C}$ labeling indicative of pyruvate carboxylase activity, and white circle are unlabeled ${ }^{12} \mathrm{C}$. 


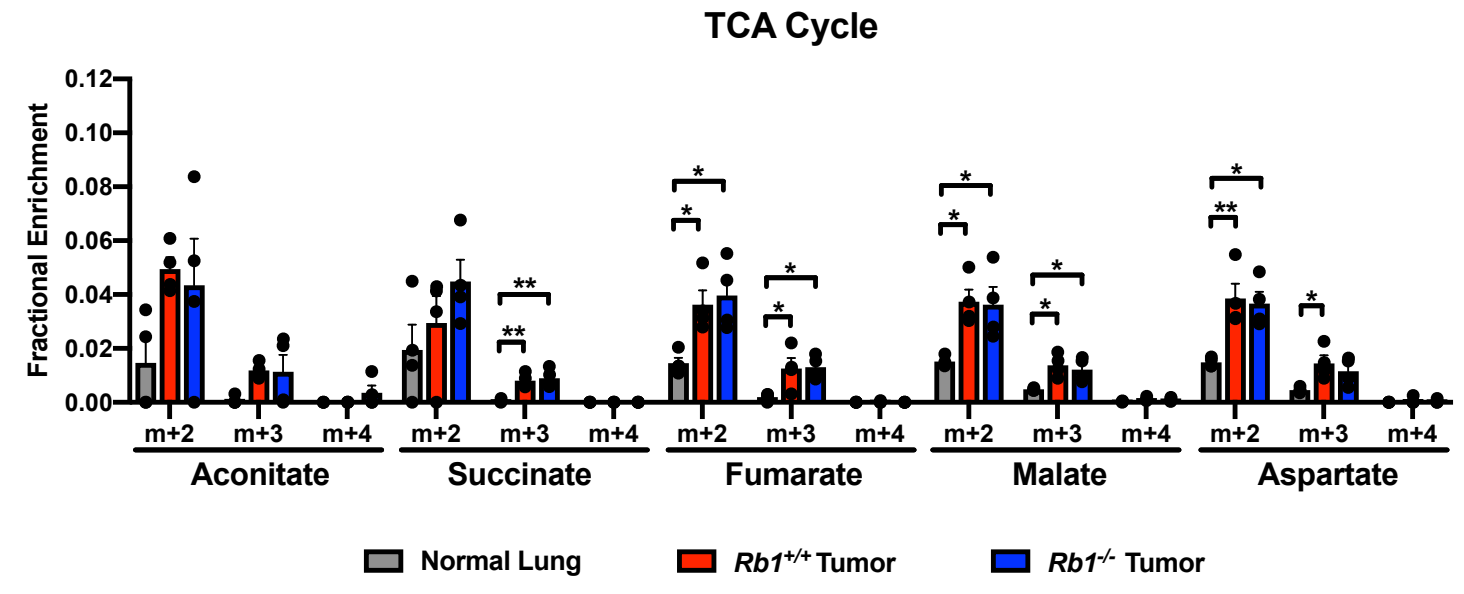

Figure 35. Loss of $R b 1$ does not affect lactate carbon oxidation in Krasdriven lung tumors in vivo. Fractional enrichment of TCA metabolites in normal lung, $R b 1^{+/+}$, and $R b 1^{-/}$lung tumors $(\mathrm{n}=4)$. Values represent mean $+/-$ SEM analyzed by analyzed by one-way ANOVA with Tukey's post-hoc comparison. Statistical significances between each group are as follows: ${ }^{*} p<0.05$ or ${ }^{* *} p<0.01$. 


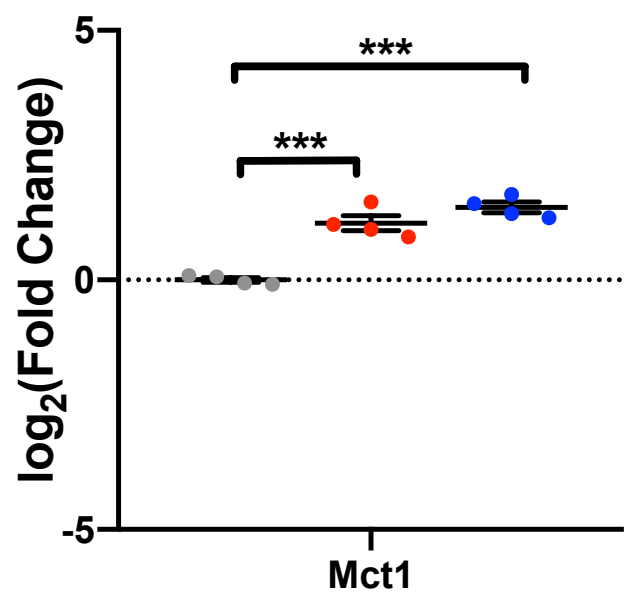

- Normal Lung

- $R b 1^{+/+}$Tumor

- $R b 1^{-/}$Tumor

Figure 36. Genetic loss of $R b 1$ does not regulate lactate import in vivo. qPCR analysis of monocarboxylate transporter 1 (Mct1) in normal lung, $R b 1^{+/+}$, and $R b 1^{-}$ 1- tumors. Expression was normalized to $\beta$-actin and reported as the log (base 2) of the fold change. Values represent mean +/- SEM analyzed by analyzed by oneway ANOVA with Tukey's post-hoc comparison $(n=4)$. Statistical significances between each group are as follows: ${ }^{* *} p<0.001$. 


\section{DISCUSSION}

In the current study, we report that loss of $R b 1$ in mutant Kras-driven lung tumors leads to a metabolic shift in which pRb-deficient tumors display enhanced glycolysis presumably via upregulation of the glucose transporter Glut1 and two rate-limiting enzymes in glycolysis, Hk2 and Pkm2 (Figure 21). Interestingly, the increase in labeled glycolytic intermediates in $R b 1^{-/}$tumors compared to $R b 1^{+/+}$ tumors was not observed in downstream metabolites within the TCA cycle. This was unexpected as studies have previously shown that $R b 1$ deletion results in increased TCA cycle activity and mitochondrial activation in non-cancer tissues in vivo $(81,145)$. Conversely, other studies have reported that the pRb/E2F1 axis directly controls PDH activity by modulating the expression of pyruvate dehydrogenase kinase 4 , suggesting loss of $R b 1$ function should decrease glucose flux into the TCA cycle $(96,97)$. Although we observed a significant increase in $m+3$ pyruvate labeling from glucose in pRb-deficient tumors, we found no accompanying increase in labeling of TCA intermediates between $R b 1^{-/}$and $R b 1^{+/+}$tumors (Figure 27); but a similar increase in labeled lactate. Additional tracer studies to examine lactate utilization also yielded no significant difference in labeling of TCA cycle intermediates in pRb-deficient tumors compared to those with intact $p R b$.

It has recently been suggested that the decoupling of mitochondrial oxidative phosphorylation from glycolysis provides a selective advantage to cancer cells to sustain cell proliferation $(55,56)$. Enhanced conversion of pyruvate to lactate regenerates the necessary NAD+ required for elevated glycolysis to persist, 
while the use of circulating lactate for mitochondrial respiration operates in parallel to support the energetic functions of the TCA cycle (55). Our studies support the use of lactate as a nutrient oxidative fuel within the mitochondria of Kras-driven tumors as has been previously reported (55). We found substantial labeling in circulating lactate in the plasma of animals administered $\left[\mathrm{U}-{ }^{13} \mathrm{C}\right]$-glucose $(\mathrm{m}+340-$ $45 \%)$. We further observed similar labeling patterns of TCA intermediates from mice administered either bolus [U-13 $\mathrm{C}]$-glucose or [U-13 $\mathrm{C}]$-lactate (Figure 27,35); wherein loss of $R b 1$ had no significant effect. The disparity in overall labeling enrichment in TCA intermediates between either glucose or lactate administration is postulated to be due to differences in the levels of circulating labeled lactate produced under these bolus dosing conditions. The use of circulating lactate as a fuel for the TCA cycle may allow glucose to supply other anabolic pathways for cell growth. Specifically, glucose serves as a carbon source for the synthesis of nucleotides, amino acids, and lipids for biomass accumulation $(43,57)$. pRb has been reported to regulate nucleotide metabolism via its interaction with E2F family members (86). The observed increase in aerobic glycolysis in pRb-deficient tumors could be to sustain nucleotide synthesis; however, the labeling duration used in our tracer studies was not sufficient to see incorporation of glucose carbon into nucleotides, therefore additional studies will need to be performed to assess the role of $\mathrm{pRb}$ in regulating nucleotide metabolism in vivo. Overall, our data indicate that loss of $R b 1$ enhances glycolysis but does not influence pyruvate oxidation in the context of Kras-driven lung tumors in vivo. 
The role of $p R b$ in immunity has been well described $(146,147)$, with recent studies demonstrating $\mathrm{pRb}$ inactivation recruits tumor-associated macrophages and immunosuppressive myeloid derived suppressor cells within the tumor microenvironment (148). This was found to be due to increased cytokine/chemokine secretion through altered AMP-activated protein kinase signaling from increased fatty-acid oxidation. These studies strongly suggests a tumor-derived metabolic contribution in regulating the immune landscape. Beyond the effects on cell proliferation, tumor-cell derived lactate produced during aerobic glycolysis has a profound effect on the tumor microenvironment and cancer progression (53). Extracellular lactate has deleterious effects on infiltrating $T$ cells while serving as a nutrient source for immunosuppressive tumor-associated macrophages (51-53). pRb-deficient tumors exhibit increased lactate production from glucose (Figure 22B), yet whether this influences the immune response in the tumor microenvironment remains unclear.

Loss of $R b 1$ in vitro promotes glutamine utilization via upregulation of the glutamine transporter Asct2 and glutaminase in MEFs (100). However, this phenomenon was not observed in vivo. pRb-deficient Kras-driven tumors do not exhibit significant differences in glutamine carbon labeling of TCA cycle intermediates compared to lung tumors with intact $\mathrm{pRb}$, nor do they increase expression of genes essential for glutamine utilization (Figure 30-32). It has been reported that while glutamine strongly contributes to oxidative metabolism in cultured cells, circulating glutamine is not utilized as a primary fuel source for TCA anaplerosis in vivo, particularly in Kras-driven lung tumors (46). This may explain, 
in part, the discrepancy in glutamine utilization between the MEF and transgenic lung tumor model and suggest the metabolic functions of $\mathrm{pRb}$ may be dependent on the in vivo environment of tumor cells.

Our studies demonstrate a role for $\mathrm{pRb}$ in regulating glycolytic metabolism in Kras-driven lung tumors in vivo. Using both steady-state metabolomics and stable-isotope tracer studies, we report that loss of $R b 1$ enhances glycolysis without altering mitochondrial pyruvate oxidation. Additionally, our studies demonstrate $\mathrm{pRb}$ does not regulate glutamine anaplerosis in vivo. Together, our data highlights a metabolic phenotype resulting from $\mathrm{pRb}$ dysfunction in Krasdriven lung tumors and may support the targeting of glycolytic metabolism in NSCLC patients with pRb-deficient tumors. 


\section{CHAPTER 4: CONCLUSIONS AND FUTURE DIRECTIONS}

This body of work highlights a role of $\mathrm{pRb}$ in mediating metabolic reprogramming in lung cancer. Specifically, activation of $p R b$ via treatment with the CDK4/6 inhibitor palbociclib results in a metabolic shift in lung adenocarcinoma cells. We found that palbociclib decreases glucose metabolism through the PPP via inhibition of G6PD activity, while increasing dependency on glutaminolysis to maintain basal mitochondrial function (Chapter 2). While the precise mechanism by which palbociclib mediates its metabolic functions remain unclear, its effect on glucose and glutamine utilization in cultured A549 NSCLC cells were observed to be $\mathrm{pRb}$-dependent as deletion of $R B 1$ mitigated the effects of the inhibitor. Although it has been demonstrated that glutaminolysis is not a preferential anaplerotic carbon source for the TCA cycle in untreated or unchallenged Krasdriven lung tumors in vivo (46), glutaminase inhibition combined with standard therapy has shown efficacy in preclinical models of lung cancer $(120,149,150)$. It would be beneficial to confirm these in vitro demonstrated metabolic effects in an in vivo model under palbociclib mediated $\mathrm{pRb}$ manipulation. Together, our data may support targeting CDK4/6 inhibition in combination with glutaminase inhibitors in NSCLC patients with pRb-proficient tumors.

In other studies, we have also demonstrated that genetic depletion of $R b 1$ in a mutant Kras-driven mouse model of lung cancer enhances glucose 
metabolism, via upregulation of key enzymes within glycolysis, without altering mitochondrial pyruvate oxidation (Chapter 3 ). One caveat to note for these studies is the observed difference in lung tumor pathology between $\mathrm{Kras} / \mathrm{Rb} 1^{+/+}$and $\mathrm{Kras} / \mathrm{Rb} 1^{-/-}$mice. $\mathrm{Kras} / \mathrm{Rb}^{+/+}$mice primarily develop lung adenomas, whereas loss of $R b 1$ has been shown to promote greater adenocarcinoma development, which more closely phenocopies human NSCLC (131). The metabolic adaptations that occur during progression from lung adenoma to adenocarcinoma are largely unknown, but we cannot rule out the possibility that this maybe a contributing factor to the metabolic differences observed between $\mathrm{pRb}$-proficient and -deficient tumors in our model. Further technical advances will be necessary to address this concern. To date there is no available protocol to separate adenoma from adenocarcinoma for the metabolic analysis described in these results. Yet, many of the metabolic changes observed in human lung cancer patients (described below) are evident within these mouse models.

While aerobic glycolysis is a known feature of cancer cells, targeting this pathway for therapy has proven challenging due to the cytotoxicity of many antiglycolytic agents (151). Biguanides, such as metformin and phenformin, are common therapeutics for the treatment of type 2 diabetes and have recently been reported to exhibit anti-cancer activity in vitro and in vivo (152-154). Specifically, both agents have an inhibitory effect on glycolysis and oxidative metabolism. The addition of metformin to standard therapy for lung adenocarcinoma patients significantly improves patient outcome (155), while phenformin inhibits tumor growth and angiogenesis in preclinical models of Kras-driven NSCLC (156). As it 
extends to this body of work, our data suggest patients with pRb-deficient lung tumors (15-30\% of NSCLC cases) may further benefit from combination therapy that are inclusive of either metformin or phenformin treatment. This strategy can be incorporated into future studies in defining therapeutic response of metabolic disruptors in these mouse models in order to support the translational potential of these findings.

Additionally, it would be of interest to expand this work into NSCLC patient samples. There have been previous reports of metabolic changes in human NSCLC following labeled glucose administration. Consistent with our in vivo findings, patient lung tumors display elevated enrichment of lactate and TCA cycle metabolites compared to adjacent lung, indicating enhanced glucose oxidation $(157,158)$. Interestingly, less perfused lung tumors rely heavily on glucose, whereas highly perfused regions utilize other fuel sources such as amino acids (158). This is primarily thought to be driven by the hypoxic environment within the individual tumors and further underscores the heterogenous nature of human NSCLC. However, no genotypic analysis of $\mathrm{pRb}$ status in these lung tumor samples was reported. We would expect that defining the potential $\mathrm{pRb}$ status in these samples would aid in correlating the patient results to those presented in our mouse model.

Comparison of our in vitro and in vivo studies raises a conflicting question as to why our in vitro findings of $\mathrm{pRb}$ dysfunction are not recapitulated in vivo and vice versa? First, we observed changes in glutaminolysis in A549 cells under palbociclib treatment, but manipulation of $R b 1$ in lung tumors in vivo did not alter 
glutamine utilization. Second, our in vivo data show that loss of $R b 1$ enhances glucose utilization, but palbociclib-induced activation of $\mathrm{pRb}$ in vitro had no effect on glycolysis. The most likely reason for this discrepancy lies in the metabolic differences between cultured cells and cells found within an in vivo environment. As stated above, solid tumors are comprised of a heterogeneous population of cells that include malignant cancer cells, immune cells, and stromal fibroblasts, all of which contribute to metabolic remodeling within the tumor microenvironment $(159,160)$. Likewise, poor vasculature in solid tumors alters nutrient and oxygen availability, conditions which are not recapitulated in normal 2D cell culture. This phenomenon is highly relevant to our studies, as Kras-driven lung tumor cells have been shown to exhibit differential nutrient utilization when grown ex vivo, switching form glucose oxidation to a reliance on glutaminolysis in culture (46). Assessment of palbociclib treatment in this model of Kras-driven lung tumor would be beneficial in determining whether the in vitro metabolic functions of palbociclib can be recapitulated in vivo.

Another potential reason for the metabolic discrepancies between our in vitro and in vivo data could be in the approach to assessing $\mathrm{pRb}$ function. In vitro, we utilized an approach of drug mediated $\mathrm{pRb}$ re-activation in Kras-driven lung cancer cells that harbor wild-type $\mathrm{pRb}$, that is rendered inactive by hyperphosphorylation. Conversely, our in vivo studies used a model of genetic deletion of $R b 1$ that occurred at the point of tumor initiation. While the precise mechanisms are unknown, many studies have shown that inactivation of $p R b$ does not phenocopy $R b 1$ deletion $(15,161,162)$. This has also been demonstrated 
clinically, as inactivation of $\mathrm{pRb}$ confers a selective advantage to specific types of cancer over RB1 loss. Recently, it was demonstrated that loss of RB1 in prostate cancer is necessary for disease progression, yet $\mathrm{pRb}$ function remains intact in the early stages of prostate cancer (163). Notably, the authors reported alterations in E2F1 transcriptional networks elicited by RB1 deletion that were distinct from those observed following phosphorylation-induced $\mathrm{pRb}$ inactivation. It seems feasible that the alterations in the transcriptomes and downstream signaling pathways between drug-induced activation of functional $\mathrm{pRb}$ in our in vitro studies and complete genetic loss of $R b 1$ within the in vivo models may contribute to their distinct metabolic phenotypes.

Prior studies have shown $\mathrm{pRb}$ can directly regulate metabolism via its interaction with $\mathrm{E} 2 \mathrm{~F}(82,83,96,97,100)$, wherein the $\mathrm{pRb} / \mathrm{E} 2 \mathrm{~F}$ complex regulates the expression of target metabolic genes. However, $\mathrm{pRb} / \mathrm{E} 2 \mathrm{~F}$ also can regulate the expression of the components of oncogenic signaling pathways that participate in metabolic reprogramming. Specifically, c-MYC is a known pRb/E2F target gene, and can regulate many of the metabolic pathways we observed to be dysregulated in our in vitro and in vivo studies such as glycolysis, nucleotide metabolism, and glutaminolysis (164). Lastly, pRb can also drive metabolic alterations independent of cell cycle machinery. For example, pRb can exert its effect on lipid metabolism via interaction with SREBPs to increase expression of genes within lipogenesis (93). Due to its wide-ranging ability to bind to over 100 proteins, many of which are transcription factors or chromatin modifying enzymes, it would be of interest to 
characterize both the transcriptome and interactome for $\mathrm{pRb}$ in our models to define precisely how $\mathrm{pRb}$ mediates metabolic reprogramming in lung cancer.

While more studies are needed to fully define the exact mechanisms by which pRb exerts its control over cellular metabolism, this body of work expands our knowledge of the metabolic phenotype resulting from $\mathrm{pRb}$ dysfunction in lung cancer. It also underscores the specific metabolic perturbations defined by $\mathrm{pRb}$ status that may potentially confer increased efficacy to targeted metabolic therapies for lung cancer patients. 


\section{REFERENCES}

1. Zappa, C., and Mousa, S. A. (2016) Non-small cell lung cancer: current treatment and future advances. Transl Lung Cancer Res 5, 288-300

2. Gridelli, C., Rossi, A., Carbone, D. P., Guarize, J., Karachaliou, N., Mok, T., Petrella, F., Spaggiari, L., and Rosell, R. (2015) Non-small-cell lung cancer. Nat Rev Dis Primers 1, 15009

3. Torre, L. A., Bray, F., Siegel, R. L., Ferlay, J., Lortet-Tieulent, J., and Jemal, A. (2015) Global cancer statistics, 2012. CA Cancer J Clin 65, 87108

4. Alberg, A. J., Brock, M. V., Ford, J. G., Samet, J. M., and Spivack, S. D. (2013) Epidemiology of lung cancer: Diagnosis and management of lung cancer, 3rd ed: American College of Chest Physicians evidence-based clinical practice guidelines. Chest 143, e1S-e29S

5. Herbst, R. S., Morgensztern, D., and Boshoff, C. (2018) The biology and management of non-small cell lung cancer. Nature 553, 446-454

6. Vineis, P., Airoldi, L., Veglia, F., Olgiati, L., Pastorelli, R., Autrup, H., Dunning, A., Garte, S., Gormally, E., Hainaut, P., Malaveille, C., Matullo, G., Peluso, M., Overvad, K., Tjonneland, A., Clavel-Chapelon, F., Boeing, H., Krogh, V., Palli, D., Panico, S., Tumino, R., Bueno-De-Mesquita, B., Peeters, P., Berglund, G., Hallmans, G., Saracci, R., and Riboli, E. (2005) Environmental tobacco smoke and risk of respiratory cancer and chronic obstructive pulmonary disease in former smokers and never smokers in the EPIC prospective study. Bmj 330, 277

7. Duma, N., Santana-Davila, R., and Molina, J. R. (2019) Non-Small Cell Lung Cancer: Epidemiology, Screening, Diagnosis, and Treatment. Mayo Clin Proc 94, 1623-1640

8. Cersosimo, R. J. (2002) Lung cancer: a review. Am J Health Syst Pharm 59, 611-642

9. Vermeulen, K., Van Bockstaele, D. R., and Berneman, Z. N. (2003) The cell cycle: a review of regulation, deregulation and therapeutic targets in cancer. Cell Prolif 36, 131-149

10. Sherr, C. J., and Roberts, J. M. (1999) CDK inhibitors: positive and negative regulators of G1-phase progression. Genes Dev 13, 1501-1512

11. Eymin, B., and Gazzeri, S. (2010) Role of cell cycle regulators in lung carcinogenesis. Cell Adh Migr 4, 114-123

12. Giacinti, C., and Giordano, A. (2006) RB and cell cycle progression. Oncogene 25, 5220-5227

13. Weinberg, R. A. (1995) The retinoblastoma protein and cell cycle control. Cell 81, 323-330 
14. Lam, E. W., and La Thangue, N. B. (1994) DP and E2F proteins: coordinating transcription with cell cycle progression. Curr Opin Cell Biol 6, 859-866

15. Knudsen, E. S., and Knudsen, K. E. (2008) Tailoring to RB: tumour suppressor status and therapeutic response. Nat Rev Cancer 8, 714-724

16. Harbour, J. W., Luo, R. X., Dei Santi, A., Postigo, A. A., and Dean, D. C. (1999) Cdk phosphorylation triggers sequential intramolecular interactions that progressively block $\mathrm{Rb}$ functions as cells move through $\mathrm{G} 1$. Cell $\mathbf{9 8}$, 859-869

17. Baldi, A., De Luca, A., Esposito, V., Campioni, M., Spugnini, E. P., and Citro, G. (2011) Tumor suppressors and cell-cycle proteins in lung cancer. Patholog Res Int 2011, 605042

18. Esposito, V. B., A.; Tonini, G.; Vincenzi, B.; Santini, M.; Ambrogi, V.; Mineo, T. C.; Persichetti, P.; Liuzzi, G.; Montesarchio, V.; Wolner, E.; Baldi, F.; and Groeger, A. M. . (2004) Analysis of Cell Cycle Regulator Proteins in Non-Small Cell Lung Cancer. Journal of Clinical Pathology 57, 58-63

19. Myong, N. (2008) Cyclin D1 Overexpression, p16 Loss, and pRb Inactivation Play a Key Role in Pulmonary Carcinogenesis and have a Prognostic Implication for the Long-term Survival in Non-small Cell Lung Carcinoma Patients. Cancer Research and Treatment 40, 45-52

20. Lapenna, S., and Giordano, A. (2009) Cell cycle kinases as therapeutic targets for cancer. Nat Rev Drug Discov 8, 547-566

21. Beaver, J. A., Amiri-Kordestani, L., Charlab, R., Chen, W., Palmby, T., Tilley, A., Zirkelbach, J. F., Yu, J., Liu, Q., Zhao, L., Crich, J., Chen, X. H., Hughes, M., Bloomquist, E., Tang, S., Sridhara, R., Kluetz, P. G., Kim, G., Ibrahim, A., Pazdur, R., and Cortazar, P. (2015) FDA Approval: Palbociclib for the Treatment of Postmenopausal Patients with Estrogen ReceptorPositive, HER2-Negative Metastatic Breast Cancer. Clin Cancer Res 21, 4760-4766

22. Gopalan, P. K., Villegas, A. G., Cao, C., Pinder-Schenck, M., Chiappori, A., Hou, W., Zajac-Kaye, M., Ivey, A. M., and Kaye, F. J. (2018) CDK4/6 inhibition stabilizes disease in patients with p16-null non-small cell lung cancer and is synergistic with mTOR inhibition. Oncotarget 9, 3735237366

23. Liu, M., Xu, S., Wang, Y., Li, Y., Li, Y., Zhang, H., Liu, H., and Chen, J. (2016) PD 0332991, a selective cyclin D kinase 4/6 inhibitor, sensitizes lung cancer cells to treatment with epidermal growth factor receptor tyrosine kinase inhibitors. Oncotarget 7, 84951-84964

24. Nie, H., Zhou, X., Shuzhang, D., Nie, C., Zhang, X., and Huang, J. (2019) Palbociclib overcomes afatinib resistance in non-small cell lung cancer. Biomed Pharmacother 109, 1750-1757

25. Pacheco, J., and Schenk, E. (2019) CDK4/6 inhibition alone and in combination for non-small cell lung cancer. Oncotarget 10, 618-619

26. Zhou, J., Zhang, S., Chen, X., Zheng, X., Yao, Y., Lu, G., and Zhou, J. (2017) Palbociclib, a selective CDK4/6 inhibitor, enhances the effect of 
selumetinib in RAS-driven non-small cell lung cancer. Cancer Lett 408, 130-137

27. Goodrich, D. W., and Lee, W. H. (1993) Molecular characterization of the retinoblastoma susceptibility gene. Biochim Biophys Acta 1155, 43-61

28. Hanahan, D., and Weinberg, R. A. (2000) The hallmarks of cancer. Cell $100,57-70$

29. Morris, E. J., and Dyson, N. J. (2001) Retinoblastoma protein partners. Adv Cancer Res 82, 1-54

30. Hutcheson, J., Bourgo, R. J., Balaji, U., Ertel, A., Witkiewicz, A. K., and Knudsen, E. S. (2014) Retinoblastoma protein potentiates the innate immune response in hepatocytes: significance for hepatocellular carcinoma. Hepatology 60, 1231-1240

31. Lee, J. S., Thomas, D. M., Gutierrez, G., Carty, S. A., Yanagawa, S., and Hinds, P. W. (2006) HES1 cooperates with pRb to activate RUNX2dependent transcription. J Bone Miner Res 21, 921-933

32. Markey, M. P., Angus, S. P., Strobeck, M. W., Williams, S. L., Gunawardena, R. W., Aronow, B. J., and Knudsen, E. S. (2002) Unbiased analysis of RB-mediated transcriptional repression identifies novel targets and distinctions from E2F action. Cancer Res 62, 6587-6597

33. Burkhart, D. L., and Sage, J. (2008) Cellular mechanisms of tumour suppression by the retinoblastoma gene. Nature reviews. Cancer 8, 671682

34. Tarrado-Castellarnau, M. d. A., P.; and Cascante, M. . (2016) Oncogenic Regulation of Tumor Metabolic Reprogramming. Oncotarget 7, 6272662753

35. DeBerardinis, R. J., and Chandel, N. S. (2016) Fundamentals of cancer metabolism. Sci Adv 2, e1600200

36. Hanahan, D., and Weinberg, R. A. (2011) Hallmarks of cancer: the next generation. Cell 144, 646-674

37. Phan, L. M., Yeung, S. C., and Lee, M. H. (2014) Cancer metabolic reprogramming: importance, main features, and potentials for precise targeted anti-cancer therapies. Cancer Biol Med 11, 1-19

38. Cairns, R. A., Harris, I. S., and Mak, T. W. (2011) Regulation of cancer cell metabolism. Nat Rev Cancer 11, 85-95

39. Deberardinis, R. J., Sayed, N., Ditsworth, D., and Thompson, C. B. (2008) Brick by brick: metabolism and tumor cell growth. Curr Opin Genet Dev 18, 54-61

40. Liberti, M. V., and Locasale, J. W. (2016) The Warburg Effect: How Does it Benefit Cancer Cells? Trends Biochem Sci 41, 211-218

41. Lunt, S. Y., and Vander Heiden, M. G. (2011) Aerobic glycolysis: meeting the metabolic requirements of cell proliferation. Annu Rev Cell Dev Biol 27, 441-464

42. Pavlova, N. N., and Thompson, C. B. (2016) The Emerging Hallmarks of Cancer Metabolism. Cell Metab 23, 27-47 
43. Vander Heiden, M. G., Cantley, L. C., and Thompson, C. B. (2009) Understanding the Warburg effect: the metabolic requirements of cell proliferation. Science 324, 1029-1033

44. Warburg, O. (1956) On respiratory impairment in cancer cells. Science 124, 269-270

45. Warburg, O. (1956) On the origin of cancer cells. Science 123, 309-314

46. Davidson, S. M., Papagiannakopoulos, T., Olenchock, B. A., Heyman, J. E., Keibler, M. A., Luengo, A., Bauer, M. R., Jha, A. K., O'Brien, J. P., Pierce, K. A., Gui, D. Y., Sullivan, L. B., Wasylenko, T. M., Subbaraj, L., Chin, C. R., Stephanopolous, G., Mott, B. T., Jacks, T., Clish, C. B., and Vander Heiden, M. G. (2016) Environment Impacts the Metabolic Dependencies of Ras-Driven Non-Small Cell Lung Cancer. Cell metabolism 23, 517-528

47. Tarrado-Castellarnau, M., de Atauri, P., and Cascante, M. (2016) Oncogenic regulation of tumor metabolic reprogramming. Oncotarget 7 , 62726-62753

48. DeBerardinis, R. J., Lum, J. J., Hatzivassiliou, G., and Thompson, C. B. (2008) The biology of cancer: metabolic reprogramming fuels cell growth and proliferation. Cell Metab 7, 11-20

49. Bonuccelli, G., Tsirigos, A., Whitaker-Menezes, D., Pavlides, S., Pestell, R. G., Chiavarina, B., Frank, P. G., Flomenberg, N., Howell, A., MartinezOutschoorn, U. E., Sotgia, F., and Lisanti, M. P. (2010) Ketones and lactate "fuel" tumor growth and metastasis: Evidence that epithelial cancer cells use oxidative mitochondrial metabolism. Cell Cycle 9, 3506-3514

50. Martinez-Outschoorn, U. E., Prisco, M., Ertel, A., Tsirigos, A., Lin, Z., Pavlides, S., Wang, C., Flomenberg, N., Knudsen, E. S., Howell, A., Pestell, R. G., Sotgia, F., and Lisanti, M. P. (2011) Ketones and lactate increase cancer cell "stemness," driving recurrence, metastasis and poor clinical outcome in breast cancer: achieving personalized medicine via Metabolo-Genomics. Cell Cycle 10, 1271-1286

51. Morrot, A., Fonseca, L. M. d., Salustiano, E. J., Gentile, L. B., Conde, L., Filardy, A. A., Franklim, T. N., da Costa, K. M., Freire-de-Lima, C. G., and Freire-de-Lima, L. (2018) Metabolic Symbiosis and Immunomodulation: How Tumor Cell-Derived Lactate May Disturb Innate and Adaptive Immune Responses. Frontiers in Oncology 8

52. Romero-Garcia, S., Moreno-Altamirano, M. M. B., Prado-Garcia, H., and Sánchez-García, F. J. (2016) Lactate Contribution to the Tumor Microenvironment: Mechanisms, Effects on Immune Cells and Therapeutic Relevance. Frontiers in Immunology 7

53. San-Millán, I., and Brooks, G. A. (2016) Reexamining cancer metabolism: lactate production for carcinogenesis could be the purpose and explanation of the Warburg Effect. Carcinogenesis

54. Kim, H. K., Lee, I., Bang, H., Kim, H. C., Lee, W. Y., Yun, S. H., Lee, J., Lee, S. J., Park, Y. S., Kim, K. M., and Kang, W. K. (2018) MCT4 Expression Is a Potential Therapeutic Target in Colorectal Cancer with Peritoneal Carcinomatosis. Mol Cancer Ther 17, 838-848 
55. Faubert, B., Li, K. Y., Cai, L., Hensley, C. T., Kim, J., Zacharias, L. G., Yang, C., Do, Q. N., Doucette, S., Burguete, D., Li, H., Huet, G., Yuan, Q., Wigal, T., Butt, Y., Ni, M., Torrealba, J., Oliver, D., Lenkinski, R. E., Malloy, C. R., Wachsmann, J. W., Young, J. D., Kernstine, K., and DeBerardinis, R. J. (2017) Lactate Metabolism in Human Lung Tumors. Cell 171, 358-371 e359

56. Hui, S., Ghergurovich, J. M., Morscher, R. J., Jang, C., Teng, X., Lu, W., Esparza, L. A., Reya, T., Le, Z., Yanxiang Guo, J., White, E., and Rabinowitz, J. D. (2017) Glucose feeds the TCA cycle via circulating lactate. Nature 551, 115

57. Zhu, J., and Thompson, C. B. (2019) Metabolic regulation of cell growth and proliferation. Nat Rev Mol Cell Biol 20, 436-450

58. Daye, D., and Wellen, K. E. (2012) Metabolic reprogramming in cancer: unraveling the role of glutamine in tumorigenesis. Semin Cell Dev Biol 23, 362-369

59. DeBerardinis, R. J., and Cheng, T. (2010) Q's next: the diverse functions of glutamine in metabolism, cell biology and cancer. Oncogene 29, 313324

60. Altman, B. J., Stine, Z. E., and Dang, C. V. (2016) From Krebs to clinic: glutamine metabolism to cancer therapy. Nat Rev Cancer 16, 749

61. Martinez-Outschoorn, U. E., Peiris-Pages, M., Pestell, R. G., Sotgia, F., and Lisanti, M. P. (2017) Cancer metabolism: a therapeutic perspective. Nat Rev Clin Oncol 14, 11-31

62. DeBerardinis, R. J., Mancuso, A., Daikhin, E., Nissim, I., Yudkoff, M., Wehrli, S., and Thompson, C. B. (2007) Beyond aerobic glycolysis: transformed cells can engage in glutamine metabolism that exceeds the requirement for protein and nucleotide synthesis. Proc Natl Acad Sci U S A 104, 19345-19350

63. Icard, P., Poulain, L., and Lincet, H. (2012) Understanding the central role of citrate in the metabolism of cancer cells. Biochim Biophys Acta 1825, 111-116

64. Metallo, C. M., Gameiro, P. A., Bell, E. L., Mattaini, K. R., Yang, J., Hiller, K., Jewell, C. M., Johnson, Z. R., Irvine, D. J., Guarente, L., Kelleher, J. K., Vander Heiden, M. G., lliopoulos, O., and Stephanopoulos, G. (2011) Reductive glutamine metabolism by IDH1 mediates lipogenesis under hypoxia. Nature 481, 380-384

65. Jiang, P., Du, W., Wang, X., Mancuso, A., Gao, X., Wu, M., and Yang, X. (2011) p53 regulates biosynthesis through direct inactivation of glucose-6phosphate dehydrogenase. Nat Cell Biol 13, 310-316

66. Li, D., Zhu, Y., Tang, Q., Lu, H., Li, H., Yang, Y., Li, Z., and Tong, S. (2009) A new G6PD knockdown tumor-cell line with reduced proliferation and increased susceptibility to oxidative stress. Cancer Biother Radiopharm 24, 81-90

67. Jonas, S. K., Benedetto, C., Flatman, A., Hammond, R. H., Micheletti, L., Riley, C., Riley, P. A., Spargo, D. J., Zonca, M., and Slater, T. F. (1992) Increased activity of 6-phosphogluconate dehydrogenase and glucose-6- 
phosphate dehydrogenase in purified cell suspensions and single cells from the uterine cervix in cervical intraepithelial neoplasia. Br J Cancer 66, 185-191

68. Riganti, C., Gazzano, E., Polimeni, M., Aldieri, E., and Ghigo, D. (2012) The pentose phosphate pathway: an antioxidant defense and a crossroad in tumor cell fate. Free Radic Biol Med 53, 421-436

69. Vizan, P., Alcarraz-Vizan, G., Diaz-Moralli, S., Solovjeva, O. N., Frederiks, W. M., and Cascante, M. (2009) Modulation of pentose phosphate pathway during cell cycle progression in human colon adenocarcinoma cell line HT29. Int J Cancer 124, 2789-2796

70. Rosenzweig, A., Blenis, J., and Gomes, A. P. (2018) Beyond the Warburg Effect: How Do Cancer Cells Regulate One-Carbon Metabolism? Front Cell Dev Biol 6, 90

71. Kalhan, S. C., and Hanson, R. W. (2012) Resurgence of serine: an often neglected but indispensable amino Acid. J Biol Chem 287, 19786-19791

72. Yang, M., and Vousden, K. H. (2016) Serine and one-carbon metabolism in cancer. Nat Rev Cancer 16, 650-662

73. Huang, C., and Freter, C. (2015) Lipid metabolism, apoptosis and cancer therapy. Int J Mol Sci 16, 924-949

74. Santos, C. R., and Schulze, A. (2012) Lipid metabolism in cancer. Febs $j$ 279, 2610-2623

75. Milgraum, L. Z., Witters, L. A., Pasternack, G. R., and Kuhajda, F. P. (1997) Enzymes of the fatty acid synthesis pathway are highly expressed in in situ breast carcinoma. Clin Cancer Res 3, 2115-2120

76. Swinnen, J. V., Brusselmans, K., and Verhoeven, G. (2006) Increased lipogenesis in cancer cells: new players, novel targets. Curr Opin Clin Nutr Metab Care 9, 358-365

77. Yahagi, N., Shimano, H., Hasegawa, K., Ohashi, K., Matsuzaka, T., Najima, Y., Sekiya, M., Tomita, S., Okazaki, H., Tamura, Y., lizuka, Y., Ohashi, K., Nagai, R., Ishibashi, S., Kadowaki, T., Makuuchi, M., Ohnishi, S., Osuga, J., and Yamada, N. (2005) Co-ordinate activation of lipogenic enzymes in hepatocellular carcinoma. Eur J Cancer 41, 1316-1322

78. Carracedo, A., Cantley, L. C., and Pandolfi, P. P. (2013) Cancer metabolism: fatty acid oxidation in the limelight. Nat Rev Cancer 13, 227232

79. Beemer, F. A., Vlug, A. M., Rijksen, G., Hamburg, A., and Staal, G. E. (1982) Characterization of some glycolytic enzymes from human retina and retinoblastoma. Cancer Res 42, 4228-4232

80. Takebayashi, S., Tanaka, H., Hino, S., Nakatsu, Y., Igata, T., Sakamoto, A., Narita, M., and Nakao, M. (2015) Retinoblastoma protein promotes oxidative phosphorylation through upregulation of glycolytic genes in oncogene-induced senescent cells. Aging Cell 14, 689-697

81. Nicolay, B. N., Danielian, P. S., Kottakis, F., Lapek, J. D., Jr., Sanidas, I., Miles, W. O., Dehnad, M., Tschop, K., Gierut, J. J., Manning, A. L., Morris, R., Haigis, K., Bardeesy, N., Lees, J. A., Haas, W., and Dyson, N. J. 
(2015) Proteomic analysis of pRb loss highlights a signature of decreased mitochondrial oxidative phosphorylation. Genes Dev 29, 1875-1889

82. Fajas, L., Landsberg, R. L., Huss-Garcia, Y., Sardet, C., Lees, J. A., and Auwerx, J. (2002) E2Fs regulate adipocyte differentiation. Dev Cell 3, 3949

83. Lu, Z., Marcelin, G., Bauzon, F., Wang, H., Fu, H., Dun, S. L., Zhao, H., Li, X., Jo, Y. H., Wardlaw, S., Dun, N., Chua, S., Jr., and Zhu, L. (2013) pRb is an obesity suppressor in hypothalamus and high-fat diet inhibits $p R b$ in this location. Embo $j$ 32, 844-857

84. Annicotte, J. S., Blanchet, E., Chavey, C., lankova, I., Costes, S., Assou, S., Teyssier, J., Dalle, S., Sardet, C., and Fajas, L. (2009) The CDK4pRB-E2F1 pathway controls insulin secretion. Nat Cell Biol 11, 1017-1023

85. Feliers, D., Frank, M. A., and Riley, D. J. (2002) Activation of cyclin D1Cdk4 and Cdk4-directed phosphorylation of RB protein in diabetic mesangial hypertrophy. Diabetes 51, 3290-3299

86. Clem, B. F., and Chesney, J. (2012) Molecular pathways: regulation of metabolism by RB. Clin Cancer Res 18, 6096-6100

87. Nicolay, B. N., and Dyson, N. J. (2013) The multiple connections between pRB and cell metabolism. Curr Opin Cell Biol 25, 735-740

88. Angus, S. P., Wheeler, L. J., Ranmal, S. A., Zhang, X., Markey, M. P., Mathews, C. K., and Knudsen, E. S. (2002) Retinoblastoma tumor suppressor targets dNTP metabolism to regulate DNA replication. J Biol Chem 277, 44376-44384

89. Duronio, R. J., O'Farrell, P. H., Xie, J. E., Brook, A., and Dyson, N. (1995) The transcription factor $\mathrm{E} 2 \mathrm{~F}$ is required for $\mathrm{S}$ phase during Drosophila embryogenesis. Genes Dev 9, 1445-1455

90. Korenjak, M., Anderssen, E., Ramaswamy, S., Whetstine, J. R., and Dyson, N. J. (2012) RBF binding to both canonical E2F targets and noncanonical targets depends on functional $\mathrm{dE} 2 \mathrm{~F} / \mathrm{dDP}$ complexes. Mol Cell Biol 32, 4375-4387

91. Nicolay, B. N., Gameiro, P. A., Tschop, K., Korenjak, M., Heilmann, A. M., Asara, J. M., Stephanopoulos, G., Iliopoulos, O., and Dyson, N. J. (2013) Loss of RBF1 changes glutamine catabolism. Genes Dev 27, 182-196

92. Chicas, A., Wang, X., Zhang, C., McCurrach, M., Zhao, Z., Mert, O., Dickins, R. A., Narita, M., Zhang, M., and Lowe, S. W. (2010) Dissecting the unique role of the retinoblastoma tumor suppressor during cellular senescence. Cancer Cell 17, 376-387

93. Shamma, A., Takegami, Y., Miki, T., Kitajima, S., Noda, M., Obara, T., Okamoto, T., and Takahashi, C. (2009) Rb Regulates DNA damage response and cellular senescence through E2F-dependent suppression of $\mathrm{N}$-ras isoprenylation. Cancer Cell 15, 255-269

94. Jeon, T. I., and Osborne, T. F. (2012) SREBPs: metabolic integrators in physiology and metabolism. Trends Endocrinol Metab 23, 65-72

95. Muranaka, H., Hayashi, A., Minami, K., Kitajima, S., Kohno, S., Nishimoto, Y., Nagatani, N., Suzuki, M., Kulathunga, L. A. N., Sasaki, N., Okada, N., Matsuzaka, T., Shimano, H., Tada, H., and Takahashi, C. (2017) A distinct 
function of the retinoblastoma protein in the control of lipid composition identified by lipidomic profiling. Oncogenesis 6, e350

96. Blanchet, E., Annicotte, J. S., Lagarrigue, S., Aguilar, V., Clape, C., Chavey, C., Fritz, V., Casas, F., Apparailly, F., Auwerx, J., and Fajas, L. (2011) E2F transcription factor-1 regulates oxidative metabolism. Nature cell biology 13, 1146-1152

97. Hsieh, M. C., Das, D., Sambandam, N., Zhang, M. Q., and Nahle, Z. (2008) Regulation of the PDK4 isozyme by the Rb-E2F1 complex. The Journal of biological chemistry 283, 27410-27417

98. Zacksenhaus, E., Shrestha, M., Liu, J. C., Vorobieva, I., Chung, P. E. D., Ju, Y., Nir, U., and Jiang, Z. (2017) Mitochondrial OXPHOS Induced by RB1 Deficiency in Breast Cancer: Implications for Anabolic Metabolism, Stemness, and Metastasis. Trends Cancer 3, 768-779

99. Ralph J. DeBerardinis, A. M., Evgueni Daikhin, Ilana Nissim, Marc Yudkofft, Suzanne Wehrli, and Craig B. Thompson. (2007) Beyond aerobic glycolysis: Transformed cells can engage in glutamine metabolism that exceeds the requirement for protein and nucleotide synthesis. Proc Natl Acad Sci USA 104, 19345-19350

100. Reynolds, M. R., Lane, A. N., Robertson, B., Kemp, S., Liu, Y., Hill, B. G., Dean, D. C., and Clem, B. F. (2014) Control of glutamine metabolism by the tumor suppressor Rb. Oncogene 33, 556-566

101. Dyson, N. J. (2016) RB1: a prototype tumor suppressor and an enigma. Genes Dev 30, 1492-1502

102. Takahashi, C., Sasaki, N., and Kitajima, S. (2012) Twists in views on RB functions in cellular signaling, metabolism and stem cells. Cancer Sci 103, 1182-1188

103. Gazzeri, B. E. a. S. (2009) Role of cell cycle regulators in lung carcinogenesis. Cell Adhesion \& Migration 4

104. Goel, S., DeCristo, M. J., McAllister, S. S., and Zhao, J. J. (2018) CDK4/6 Inhibition in Cancer: Beyond Cell Cycle Arrest. Trends Cell Biol 28, 911925

105. Klein, M. E., Kovatcheva, M., Davis, L. E., Tap, W. D., and Koff, A. (2018) CDK4/6 Inhibitors: The Mechanism of Action May Not Be as Simple as Once Thought. Cancer Cell 34, 9-20

106. Franco, J., Balaji, U., Freinkman, E., Witkiewicz, A. K., and Knudsen, E. S. (2016) Metabolic Reprogramming of Pancreatic Cancer Mediated by CDK4/6 Inhibition Elicits Unique Vulnerabilities. Cell Rep 14, 979-990

107. Tarrado-Castellarnau, M., de Atauri, P., Tarrago-Celada, J., Perarnau, J., Yuneva, M., Thomson, T. M., and Cascante, M. (2017) De novo MYC addiction as an adaptive response of cancer cells to CDK4/6 inhibition. Mol Syst Biol 13, 940

108. Wang, H., Nicolay, B. N., Chick, J. M., Gao, X., Geng, Y., Ren, H., Gao, H., Yang, G., Williams, J. A., Suski, J. M., Keibler, M. A., Sicinska, E., Gerdemann, U., Haining, W. N., Roberts, T. M., Polyak, K., Gygi, S. P., Dyson, N. J., and Sicinski, P. (2017) The metabolic function of cyclin D3CDK6 kinase in cancer cell survival. Nature 546, 426-430 
109. Klavins, K., Drexler, H., Hann, S., and Koellensperger, G. (2014) Quantitative metabolite profiling utilizing parallel column analysis for simultaneous reversed-phase and hydrophilic interaction liquid chromatography separations combined with tandem mass spectrometry. Analytical chemistry 86, 4145-4150

110. Adusumilli, R., and Mallick, P. (2017) Data Conversion with ProteoWizard msConvert. Methods Mol Biol 1550, 339-368

111. Agrawal, S., Sahil, Sehgal, R., George, S., Gupta, R., Poddar, S., Jha, A., and Pathak, S. (2019) El-MAVEN: A Fast, Robust, and User-Friendly Mass Spectrometry Data Processing Engine for Metabolomics. in HighThroughput Metabolomics: Methods and Protocols (D'Alessandro, A. ed.), Springer New York. pp

112. Salabei, J. K., Lorkiewicz, P. K., Mehra, P., Gibb, A. A., Haberzettl, P., Hong, K. U., Wei, X., Zhang, X., Li, Q., Wysoczynski, M., Bolli, R., Bhatnagar, A., and Hill, B. G. (2016) Type 2 Diabetes Dysregulates Glucose Metabolism in Cardiac Progenitor Cells. J Biol Chem 291, 1363413648

113. Wei, X., Lorkiewicz, P. K., Shi, B., Salabei, J. K., Hill, B. G., Kim, S., McClain, C. J., and Zhang, X. (2017) Analysis of stable isotope assisted metabolomics data acquired by high resolution mass spectrometry. Analytical Methods 9, 2275-2283

114. Lorkiewicz, P. K., Gibb, A. A., Rood, B. R., He, L., Zheng, Y., Clem, B. F., Zhang, X., and Hill, B. G. (2019) Integration of flux measurements and pharmacological controls to optimize stable isotope-resolved metabolomics workflows and interpretation. Scientific Reports 9

115. Kruer, T. L., Dougherty, S. M., Reynolds, L., Long, E., de Silva, T., Lockwood, W. W., and Clem, B. F. (2016) Expression of the IncRNA Maternally Expressed Gene 3 (MEG3) Contributes to the Control of Lung Cancer Cell Proliferation by the Rb Pathway. PLoS One 11, e0166363

116. Cretella, D., Fumarola, C., Bonelli, M., Alfieri, R., La Monica, S., Digiacomo, G., Cavazzoni, A., Galetti, M., Generali, D., and Petronini, P. G. (2019) Pre-treatment with the CDK4/6 inhibitor palbociclib improves the efficacy of paclitaxel in TNBC cells. Sci Rep 9, 13014

117. Cretella, D., Ravelli, A., Fumarola, C., La Monica, S., Digiacomo, G., Cavazzoni, A., Alfieri, R., Biondi, A., Generali, D., Bonelli, M., and Petronini, P. G. (2018) The anti-tumor efficacy of CDK4/6 inhibition is enhanced by the combination with PI3K/AKT/mTOR inhibitors through impairment of glucose metabolism in TNBC cells. J Exp Clin Cancer Res 37,72

118. Knudsen, E. S., and Witkiewicz, A. K. (2016) Defining the transcriptional and biological response to CDK4/6 inhibition in relation to ER+/HER2breast cancer. Oncotarget 7, 69111-69123

119. Bouzier-Sore, A. K., and Bolanos, J. P. (2015) Uncertainties in pentosephosphate pathway flux assessment underestimate its contribution to neuronal glucose consumption: relevance for neurodegeneration and aging. Front Aging Neurosci 7, 89 
120. Boysen, G., Jamshidi-Parsian, A., Davis, M. A., Siegel, E. R., Simecka, C. M., Kore, R. A., Dings, R. P. M., and Griffin, R. J. (2019) Glutaminase inhibitor CB-839 increases radiation sensitivity of lung tumor cells and human lung tumor xenografts in mice. Int J Radiat Biol 95, 436-442

121. Bonelli, M., La Monica, S., Fumarola, C., and Alfieri, R. (2019) Multiple effects of CDK4/6 inhibition in cancer: From cell cycle arrest to immunomodulation. Biochem Pharmacol 170, 113676

122. Gao, P., Tchernyshyov, I., Chang, T. C., Lee, Y. S., Kita, K., Ochi, T., Zeller, K. I., De Marzo, A. M., Van Eyk, J. E., Mendell, J. T., and Dang, C. V. (2009) C-Myc suppression of miR-23a/b enhances mitochondrial glutaminase expression and glutamine metabolism. Nature 458, 762-765

123. Goetzman, E. S., and Prochownik, E. V. (2018) The Role for Myc in Coordinating Glycolysis, Oxidative Phosphorylation, Glutaminolysis, and Fatty Acid Metabolism in Normal and Neoplastic Tissues. Front Endocrinol (Lausanne) 9, 129

124. Thangavel, C., Boopathi, E., Liu, Y., McNair, C., Haber, A., Perepelyuk, M., Bhardwaj, A., Addya, S., Ertel, A., Shoyele, S., Birbe, R., Salvino, J. M., Dicker, A. P., Knudsen, K. E., and Den, R. B. (2018) Therapeutic Challenge with a CDK 4/6 Inhibitor Induces an RB-Dependent SMACMediated Apoptotic Response in Non-Small Cell Lung Cancer. Clin Cancer Res

125. Vijayaraghavan, S., Karakas, C., Doostan, I., Chen, X., Bui, T., Yi, M., Raghavendra, A. S., Zhao, Y., Bashour, S. I., Ibrahim, N. K., Karuturi, M., Wang, J., Winkler, J. D., Amaravadi, R. K., Hunt, K. K., Tripathy, D., and Keyomarsi, K. (2017) CDK4/6 and autophagy inhibitors synergistically induce senescence in $\mathrm{Rb}$ positive cytoplasmic cyclin $\mathrm{E}$ negative cancers. Nat Commun 8, 15916

126. Kwon, S. M., Hong, S. M., Lee, Y. K., Min, S., and Yoon, G. (2019) Metabolic features and regulation in cell senescence. BMB Rep 52, 5-12

127. Salama, R., Sadaie, M., Hoare, M., and Narita, M. (2014) Cellular senescence and its effector programs. Genes Dev 28, 99-114

128. Rabinowitz, J. D., and White, E. (2010) Autophagy and metabolism. Science 330, 1344-1348

129. Weinberg, R. A. (1995) The Retinoblastoma Protein and Cell Cycle Control. Cell 81, 323-330

130. Bhateja, P., Chiu, M., Wildey, G., Lipka, M. B., Fu, P., Yang, M. C. L., Ardeshir-Larijani, F., Sharma, N., and Dowlati, A. (2019) Retinoblastoma mutation predicts poor outcomes in advanced non small cell lung cancer. Cancer Med 8, 1459-1466

131. Ho, V. M., Schaffer, B. E., Karnezis, A. N., Park, K. S., and Sage, J. (2009) The retinoblastoma gene $\mathrm{Rb}$ and its family member $\mathrm{p} 130$ suppress lung adenocarcinoma induced by oncogenic K-Ras. Oncogene 28, 13931399

132. Fan, T. W., Lane, A. N., Higashi, R. M., and Yan, J. (2011) Stable isotope resolved metabolomics of lung cancer in a SCID mouse model. Metabolomics : Official journal of the Metabolomic Society 7, 257-269 
133. Lane, A. N. Y., J.; Fan, T. . (2015) 13C Tacer studies of Metabolism in Mouse Tumor Xenografts Bio Protoc 5

134. Jung, J. Y. a. O., M.K. (2015) Isotope labeling pattern study of central carbon metabolites using GC/MS. Journal of Chromatography B 974, 101108

135. MacRae, J. I. S., L.; Nahid, A.; Tonkin, C.; Striepen, B.; and McConville, M. J. . (2012) Mitochondrial metabolism of glucose and glutamine is required for intracellular growth of Toxoplasma gondii. Cell host \& microbe 12, 682-696

136. Fiehn, O. (2016) Metabolomics by gas chromatography-mass spectrometry: Combined targeted and untargeted profiling. Current protocols in molecular biology 114, 30-34

137. Fiehn, O., Kopka, J., Dormann, P., Altmann, T., Trethewey, R. N., and Willmitzer, L. (2000) Metabolite profiling for plant functional genomics. Nat Biotechnol 18, 1157-1161

138. Kind, T., Wohlgemuth, G., Lee, D. Y., Lu, Y., Palazoglu, M., Shahbaz, S., and Fiehn, O. (2009) FiehnLib: mass spectral and retention index libraries for metabolomics based on quadrupole and time-of-flight gas chromatography/mass spectrometry. Analytical chemistry 81, 1003810048

139. Dagley, M. J., and McConville, M. J. (2018) DExSI: a new tool for the rapid quantitation of 13C-labelled metabolites detected by GC-MS.

Bioinformatics 34, 1957-1958

140. Young, L. E. B., C.O.; Macedo, J.K.; Gentry, M.S.; and Sun, R.C. (2019) Rapid and sensitive quantitation of glucose and glucose phosphates derived from storage carbohydrates using gas chromatography mass spectrometry. bioRxiv

141. Sellers, K., Fox, M. P., Bousamra, M., 2nd, Slone, S. P., Higashi, R. M., Miller, D. M., Wang, Y., Yan, J., Yuneva, M. O., Deshpande, R., Lane, A. N., and Fan, T. W. (2015) Pyruvate carboxylase is critical for non-smallcell lung cancer proliferation. J Clin Invest 125, 687-698

142. Shin-ichiro Takebayashi, H. T., Shinjiro Hino, Yuko Nakatsu, Tomoka Igata, Akihisa Sakamoto, Masashi Narita, and Mitsuyoshi Nakao. (2015) Retinoblastoma protein promotes oxidative phosphorylation through upregulation of glycolytic genes in oncogene-induced senescent cells. Aging Cell 14, 689-697

143. Jiang, L., Shestov, A. A., Swain, P., Yang, C., Parker, S. J., Wang, Q. A., Terada, L. S., Adams, N. D., McCabe, M. T., Pietrak, B., Schmidt, S., Metallo, C. M., Dranka, B. P., Schwartz, B., and DeBerardinis, R. J. (2016) Reductive carboxylation supports redox homeostasis during anchorageindependent growth. Nature 532, 255-258

144. Jang, C., Chen, L., and Rabinowitz, J. D. (2018) Metabolomics and Isotope Tracing. Cell 173, 822-837

145. Dali-Youcef, N., Mataki, C., Coste, A., Messaddeq, N., Giroud, S., Blanc, S., Koehl, C., Champy, M. F., Chambon, P., Fajas, L., Metzger, D., Schoonjans, K., and Auwerx, J. (2007) Adipose tissue-specific inactivation 
of the retinoblastoma protein protects against diabesity because of increased energy expenditure. Proc Natl Acad Sci U S A 104, 1070310708

146. Hutcheson, J., Witkiewicz, A. K., and Knudsen, E. S. (2015) The RB tumor suppressor at the intersection of proliferation and immunity: relevance to disease immune evasion and immunotherapy. Cell Cycle 14, 3812-3819

147. Kitajima, S., and Takahashi, C. (2017) Intersection of retinoblastoma tumor suppressor function, stem cells, metabolism, and inflammation. Cancer Sci 108, 1726-1731

148. Li, F., Kitajima, S., Kohno, S., Yoshida, A., Tange, S., Sasaki, S., Okada, N., Nishimoto, Y., Muranaka, H., Nagatani, N., Suzuki, M., Masuda, S., Thai, T. C., Nishiuchi, T., Tanaka, T., Barbie, D. A., Mukaida, N., and Takahashi, C. (2019) Retinoblastoma Inactivation Induces a Protumoral Microenvironment via Enhanced CCL2 Secretion. Cancer Res 79, 39033915

149. Momcilovic, M., Bailey, S. T., Lee, J. T., Fishbein, M. C., Magyar, C., Braas, D., Graeber, T., Jackson, N. J., Czernin, J., Emberley, E., Gross, M., Janes, J., Mackinnon, A., Pan, A., Rodriguez, M., Works, M., Zhang, W., Parlati, F., Demo, S., Garon, E., Krysan, K., Walser, T. C., Dubinett, S. M., Sadeghi, S., Christofk, H. R., and Shackelford, D. B. (2017) Targeted Inhibition of EGFR and Glutaminase Induces Metabolic Crisis in EGFR Mutant Lung Cancer. Cell Rep 18, 601-610

150. Wang, L., Peng, W., Wu, T., Deng, P., and Zhao, Y. L. (2018) Increased glutamine anabolism sensitizes non-small cell lung cancer to gefitinib treatment. Cell Death Discov 4, 24

151. Abdel-Wahab, A. F., Mahmoud, W., and Al-Harizy, R. M. (2019) Targeting glucose metabolism to suppress cancer progression: prospective of antiglycolytic cancer therapy. Pharmacol Res 150, 104511

152. Garcia Rubino, M. E., Carrillo, E., Ruiz Alcala, G., Dominguez-Martin, A., J, A. M., and Boulaiz, H. (2019) Phenformin as an Anticancer Agent: Challenges and Prospects. Int $\mathrm{J} \mathrm{Mol} \mathrm{Sci} 20$

153. Li, C., Xue, Y., Xi, Y. R., and Xie, K. (2017) Progress in the application and mechanism of metformin in treating non-small cell lung cancer. Oncol Lett 13, 2873-2880

154. Yu, X., Mao, W., Zhai, Y., Tong, C., Liu, M., Ma, L., Yu, X., and Li, S. (2017) Anti-tumor activity of metformin: from metabolic and epigenetic perspectives. Oncotarget 8, 5619-5628

155. Arrieta, O., Barron, F., Padilla, M. S., Aviles-Salas, A., Ramirez-Tirado, L. A., Arguelles Jimenez, M. J., Vergara, E., Zatarain-Barron, Z. L., Hernandez-Pedro, N., Cardona, A. F., Cruz-Rico, G., Barrios-Bernal, P., Yamamoto Ramos, M., and Rosell, R. (2019) Effect of Metformin Plus Tyrosine Kinase Inhibitors Compared With Tyrosine Kinase Inhibitors Alone in Patients With Epidermal Growth Factor Receptor-Mutated Lung Adenocarcinoma: A Phase 2 Randomized Clinical Trial. JAMA Oncol, e192553 
156. Wang, Z. D., Wei, S. Q., and Wang, Q. Y. (2015) Targeting oncogenic KRAS in non-small cell lung cancer cells by phenformin inhibits growth and angiogenesis. Am J Cancer Res 5, 3339-3349

157. Fan, T. W., Lane, A. N., Higashi, R. M., Farag, M. A., Gao, H., Bousamra, M., and Miller, D. M. (2009) Altered regulation of metabolic pathways in human lung cancer discerned by (13)C stable isotope-resolved metabolomics (SIRM). Mol Cancer 8, 41

158. Hensley, C. T., Faubert, B., Yuan, Q., Lev-Cohain, N., Jin, E., Kim, J., Jiang, L., Ko, B., Skelton, R., Loudat, L., Wodzak, M., Klimko, C., McMillan, E., Butt, Y., Ni, M., Oliver, D., Torrealba, J., Malloy, C. R., Kernstine, K., Lenkinski, R. E., and DeBerardinis, R. J. (2016) Metabolic Heterogeneity in Human Lung Tumors. Cell 164, 681-694

159. Egeblad, M., Nakasone, E. S., and Werb, Z. (2010) Tumors as organs: complex tissues that interface with the entire organism. Dev Cell 18, 884901

160. Lyssiotis, C. A., and Kimmelman, A. C. (2017) Metabolic Interactions in the Tumor Microenvironment. Trends Cell Biol 27, 863-875

161. Di Fiore, R., D'Anneo, A., Tesoriere, G., and Vento, R. (2013) RB1 in cancer: different mechanisms of RB1 inactivation and alterations of $\mathrm{pRb}$ pathway in tumorigenesis. J Cell Physiol 228, 1676-1687

162. Viatour, P., and Sage, J. (2011) Newly identified aspects of tumor suppression by RB. Dis Model Mech 4, 581-585

163. McNair, C., Xu, K., Mandigo, A. C., Benelli, M., Leiby, B., Rodrigues, D., Lindberg, J., Gronberg, H., Crespo, M., De Laere, B., Dirix, L., Visakorpi, T., Li, F., Feng, F. Y., de Bono, J., Demichelis, F., Rubin, M. A., Brown, M., and Knudsen, K. E. (2018) Differential impact of RB status on E2F1 reprogramming in human cancer. J Clin Invest 128, 341-358

164. Stine, Z. E., Walton, Z. E., Altman, B. J., Hsieh, A. L., and Dang, C. V. (2015) MYC, Metabolism, and Cancer. Cancer Discov 5, 1024-1039 


\section{CURRICULUM VITA \\ Lindsey R. Conroy \\ 505 S Hancock Street \\ Louisville, KY 40202 \\ (502) 963-8478}

Ireynolds7291@gmail.com

\section{Education}

$2017 \quad$ University of Louisville, Louisville, KY

M. S. Biochemistry and Molecular Genetics

2014 Indiana University Southeast, New Albany, Indiana

B. S. Biochemistry, High Distinction, Advisor: Dr. Aaron Setterdahl

Research Positions

2016-present University of Louisville, Louisville, KY

Graduate Research Assistant

The Retinoblastoma Protein Mediates Metabolic

Reprogramming in Lung Cancer, Thesis Advisor: Dr. Brian

Clem

2014

Indiana University Southeast, New Albany, Indiana

Undergraduate Research Assistant

Characterization of the RSP_2415 Gene Product in

Rhodobacter sphaeroides, Advisor: Dr. Aaron Setterdahl

\section{Abstracts and Presentations}

\section{Poster Presentations}

2019 Hallmarks of Cancer Cell Symposia, Seattle, WA

2019 Biochemistry and Molecular Genetics Department Retreat, Louisville, KY

2018 Research!Louisville, Louisville, KY

2018 AACR Annual Meeting, Chicago, IL

2017 Research!Louisville, Louisville, KY

2017 Biochemistry and Molecular Genetics Department Retreat, Louisville, KY

2015 ASM Annual Meeting, New Orleans, LA

2015 IBASM Annual Meeting, Brown County, IN 


\section{Oral Presentations}

2019 Biochemistry and Molecular Genetics Department Retreat, Louisville, KY

\section{Publications}

1. Conroy, L. R., Lorkiewicz, P., He, L., Yin, X., Zhang, X., Clem, B. Palbociclib treatment alters nucleotide biosynthesis and glutamine dependency in A549 cells. J. Cell. Biochem. In preparation.

2. Conroy, L. R., Dougherty, S., Kruer, T., Metcalf, S., Lorkiewicz, P., He, L., Yin, X., Zhang, X., Arumugam, S., Young, L., Sun, R., Clem, B. Loss of $R b 1$ enhances glycolytic metabolism in Kras-driven lung tumors in vivo. Cancers (2020) 12:1. doi: 10.3390/cancers12010237

3. Metcalf, S., Dougherty S, Kruer T., Hasan N., Biyik-Sit R., Reynolds L., Clem BF. Selective Loss of Phosphoserine Aminotransferase 1 (PSAT1) Suppresses Migration, Invasion, and Experimental Metastasis in Triple Negative Breast Cancer. Clin and Exper Metastasis (2019) https://doi.org/10.1007/s10585-019-10000-7

4. Kruer, T., Dougherty, S., Reynolds, L. et al. Expression of the IcnRNA Maternally Expressed Gene 3 (MEG3) Contributes to the Control of Lung Cancer Cell Proliferation by the Rb Pathway. PLoS One (2016) 11: 11. PMID: 27832204.

5. O'Neal, J., Clem, A., Reynolds, L. et al. Inhibition of 6-phosphofructo-2kinase (PFKFB3) suppresses glucose metabolism and the growth of HER2+ breast cancer. Breast Cancer Res Treat (2016) 160: 29. PMID: 27613609 .

\section{Awards and Honors}

$2018 \quad$ University of Louisville Graduate Student Council Travel Award 2018 AACR-Bristol Myers Squibb Oncology Scholar-in Training Award

2018 Biochemistry and Molecular Genetics Department Student Travel Award

2017 Biochemistry and Molecular Genetics Department Retreat Poster Session, $1^{\text {st }}$ Place

2015 ASM Student Travel Award

\section{Teaching Experience}

University of Louisville

2017 Teaching Assistant

2016 Teaching Assistant
BIOC-647: Advanced Biochemistry II

BIOC-611: Advanced Techniques in Biochemistry \& Molecular Biology

Indiana University Southeast 
Fall '14 Teaching Assistant

Spring '14- Teaching Assistant Fall '12
Chem-C 121/122: Elementary

Chemistry Lab 1/2

Chem-C 125: Principles of Chemistry

Lab 1

Chem-C 343: Organic Chemistry Lab 1 Chem-C 102: Elementary Chemistry 2

Chem-C 105: Principles of Chemistry 1

Chem-C 121/122: Elementary

Chemistry Lab 1/2

\section{Leadership Experience}

2016-2017 Department of Biochemistry \& Molecular Genetics Student President, University of Louisville

\section{Affiliations}

2017-present Member, American Association for Cancer Research

2017-present Member, American Society for Biochemistry and Molecular Biology

2016-2017 Member, American Society of Microbiology 